\title{
CULTIVO HIDROPÔNICO DO TOMATEIRO (Lycopersicon esculentum Mill.) UTILIZANDO DOIS SISTEMAS DE APLICAÇÃO DA SOLUÇÃO NUTRITIVA, COM DIFERENTES RELAÇÕ̃ES K:N
}

\section{ADRIANA LUZIA PONTES \\ Engenheira Agrônoma}

Orientador: Prof. Dr. JOÃO TESSARIOLI NETO

Dissertação apresentada à Escola Superior de Agricultura "Luiz de Queiroz", da Universidade de São Paulo, para obtenção do título de Mestre em Agronomia, Área de Concentração: Fitotecnia.

PIRACICABA

Estado de São Paulo - Brasil

Outubro - 2000 


\title{
Dados Internacionais de Catalogação na Publicação (CIP) DIVISÃO DE BIBLIOTECA E DOCUMENTAÇÃO - Campus "Luiz de Queiroz"/USP
}

\author{
Pontes, Adriana Luzia \\ Cultivo hidropônico do tomateiro ( Lycopersicon esculentum Mill.) utilizando dois \\ sistemás de aplicação da solução nutritiva, com diferentes relações K:N / Adriana Luzia \\ Pontes. - - Piracicaba, 2000. \\ 83 p. : il. \\ Dissertação (mestrado) - - Escola Superior de Agricultura Luiz de Queiroz, 2000. \\ Bibliografia. \\ 1. Cultivo protegido 2. Hidroponia 3. Nitrogênio 4. Potássio 5. Sistema de cultivo \\ 6. Solução nutritiva 7. Tomate I. Título
}

CDD 635.642

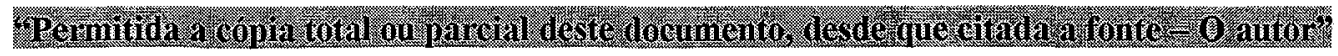


A Deus e todos os meus guias pela força espiritual, Agradeço.

Aos meus pais Reducino e Bernadete, meus avós Romeu e Juraci, minha irmã Fabiana e minha Sobrinha Nathália pelo apoio, Confiança e carinho,

Ofereço

Ao meu marido Maurício e meu filho Victor Felippe, 


\section{AGRADECIMENTOS}

Ao Prof. Dr. João Tessarioli Neto pela orientação, amizade e apoio que contribuíram para a realização deste trabalho;

Ao Prof. Dr. Keigo Minami pela co-orientação, amizade e apoio não somente durante $o$ trabalho de mestrado como durante toda a minha permanência na Universidade;

Ao Departamento de Produção Vegetal da Escola Superior de Agricultura "Luiz de Queiroz"/ Universidade de São Paulo, pela infra-estrutura concedida para a realização deste projeto;

À Fundação de Amparo a Pesquisa do Estado de São Paulo (FAPESP) pelo apoio financeiro através da Bolsa de Pesquisa concedida assim como da Reserva Técnica que auxiliou no financiamento do projeto;

Às Empresas Agroflora S.A. Reflorestamento e Agropecuária, Novartis Biociências, Irrigaplan Comércio e Representações Ltda., Plantprotec Indústria Comércio e Assistência Técnica Ltda., pelo apoio financeiro sem o qual não seria possível a realização deste projeto;

Ao Maurício Gusmão Rangel, meu marido, pela ajuda na elaboração da dissertação, compreensão e apoio em todos os momentos;

Aos funcionários da Prefeitura do Campus que sempre colaboraram nos momentos de necessidade;

Aos funcionários do Departamento de Produção Vegetal pela amizade e ajuda: Francisco Antonio Rossate, Antonio Pereira Goulart, Aparecido Serrano, Francisco Rodrigues de Souza, José Benedicto Casarollo, Antonio Rodrigues dos Santos, Edimundo Ferreira Costa, José Augusto da Silva, Mário Natal Tadao, Galdêncio Stênico, José Nivaldo dos Santos, Gerson Alexandre de Almeida, Erreinaldo Bortolazzo, Maria Celia, Elisabete, Sílvia Borghesi, Maria Ivete e $D^{a}$ Helena, sem os quais a estrutura do experimento não teria sido montada; 
Aos estagiários Fabrício, Gilberto, Leonardo, Marília e Tiago, pela ajuda, amizade e esforço, sem os quais a realização do trabalho seria impossivel;

Às amigas de hoje e sempre, Alexssandra e Márcia, por me ajudarem nos momentos dificeis e partilharem de minha alegria;

Ao amigo Richard Bierwagen pela amizade e grande auxilio na realização da análise estatística;

Ao amigo Wagner Ortelan pelas sugestões e materiais de estudo concedidos para a elaboração do projeto $\mathrm{e}$

Aos amigos de Pós - Graduação do Departamento de Horticultura Valéria, Walter, Paulo, Fagoni, Francine e Valter Henrique, e de outros Departamentos Norberto, Jonas, Marcos Piedade, Enio, e Lucimara pela amizade, sugestões no estudo e experiências de vida transmitidas. 


\section{SUMÁRIO}

Página

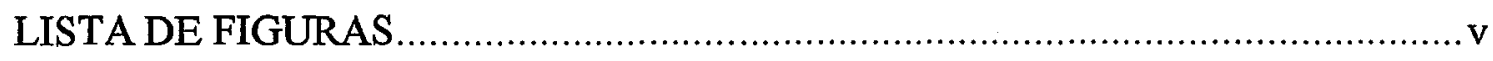

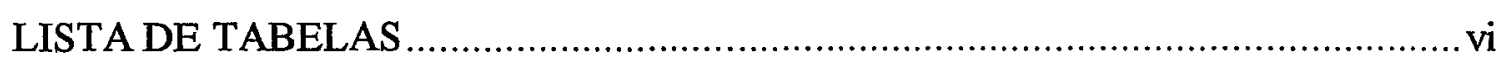

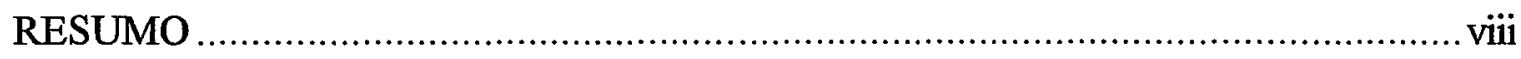

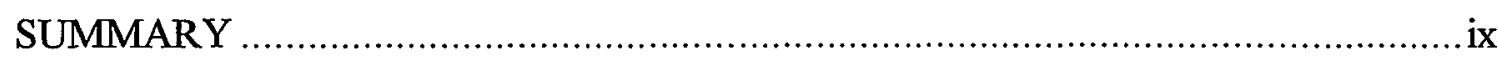

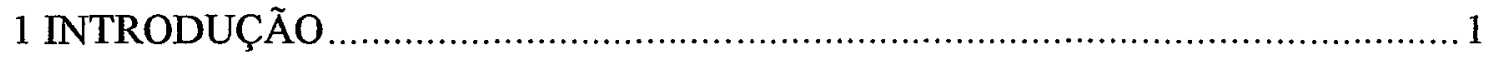

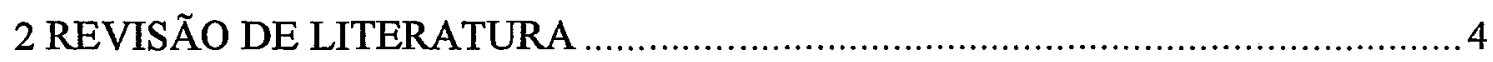

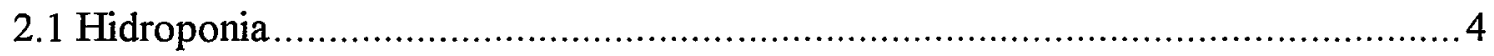

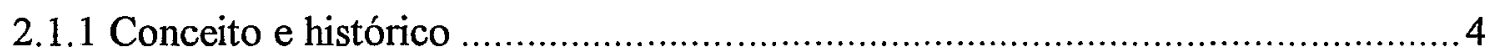

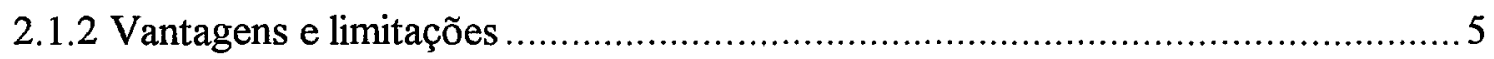

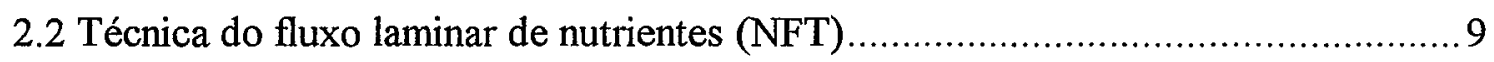

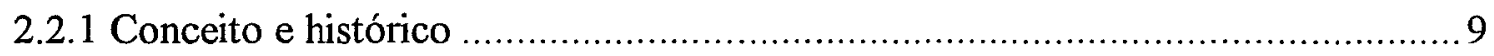

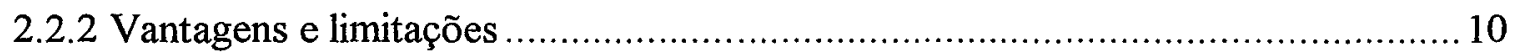

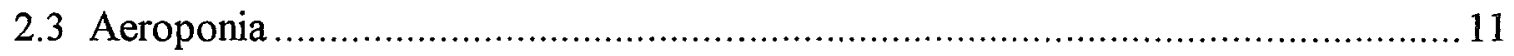

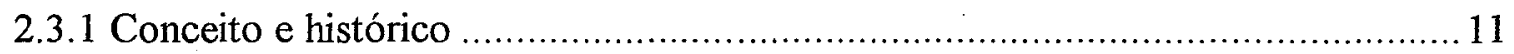

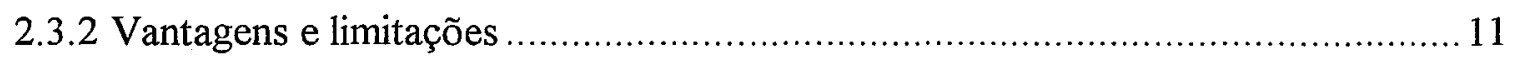

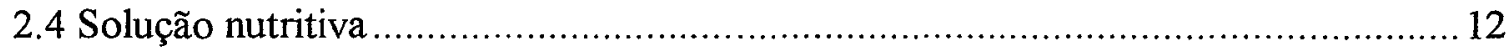

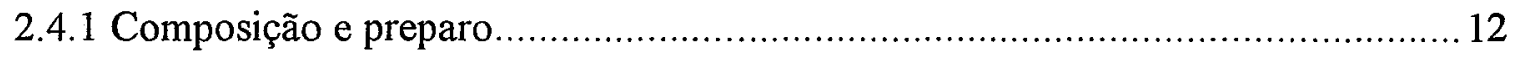

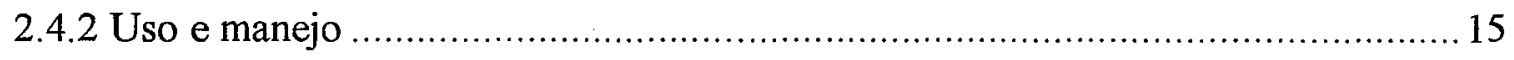

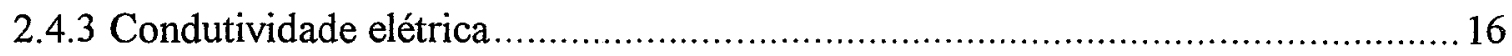

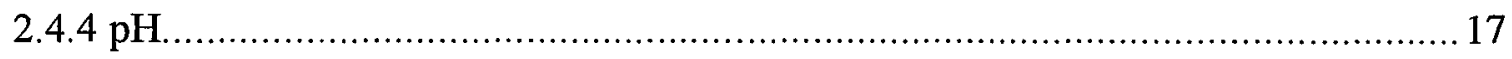

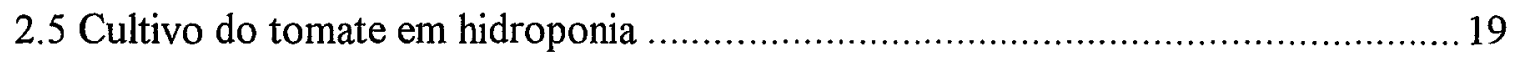

2.5.1 Absorção de nutrientes e produção ................................................................ 19

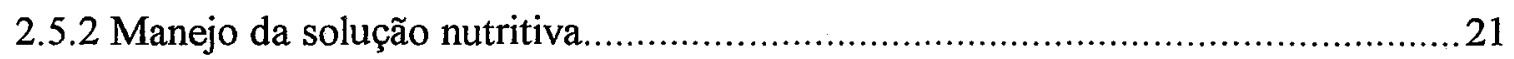

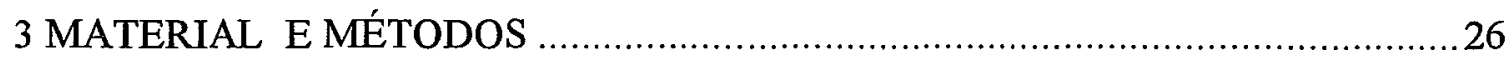

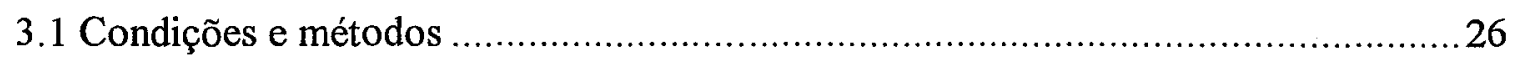

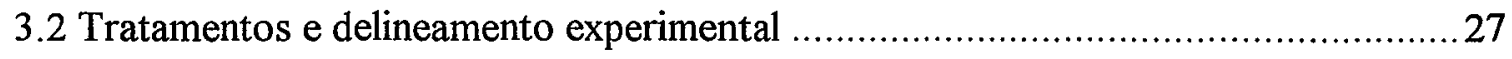

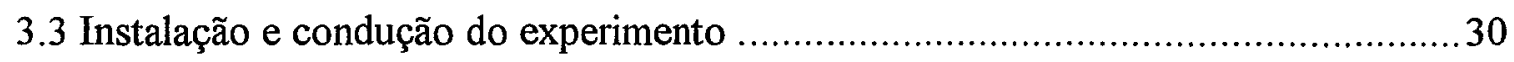

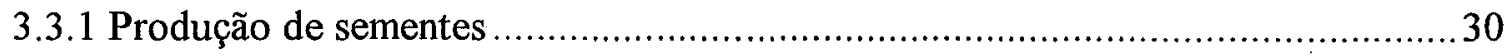




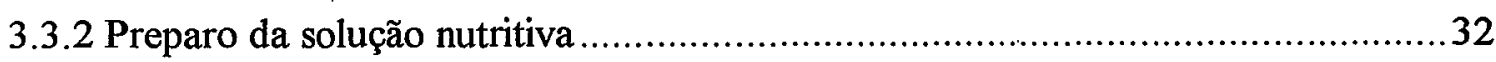

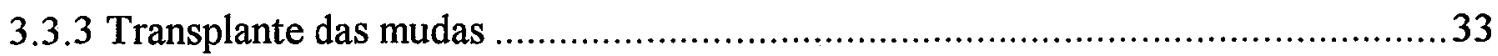

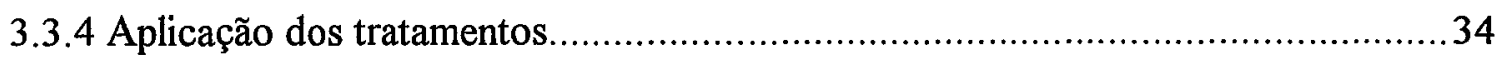

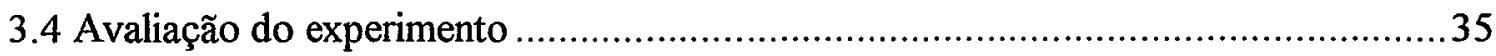

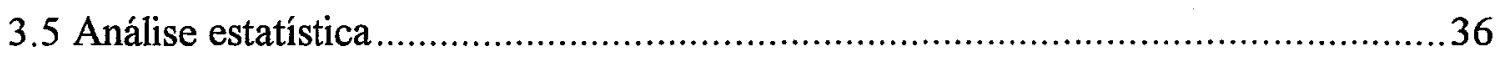

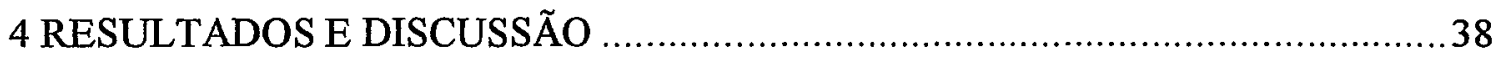

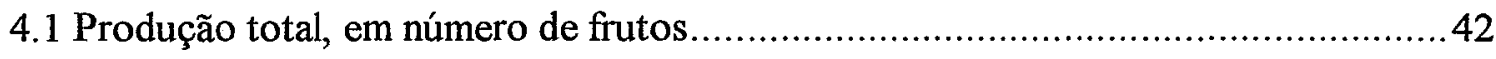

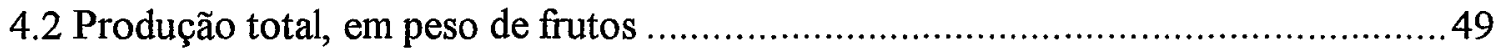

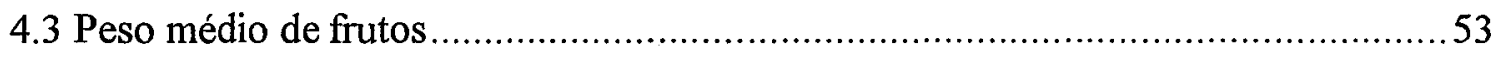

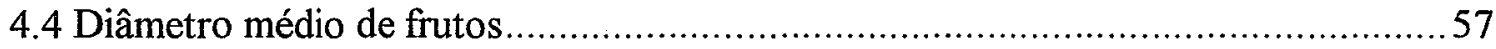

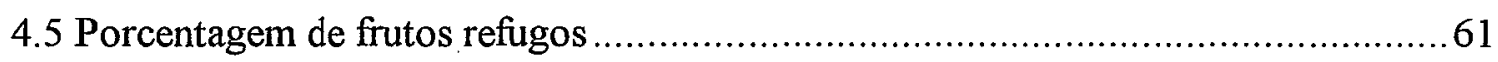

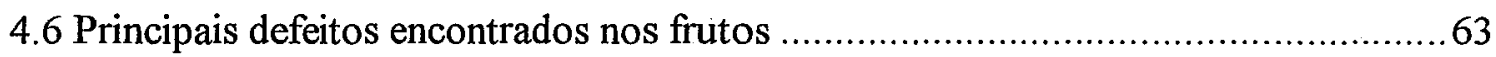

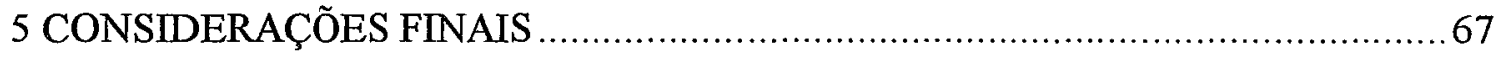

6 CONCLUSÃO

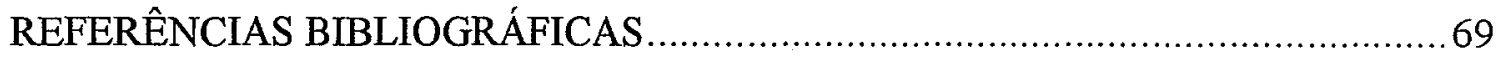

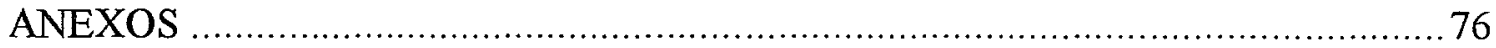




\section{LISTA DE FIGURAS}

Página

1 Produção total, em número de frutos, por penca, por combinação, ESALQ-USP, Piracicaba, SP.............................................................. 44

2 Produção total, em peso de frutos, por penca, por combinação, ESALQ-USP, Piracicaba, SP........................................................... 51

3 Peso médio de frutos, por penca, por combinação, ESALQ-USP, Piracicaba, SP............................................................................ 56

4 Diâmetro médio de frutos, por penca, por combinação ESALQ-USP, Piracicaba, SP

5 Comparativo entre frutos rachados e frutos normais, por combinação, ESALQ-USP, Piracicaba, SP 65 


\section{LISTA DE TABELAS}

Página

1 Resultado do teste $\mathrm{F}$, aplicado à análise de variância, para os fatores produção total em $n^{\circ}$ de frutos, produção total em peso de frutos, peso médio de frutos e diâmetro médio de frutos, ESALQ-USP, Piracicaba, SP.

2 Resultados do teste de Tukey para sistema, por penca, de acordo com os parâmetros avaliados, ESALQ-USP, Piracicaba, SP.

3 Resultados do teste de Tukey para solução, por penca, de acordo com os parâmetros avaliados, ESALQ-USP, Piracicaba, SP.

4 Produção total, em número de frutos, por penca, por combinação, ESALQ-USP, Piracicaba, SP

5 Variação de rendimento (\%) entre pencas, considerando as médias de número total de frutos, por combinação, ESALQ-USP, Piracicaba, SP.

6 Produção total, em número de frutos por penca, segundo um "ranking" decrescente, produção relativa em número de frutos e diferença entre as pencas com maior e menor número de frutos, de acordo com as combinações, ESALQ-USP, Piracicaba, SP

7 Produção total, em peso $(\mathrm{kg})$ de frutos, por penca, por combinação, ESALQ-USP, Piracicaba, SP

8 Produção total, em peso de frutos $(\mathrm{kg})$, por penca, segundo um "ranking" decrescente, produção relativa de frutos e diferença entre as pencas mais e menos produtivas, de acordo com as combinações, ESALQ-USP, Piracicaba, SP......

9 Peso médio de fruto por penca, por planta, por combinação, ESALQUSP, Piracicaba, SP.

10 Peso médio de frutos por penca, por planta, segundo um "ranking" decrescente, peso médio relativo de frutos e diferença entre os frutos com maior e menor peso médio, de acordo com as combinações 
ESALQ-USP, Piracicaba, SP

11 Diâmetro médio de frutos, por penca, por combinação, ESALQ-USP, Piracicaba, SP

12 Diâmetro médio de frutos por penca, por planta, segundo um "ranking" decrescente, diâmetro médio relativo de frutos e diferença entre os frutos com maior e menor diâmetro médio, de acordo com as combinações, ESALQ-USP, Piracicaba, SP.

13 Porcentagem de frutos refugo, por penca, por combinação, de acordo com 2 sistemas de classificação: CEAGESP e supermercados ESALQUSP, Piracicaba, SP.

14 Porcentagem de frutos refugo acumulada, com base na produção total, por combinação, de acordo com 2 sistemas de classificação: CEAGESP e supermercado, ESALQ-USP, Piracicaba, SP.

15 Principais defeitos de frutos, que ocorreram durante o experimento, ESALQ-USP, Piracicaba, SP 


\title{
CULTIVO HIDROPÔNICO DO TOMATEIRO (Lycopersicon esculentum Mill.) UTILIZANDO DOIS SISTEMAS DE APLICAÇÃO DA SOLUÇÃO NUTRITIVA, COM DIFERENTES RELAÇÕES K:N
}

\author{
Autora: ADRIANA LUZIA PONTES \\ Orientador: Prof. Dr. JOÃO TESSARIOLI NETO
}

\section{RESUMO}

O experimento foi conduzido no período de julho a dezembro de 1998, na área experimental do Departamento de Produção Vegetal Horticultura, ESALQ-USP. Plantas de tomate (Lycopersicon esculentum Mill, híbrido Carmem), foram conduzidas em dois sistemas hidropônicos diferentes: NFT (Nutrient Film Technique) e NNT (Nutrient Nebulization Technique), onde as raízes das plantas recebiam solução de forma nebulizada, dentro de tubulações de PVC. Também foram testadas duas relações $\mathrm{K}: \mathrm{N}(2: 1$ e $3: 1)$. Estas duas relações foram utilizadas durante todo o ciclo e combinadas da seguinte maneira: $(2: 1 / 3: 1$ e $3: 1 / 2: 1)$ sendo uma relação até o início do florescimento e outra até o fim do ciclo. Todas as quatro soluções foram utilizadas nos dois sistemas mencionados totalizando 8 combinações. As plantas foram conduzidas até a $6^{\mathrm{a}}$ penca e a produção foi avaliada através dos parâmetros peso, número, diâmetro e \% de refugo de frutos que foram classificados de acordo com dois sistemas de comercialização: sistema CEAGESP e sistema supermercado).

Nas condições do experimento, não houve diferença significativa entre sistemas. Para o sistema NFT, as relações $\mathrm{K}: \mathrm{N}$ 2:1/2:1, 3:1/3:1 e 2:1/3:1, respectivamente, proporcionaram os melhores resultados. Para o sistema NNT, as relações $\mathrm{K}: \mathrm{N}$ 3:1/3:1 e 2:1/3:1, respectivamente, proporcionaram os melhores resultados. 
HYDROPONICS CULTIVATION OF TOMATO CROP (Lycopersicon esculentum Mill.) USING TWO APPLICATION SYSTEMS OF THE NUTRIENT SOLUTION WITH DIFFERENTS RATIOS OF K:N

\author{
Author: ADRIANA LUZIA PONTES \\ Adviser: Prof. Dr. JOÃO TESSARIOLI NETO
}

\title{
SUMMARY
}

The trial was conducted from July to December of 1998 , at an experimental area of the Vegetable Production Department, São Paulo University.

Tomato plants were grown on two different hydroponics systems: NFT (Nutrient Film Technique) and NNT (Nutrient Nebulization Technique). In NNT, the root systems of the plants received nebulized solution inside PVC pipeline. Two $\mathrm{K}: \mathrm{N}$ ratios $(2: 1$ and 3:1) also were evaluated. These two ratios were used during all cycle and combined as follows: one of the ratio until beginning of flowering and the other, until the end of the cycle. Each mentioned systems (NFT and NNT), received four proposed solutions, totaling eight treatment combinations. All plants were conducted until $6^{\text {th }}$ raceme. Production characteristics were evaluated based on: weight, number, diameter and cull fruits (\%). Two market classification systems were also used (CEAGESP and supermarket).

In the experimental conditions, there was not found any statistical difference at $\mathbf{P}<0.05$ between hydroponics systems. The ratios $\mathrm{K}: \mathrm{N} 2: 1 / 2: 1$ and $3: 1 / 3: 1$ (all cycle) and the combination $\mathrm{K}: \mathrm{N} 2: 1 / 3: 1$, respectively, showed the best results, for NFT. The ratios $\mathrm{K}: \mathrm{N}$ 3:1/3:1 (all cycle) and the combination $2: 1 / 3: 1$, respectively, presented the best results, for NNT. 


\section{INTRODUÇÃO}

O tomateiro hoje pode ser considerado a mais importante espécie olerícola cultivada da agricultura brasileira. De acordo com o Agrianual 2000, a produção brasileira desta olerícola deve apresentar expressivo crescimento em 1999, atingindo a marca de 3,1 milhões de toneladas, cultivadas em mais de 65 mil hectares. $O$ valor de sua produção anual está em torno de 1,249 bilhão de dólares. O seu consumo é crescente e $68 \%$ da produção brasileira destina-se ao mercado de mesa (Agrianual 1997).

A cadeia produtiva do tomate tem caminhado para a modernização. Importantes mudanças têm ocorrido no que diz respeito a utilização de novas cultivares, tecnologias de produção e comercialização.

Dentre as tecnologias de produção, a plasticultura surgiu como um passo determinante para o aumento da eficiência produtiva na horticultura, principalmente no que se refere a cultura do tomateiro. É uma técnica já bastante antiga, porém, relativamente recente no país, onde tem contribuído para a oferta de produtos de consumo "in natura" de excelente qualidade, em época de condições climáticas totalmente desfavoráveis ao cultivo, como durante o verão, devido às intensas chuvas. Aliás, a principal função da plasticultura no Brasil tem sido a proteção contra chuvas e ventos, ao contrário de outros países que visam controlar principalmente a temperatura com esta tecnologia de produção.

O cultivo protegido utilizando-se o solo, permite um maior controle dos fatores climáticos (chuva e vento entre outros), contudo o solo continua sendo um fator limitante, principalmente com relação a doenças causadas por patógenos de solo. 
Takazaki \& Della Vecchia (1993) salientam ainda que no cultivo intensivo é comum encontrar solos com teores elevados de nutrientes, essenciais para o desenvolvimento das plantas, porém extremamente desbalanceados.

A hidroponia, cultivo de plantas em meio líquido, com ou sem meio de sustentação para as plantas (substrato), é uma técnica alternativa do cultivo protegido que permite a substituição do solo por uma solução nutritiva totalmente balanceada.

Em países onde esta técnica já vem sendo utilizada a muito tempo (Japão, EUA, Holanda, Israel, entre outros), o objetivo normalmente é superar determinadas dificuldades como: pouca área disponível, deficiência de água, solo ou clima que não permitem a agricultura convencional

É também uma técnica bastante antiga, mas recente no que diz respeito a cultivos comerciais, visando altos rendimentos. No Brasil esta técnica vem se difundindo com muita rapidez atingindo cinturões verdes de Belo Horizonte, São Paulo, Rio de Janeiro, tanto das capitais como do interior. A principal cultura desenvolvida através desta técnica é a alface seguida de tomate, pepino, pimentão e melão. $O$ sistema mais utilizado no país, para o cultivo da alface é o NFT (Nutriente Film Technique), ou seja, técnica do fluxo laminar de nutrientes.

- > Para a alface existem algumas informações científicas para o seu cultivo hidropônico no Brasil, uma vez que foi a cultura pioneira; porém com relação as outras culturas, existe uma grande carência de informações.

Por este motivo, objetivou-se com este trabalho o estudo do comportamento de um híbrido de tomate (tipo caqui longa vida), bastante cultivado atualmente, submetido a dois sistemas de cultivo hidropônico e diferentes soluções nutritivas, para avaliações de produção. Com este estudo acredita-se que possa ser possível fornecer uma gama maior de informações aos produtores para que haja maior conhecimento do sistema e do comportamento nutricional, de uma cultura de alta rentabilidade.

Por enquanto, os produtos obtidos via hidroponia, têm sido direcionados a segmentos específicos de consumidores, de maior poder aquisitivo, dos grandes centros urbanos, porém a tendência é a mudança desta situação quando a tecnologia estiver mais 
adaptada as nossas condições e, principalmente, mais acessível aos produtores, a custos menores de implantação e produção.

Para se chegar a estes níveis, muitos trabalhos de pesquisa precisam ser desenvolvidos, uma vez que, tem-se poucos dados oriundos de trabalhos realizados em nossas condições. 


\section{REVISÃO DE LITERATURA}

\subsection{Hidroponia}

\subsubsection{Conceito e histórico}

De acordo com Douglas (1989), o termo hidroponia deriva de duas palavras gregas: hydro (água) e ponos (trabalho) e a combinação destas duas palavras resulta em "trabalhar com água". Tudo começou há cerca de três séculos, quando John Woodward tentou determinar se era a água ou o solo que nutria as plantas, porém devido a escassez de equipamentos adequados, os avanços foram limitados. Somente no século $\mathrm{XIX}$, com os avanços no campo da química, é que foi possível preparar uma lista provisória dos nutrientes usados pelas plantas. Em 1930 ocorreu a primeira tentativa de cultivo fora de laboratórios, quando o Dr. W.F. Gerike utilizou pela primeira vez, na Universidade da Califórnia, o termo "hydroponics".

Segundo Castelane \& Araújo (1995) quase todos os elementos minerais essenciais às plantas foram descobertos durante o período de 1850 a 1955, e para tanto, quase a totalidade deles foram descobertos utilizando-se alguma forma de cultivo sem solo.

Mas foi com a $2^{\mathrm{a}}$ Guerra Mundial que esta nova técnica recebeu um grande impulso devido a necessidade de alimentos nas bases militares.

Estes autores ainda afirmam que o método já está difundido em muitos países. Na América do Norte, Europa e Japão existem unidades comerciais que produzem grandes quantidades de hortaliças frescas durante todo o ano. No deserto do 
Saara e nas regiões áridas da Península Arábica, companhias petrolíferas e organizações governamentais mantêm instalações hidropônicas. Regiões como as Ilhas Canárias, conseguem equilibrar sua economia exportando, anualmente, grandes quantidades de tomates, pepinos e outras hortaliças produzidas pelo método hidropônico. $O$ mesmo acontece com Porto Rico, México e vários países da Europa, produtores de flores.

Segundo Resh (1995), a hidroponia é uma ciência muito recente e tem sido explorada comercialmente nos últimos 50 anos. Exemplificando o avanço rápido desta tecnologia, recentes estimativas indicam, entre hortaliças e flores, que o sistema de cultivo sem solo está instalado em áreas de 4000 ha na Holanda, 1700 ha na Inglaterra, 400 ha no Canadá, 240 ha nos EUA, além de outros países como Austrália, Rússia, Espanha, México, Nova Zelândia, África do Sul, Kuwait, Singapura, China, Japão, Malásia, Brasil, Polônia, entre outros. Cita ainda alguns números relativos a América do Norte: Bonita Nurseries, Bonita, Arizona (8 ha de tomate), Ringgold Nurseries, Ringgold, Pennsylvania ( 4 ha de tomate), SunGro Greenhouses, Las Vegas, Nevada (5 ha de tomate), Bernac, Fort Pierce, Flórida (12 ha de pepino), Houweling Nurseries Ltd., Delta, British Columbia, Canadá (12 ha de pepino, tomate e pimentão), Rifle, Colorado ( 4 ha de tomate), Wolf Creek Produce, Brush, Colorado (15 ha de tomate).

\subsubsection{Vantagens e limitações}

De acordo com Resh (1992), o cultivo sem solo apresenta uma série de vantagens sobre os cultivos convencionais no que diz respeito a vários aspectos (quadro 1).

O mesmo autor ainda estabelece um comparativo de produção entre o cultivo convencional, em solo, e o cultivo hidropônico (quadro 2).

Castellane \& Araújo (1994) também apresentam, no quadro 3, um comparativo entre algumas hortaliças cultivadas em estufas, com sistema hidropônico e em campo aberto. 
Quadro 1- Comparação entre cultivo sem solo e convencional

\begin{tabular}{|c|c|c|}
\hline Why & (6) & (6) \\
\hline Esterilização do meio de cultivo & Trabalho intensivo, demorado. & Trabalho muito rápido. \\
\hline Nutrição vegetal & $\begin{array}{l}\text { Muitas deficiências causadas por } \\
\text { desbalanceamento de pH do solo, } \\
\text { que é mais difícil de ajustar. }\end{array}$ & $\begin{array}{l}\text { Controle completo e estável dos } \\
\text { nutrientes devido ao } \mathrm{pH} \\
\text { constante e facilmente } \\
\text { balanceado. }\end{array}$ \\
\hline Número de plantas & $\begin{array}{l}\text { Limitado pela nutrição e } \\
\text { disponibilidade de luz. }\end{array}$ & $\begin{array}{l}\text { Limitado somente por } \\
\text { disponibilidade de luz, portanto } \\
\text { pode haver maior adensamento e, } \\
\text { consequentemente maior } \\
\text { rendimento. }\end{array}$ \\
\hline Ervas daninhas & $\begin{array}{l}\text { Estão sempre presentes. Tem que ser } \\
\text { feito controle. }\end{array}$ & Não existem. \\
\hline Pragas e doenças do solo & $\begin{array}{l}\text { Grande número de doenças, } \\
\text { nematóides, insetos e outros males } \\
\text { que podem afetar o rendimento da } \\
\text { cultura. Há necessidade de se fazer } \\
\text { rotação de culturas. }\end{array}$ & $\begin{array}{l}\text { Não ocorrem pragas e nem } \\
\text { doenças quando o controle de } \\
\text { sanidade é rigoroso, portanto não } \\
\text { há necessidade de rotação de } \\
\text { culturas. }\end{array}$ \\
\hline Água & $\begin{array}{l}\text { Águas salinas não podem ser } \\
\text { utilizadas. O aproveitamento da água } \\
\text { pode se tornar pouco eficiente } \\
\text { dependendo das características do } \\
\text { solo e condições climáticas. }\end{array}$ & $\begin{array}{l}\text { Não existe estress hídrico. O } \\
\text { aproveitamento da água é } \\
\text { altamente eficiente, uma vez que } \\
\text { a salinidade e a aeração são } \\
\text { controlados. }\end{array}$ \\
\hline Qualidade do fruto & $\begin{array}{l}\text { Fruto mais frágil devido as } \\
\text { deficiências de Cálcio, resultando } \\
\text { em menor tempo de conservação. }\end{array}$ & $\begin{array}{l}\text { Fruto firme, com boa } \\
\text { conservação, permitindo colher o } \\
\text { fruto maduro e ainda ser } \\
\text { transportado. Deve-se salientar } \\
\text { também maior quantidade de } \\
\text { vitamina A. }\end{array}$ \\
\hline Fertilizantes & $\begin{array}{l}\text { Utilizam-se grandes quantidades } \\
\text { devido às perdas, sem distribuição } \\
\text { uniforme. }\end{array}$ & $\begin{array}{l}\text { Utilizam-se pequenas } \\
\text { quantidades, uma vez que, por } \\
\text { não ter perda, coloca-se apenas o } \\
\text { necessário para o } \\
\text { desenvolvimento das plantas. }\end{array}$ \\
\hline Estado fitossanitário & $\begin{array}{l}\text { Produtos podem ser comercializados } \\
\text { com enfermidades. }\end{array}$ & Produtos sadios. \\
\hline Transplante & $\begin{array}{l}\text { O solo tem que ser preparado, não há } \\
\text { controle de patógenos e temperatura } \\
\text { do solo, o que prejudica o } \\
\text { pegamento das mudas. }\end{array}$ & $\begin{array}{l}\text { Não há necessidade de preparo } \\
\text { do solo, pode-se controlar a } \\
\text { temperatura, não existe } \\
\text { patógenos. }\end{array}$ \\
\hline Maturação & & $\begin{array}{l}\text { Mais eficiente em cultivos } \\
\text { hidropônicos, uma vez que se } \\
\text { pode conseguir condições } \\
\text { adequadas de iluminação. }\end{array}$ \\
\hline Produção (t/ha) & $13-25 \mathrm{t} / \mathrm{ha}$. & $148-300 \mathrm{t} / \mathrm{ha}$. \\
\hline
\end{tabular}


Quadro 2 - Comparativo de produção (t), em $4050 \mathrm{~m}^{2}$, entre o cultivo no solo e o cultivo hidropônico.

\begin{tabular}{|c|c|c|}
\hline 4\% & \%) & HOL \\
\hline Soja & 0,27 & 0,70 \\
\hline Feijão & 5,00 & 21,00 \\
\hline Ervilha & 1,00 & 9,00 \\
\hline Trigo & 0,27 & 1,80 \\
\hline Arroz & 0,45 & 2,20 \\
\hline Aveia & 0,45 & 1,10 \\
\hline Beterraba & 4,00 & 12,00 \\
\hline Batata & 8,00 & 70,00 \\
\hline Repolho & 6,00 & 8,20 \\
\hline Alface & 4,00 & 9,50 \\
\hline Tomate & 7,50 & 150,00 \\
\hline Pepino & 3,20 & 12,70 \\
\hline
\end{tabular}

Fonte: Resh (1992)

Quadro 3 - Comparativo entre cultivo hidropônico e convencional

\begin{tabular}{|c|c|c|c|c|}
\hline \multicolumn{4}{|c|}{ 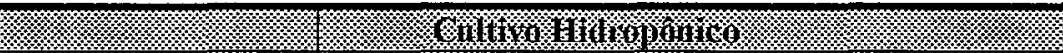 } & 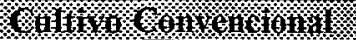 \\
\hline 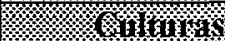 & 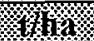 & 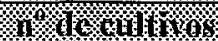 & 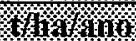 & 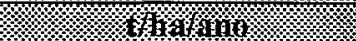 \\
\hline Brócolis & 32.5 & 3 & 97.5 & 10.5 \\
\hline Feijão-vagem & 11.5 & 4 & 46 & 6 \\
\hline Repolho & 57.5 & 3 & 172.5 & 30 \\
\hline Couve-chinesa & 50 & 4 & 200 & - \\
\hline Pepino & 250 & 3 & 750 & 30 \\
\hline Berinjela & 28 & 2 & 56 & 20 \\
\hline Alface & 31.3 & 10 & 313 & 52 \\
\hline Pimentão & 32 & 3 & 96 & 16 \\
\hline Tomate & 187.5 & 2 & 375 & 100 \\
\hline
\end{tabular}

Fonte: Castellane \& Araújo (1995)

De acordo com Martinez (1995) o sistema NFT tem as seguintes vantagens em relação a outros sistemas hidropônicos: menor custo de implantação, facilidade de operação, facilidade e rapidez de desinfecção entre as colheitas e a utilização de produtos pouco tóxicos, plantio e colheita simples, facilidade do uso do espaço, conservação e economia da água e nutrientes, menor contaminação ambiental proveniente dos efluentes das casas-de-vegetação, grande potencial de automação pois, 
o controle de ajuste, distribuição e retorno das soluções nutritivas podem ser feitos automaticamente e, por fim, maior homogeneização da solução devido a circulação.

Ueda (1990) afirma que são inúmeras as vantagens da hidroponia, sendo as principais:

1. não tendo contato com a terra, não aparecem os problemas relacionados com ela, portanto pode-se repetir a cultura quantas vezes quiser, não havendo necessidade de se fazer rotação de cultura;

2. plantas de melhor qualidade - controle da área cultivada criando-se condições ótimas para o crescimento da planta;

3. crescimento rápido - menor tempo para o crescimento e desenvolvimento das plantas (30\% mais rápido que os cultivos convencionais) uma vez que se mantém constantes as condições ideais de crescimento;

4. alto rendimento - maior número de ciclos/ano uma vez que não é preciso preparar o solo;

5. racionalização de trabalho - economia de tempo uma vez que não existem tarefas como irrigar, capinar, adubar o solo, entre outras;

6. produto com menor quantidade de defensivo, uma vez que não existem os contaminantes advindos do solo;

7. pouco consumo de água e adubo - no caso de solução circulante;

8. produto mais limpo por ocasião da comercialização.

Garcia (1993) afirma que a vantagem do sistema NFT é não precisar de aeração suplementar pois, a própria circulação da solução promove aeração suficiente para a maioria das culturas.

Segundo Jones Jr (1983), o sistema NFT tem a vantagem de possibilitar instalação dos canais onde se desenvolvem as raízes, nas mais variadas configurações, o que permite uma melhor utilização do espaço, além de preços mais baixos, uma vez que os materiais utilizados podem ser madeira ou chapas metálicas.

Graves (1983) ressalta que o sistema NFT permite um maior número de cultivos por ano em função da facilidade de colheita e replantio. 
De acordo com Furlani (1995), a composição ideal das soluções nutritivas não deve apenas depender das concentrações dos nutrientes, mas também dos fatores ligados ao cultivo, inclusive devendo ser alterada de acordo com o sistema hidropônico adotado, bem como de acordo com os fatores ambientais (luminosidade, temperatura e umidade), época do ano (fotoperíodo), idade das plantas, espécie e cultivar utilizada.

Segundo Martinez (1988), apesar da variabilidade entre a composição das soluções mais conhecidas, a obtenção de soluções nutritivas ideais para as espécies, variedades e condições particulares, permanece uma incógnita.

\subsection{Técnica do fluxo laminar de nutrientes (NFT)}

\subsubsection{Conceito e histórico}

De acordo com Resh (1997) é uma técnica de cultivo ém água onde as plantas crescem com o seu sistema radicular dentro de um recipiente, através do qual circula continuamente a solução nutritiva. Por estes canais, instalados em desnível de 1 a $3 \%$, a solução nutritiva é introduzida e retorna por gravidade e assim continuamente pois, trata-se de um sistema fechado, que pode ser intermitente ou não.

Estes canais podem ser ao nivel do solo ou em bancadas elevadas e, se forem recobertos com plástico podem ser feitos de qualquer material, porém se não forem recobertos, devem ser utilizados materiais inertes que não liberem substâncias nocivas e também não ocorra reação com a solução que passará sobre o material continuamente. A liberação de qualquer elemento químico causaria um desbalanço nutricional na solução nutritiva.

O pioneiro a trabalhar com esta técnica foi Allan Cooper na Inglaterra em 1973 (Resh, 1997).

Durante o cultivo, o volume da solução nutritiva reduz-se devido às perdas por evaporação e devido à transpiração das plantas. A concentração dos nutrientes na solução também diminui em função da absorção pelas plantas em desenvolvimento. Esse volume perdido e os nutrientes absorvidos devem ser repostos 
periodicamente à solução que deve ser constantemente monitorada quanto ao seu $\mathrm{pH}$, à condutividade elétrica (CE) e à temperatura (Graves, 1983).

\subsubsection{Vantagens e limitações}

Garcia (1993) afirmou que o sistema NFT tem a vantagem de não necessitar de aeração suplementar, pois a circulação da solução promove aeração suficiente para a maioria das culturas. Além disso, não necessita de substrato, pois as raízes das plantas ficam fixadas diretamente nos canais de cultivo.

Jones (1983) ressalta a vantagem do sistema permitir a instalação de canais para as mais variadas formas de raízes e nos mais variados tipos de materiais, permitindo uma melhor utilização do espaço a um custo acessível.

De acordo com Martinez (1995) o sistema NFT possui as seguintes vantagens: menor custo de instalação, facilidade de operação, facilidade e rapidez de esterilização entre ciclos e utilização de produtos pouco tóxicos, menor contaminação ambiental proveniente de efluentes de casas-de-vegetação, grande potencial de automação e maior homogeneização da solução devido à circulação.

Trata-se de um sistema que, de acordo com Graves (1983), permite um maior número de cultivos por ano, em função da facilidade de colheita e de replantio.

Como desvantagem, Martinez (1995) ressalta: a possibilidade de acúmulo de etileno nos canais de cultivo; ocorrência de deficiência de oxigênio em canais muito longos, pelo aquecimento da solução ou pela concentração da solução, pois as plantas absorvem mais água do que nutrientes; a esterilização entre as colheitas não garante a isenção de patógenos, pois a contaminação pode ocorrer durante o ciclo e é de fácil disseminação e dificuldade em se fazer reparos ou substituições durante o cultivo, pois o fornecimento da solução não pode ser interrompido.

Martinez (1995) concorda com Jones Jr. (1983) que o controle de doenças pode ser dificultado no sistema NFT, pois uma vez que os agentes causadores entram no sistema, eles são rapidamente disseminados de uma planta para outra. Além disso, comenta sobre a morte de raízes, que ocorre nos períodos de elevada demanda de 
carboidratos, como por exemplo, durante a frutificação e nos períodos de estresse. Quando essa fase cessa, as plantas recuperam o suprimento adequado de carboidratos e novas raízes se desenvolvem. De acordo com a autora, este fenômeno, provavelmente, ocorre em todos os sistemas de cultivo, porém é mais visível no sistema NFT.

Por fim Graves (1983) cita como desvantagem a necessidade de mão-deobra especializada uma vez que, deve-se conhecer muito bem a planta com a qual se está trabalhando, principalmente com relação a nutrição.

\subsection{Aeroponia}

\subsubsection{Conceito e histórico}

Vicenzoni (1980) comenta que a primeira instalação aeropônica foi construída em 1969, em tubulações de PVC, buscando-se utilizar o máximo possível da superficie disponível, aumentando assim a oferta de alimentos.

De acordo com Resh (1997) a aeroponia é um tipo de cultivo onde as raízes ficam suspensas e a solução nutritiva é aplicada sob a forma de nebulização. Trata-se de um cultivo muito utilizado em laboratórios de fisiologia vegetal e não é facilmente encontrado em escala comercial.

Segundo Staff (1997) trata-se de uma técnica que visa economia de espaço, uma vez que as plantas ficam dispostas em tubulações verticais, recebendo de forma intermitente, a solução nutritiva nebulizada.

\subsubsection{Vantagens e limitações}

A aeroponia tem como uma das principais vantagens, permitir que a solução nutritiva seja inserida em um espaço bem maior que o atingido pelo sistema NFT, também proporciona maior desenvolvimento do sistema radicular, além de proporcionar excelente aeração, uma vez que as raízes não ficam imersas na solução e sim suspensas. 
Uma das limitações seria o custo elevado, pois há a necessidade da aquisição de bicos com capacidade de injeção da solução sob alta pressão, de maneira a criar uma névoa no ambiente onde se encontram as raizes. Além disso, em caso de falta de energia, as raízes, que permanecem constantemente suspensas, são mais vulneráveis ao ressecamento àquelas que ficam imersas na solução nutritiva.

Outra limitação, de acordo com Staff (1997), seria a não adaptabilidade deste sistema à culturas que exigem tutoramento para o seu crescimento, como o tomate, o pimentão e o melão.

\subsection{Solução nutritiva}

\subsubsection{Composição e preparo}

Quando se pretende iniciar o cultivo hidropônico de uma determinada cultura, sem o conhecimento de sua necessidade nutricional, basta coletar uma planta inteira, madura (em época de colheita), sadia e bem nutrida, dividir as partes e, proporcionalmente a matéria seca, obtém-se a quantidade aproximada dos nutrientes exigidos. Neste caso, normalmente, não se usa raiz, pois geralmente tem contaminação. Pode-se também partir de uma solução recomendada para outra cultura da mesma família e, durante o ciclo, fazer-se os ajustes necessários específicos para a espécie em questão (Carmello ${ }^{1}$.

Martinez et al. (1997) concordam com a afirmação do autor anterior e comentam que o conhecimento do processo de absorção de nutrientes de uma espécie ou variedade dá subsídios para um manejo adequado da solução nutritiva, pois mostra os picos de demanda por parte da planta, alterações nas taxas de absorção durante o ciclo da cultura e a proporção relativa entre os nutrientes no material seco.

${ }^{1}$ CARMELLO, Q.A. de C. (ESALQ-Escola Superior de Agricultura "Luiz de Queiroz", Piracicaba-SP). Anotações de aula, 1998. 
Shippers (1980) ressalta que não é possível fornecer de uma só vez todos os nutrientes necessários para as plantas durante todo o seu ciclo, pois isso resultaria em concentrações salinas excessivas para a cultura.

Resh (1995) concorda e sugere que as soluções nutritivas devem ser modificadas de acordo com o estágio de desenvolvimento de cada cultura.

Furlani (1995) afirma que a composição ideal da solução nutritiva não depende apenas das concentrações dos nutrientes, mas também de outros fatores de produção: fatores ambientais como luminosidade, umidade, temperatura; fatores fisiológicos como idade da planta, espécie, cultivar e fatores estruturais como sistemas de cultivo. Afirma ainda que esta composição deve ser alterada conforme o nível de interferência destes fatores.

De acordo com Benoit (1992), quando se trata de hidroponia, a qualidade da água é um fator decisivo para o êxito dos cultivos e, para ilustrar, estabeleceu alguns parâmetros que devem ser seguidos por ocasião da avaliação da água a ser utilizada no cultivo hidropônico (quadro 4).

Quadro 4-Padrões de qualidade de água para hidroponia.

\begin{tabular}{|c|c|}
\hline 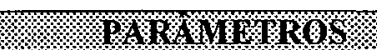 & 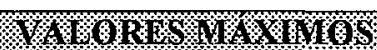 \\
\hline 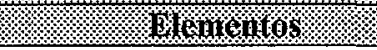 & 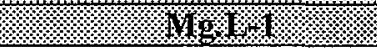 \\
\hline $\mathrm{Na}$ & 11,5 \\
\hline $\mathrm{Cl}$ & 33,5 \\
\hline $\mathrm{Ca}$ & 80,2 \\
\hline $\mathrm{Mg}$ & 12,2 \\
\hline $\mathrm{SO}^{--}$ & 48,1 \\
\hline $\mathrm{HCO}^{-}$ & 244,0 \\
\hline $\mathrm{B}$ & 0,00270 \\
\hline $\mathrm{Cu}$ & 0,00063 \\
\hline $\mathrm{Fe}$ & 0,00028 \\
\hline $\mathrm{Mn}$ & 0,00549 \\
\hline $\mathrm{Zn}$ & 0,00327 \\
\hline$F$ & 0,00475 \\
\hline 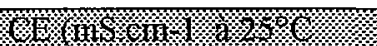 & 10.02 \\
\hline
\end{tabular}


De acordo com Carmello (1997) antes da implantação do cultivo hidropônico, a água a ser utilizada deverá sofrer rigorosa análise e, mesmo após a implantação do sistema, a água deverá ser, constantemente, monitorada através de análises. Depois da análise, se a água contiver mais que $50 \mathrm{ppm}$ de cloreto de sódio, não poderá ser considerada adequada para o bom desenvolvimento das plantas.

A dureza representa o conteúdo de íons bicarbonato ( $\left.\mathrm{HCO}^{-}\right)$que, quando presentes em altas concentrações, afetam diretamente o $\mathrm{pH}$. Normalmente as águas de minas, situadas em camadas de rochas calcárias ou dolomíticas, podem conter níveis altos de carbonato de cálcio e de magnésio, disponíveis para as plantas, daí o cuidado por ocasião do cálculo da solução nutritiva. Se os níveis de íons bicarbonato estiverem baixos, não causam efeitos negativos e até ajudam a estabilizar o $\mathrm{pH}$ da solução, sendo recomendado, inclusive, a adição de $30-50 \mathrm{ppm}$ de carbonato ou bicarbonato para se evitar flutuações acentuadas de pH (Carmello, 1997).

Outro fator a ser observado, segundo o mesmo autor, é a pressão osmótica que trata-se da tendência que a solução tem de penetrar nas raízes das plantas, dependendo da quantidade de partículas colocadas nela. Sabe-se que a água se movimenta no sentido de uma solução menos concentrada para outra mais concentrada, assim quando se coloca sais na água, a pressão osmótica aumenta, isto é, a solução fica mais concentrada e a água se movimenta mais devagar diminuindo a tendência da solução de penetrar nas raízes, o que acarreta um crescimento deficiente.

A partir de uma certa quantidade de partículas na solução, ou seja, a partir de uma certa concentração, a tendência se inverte e a água passa a sair das raízes causando a sua morte. Daí o limite de pressão osmótica em uma solução nutritiva que está entre 0,5 e $1 \mathrm{~atm}$. Vale salientar que a exposição de plantas a pressões osmóticas extremamente altas (acima de $10 \mathrm{~atm}$ ), por curtos períodos, causa menos danos do que a exposição a pressões osmóticas moderadamente altas (entre 4 e 5 atm), porém por longos períodos (Carmello, 1997).

Com relação aos sais, qualquer sal solúvel pode ser utilizado para o preparo da solução nutritiva, desde que contenha o nutriente necessário à planta e não contenha nenhum elemento que possa prejudicar o seu desenvolvimento, assim como 
devem ser evitados sais que provoquem a precipitação de partículas ou reações químicas. Os sais utilizados no cultivo comercial não necessitam de pureza química elevada, pois possuem custo muito alto, portanto sais com grau técnico e mesmo fertilizantes químicos podem ser utilizados (Carmello, 1997).

Ainda de acordo com o mesmo autor, deve-se dar preferência aos nitratos em relação aos sulfatos e aos cloretos, uma vez que o nitrato é melhor absorvido pelas plantas. Outras precauções também devem ser tomadas como: utilizar sempre os fertilizantes mais solúveis; não ultrapassar $10 \%$ de amônio na quantidade total de nitrogênio; evitar o uso de uréia, uma vez que, na água, sofre hidrólise e libera amônia; e

dissolver os sais separadamente para evitar reações entre eles, nunca misturando, de forma concentrada, soluções de nitrato de cálcio e sulfatos, uma vez que pode ocorrer precipitação do cálcio como sulfato de cálcio.

Castellane \& Araújo (1995) discordam a respeito da quantidade de amônio na solução nutritiva afirmando que, do nitrogênio total, tolera-se até $25 \%$ de amônio na solução nutritiva.

Segundo Steiner (1984) o produto das concentrações dos íons $\mathrm{Ca}^{++} \mathrm{e}$ $\mathrm{SO}_{4}{ }^{-}$, em $\mathrm{mg} / \mathrm{l}$, não deve exceder o valor de 60 para que não ocorra precipitação como $\mathrm{CaSO}_{4}$, independente do $\mathrm{pH}$. Outro cuidado que se deve tomar, segundo este mesmo autor, é com relação a mistura de $\mathrm{Ca}^{++}$e $\mathrm{HPO}_{4}^{-}$, cujo produto não deve exceder 2,2 para que não ocorra precipitação como $\mathrm{CaHPO}_{4}$.

\subsubsection{Uso e manejo}

De acordo com Castellane \& Araújo (1994) quanto maior for o volume de solução por planta, menores serão as alterações nas concentrações de nutrientes, além disso, um maior volume por planta, permite um maior contato dos elementos essenciais com o sistema radicular e uma maior diluição dos efeitos de substâncias tóxicas ou inibitórias, que por ventura possam estar inseridas nos sistema (Jones Jr., 1983).

Carmello (1997) concorda com Castellane \& Araújo (1994) e afirma que no sistema NFT, o volume de solução nutritiva para cada planta, no caso de folhosas, 
não deve ser inferior a 1,0 litro. Afirma ainda que o volume de água evaporada deve ser reposto diariamente.

Com relação à oxigenação da solução nutritiva, trata-se de um fator muito importante pois, como a planta necessita de energia para a absorção de nutrientes e esta energia é obtida pela respiração, há necessidade de oxigênio para que ocorra a absorção dos elementos essenciais ao seu desenvolvimento. Quando se trata do sistema NFT, sua circulação contínua de água promove excelente aeração na solução nutritiva, porém se houver necessidade de aumentar esta aeração, sugere-se o borbulhamento de ar dentro da solução nutritiva (Carmello, 1997).

Quanto à temperatura, Castellane \& Araújo (1995) afirmam que a faixa mais adequada às plantas é de $20 \mathrm{a} 30^{\circ} \mathrm{C}$.

Para a renovação da solução nutritiva, Jones Jr. (1982) sugere duas possibilidades: aumentar o volume de solução por planta, utilizando-a por curtos períodos (5-10 dias), antes da substituição total por uma nova ou monitorar a composição da solução durante o seu uso e fazer adições para manter a sua composição $\mathrm{e} \mathrm{pH}$ iniciais.

Jansen \& Collins (1983) sugerem começar uma nova solução, e após uma semana de uso adicionar uma solução com metade da concentração inicial, para repor os volumes e nutrientes gastos e, após a segunda semana descarta-se tudo, para então repetir todo o procedimento.

Carmello (1997) apresenta outro método, onde sugere acrescentar água todos os dias e acompanhar a CE até atingir $1 \mathrm{mS} . \mathrm{cm}^{-1}$. A partir disso opta-se por colocar os sais para repor ou trocar toda a solução. Uma terceira opção seria uma reposição diária de solução nutritiva na quantidade equivalente a que foi reduzida do recipiente.

\subsubsection{Condutividade elétrica (CE)}

A condutividade elétrica de uma solução indica a quantidade de sais que ela contém, pois uma vez que a água pura não pe uma boa condutora de eletricidade, na 
medida que sais vão sendo adicionados a ela, a sua condutividade elétrica aumenta. A condutividade elétrica é medida por um aparelho chamado condutivímetro e sua unidade é $\mathrm{mS} . \mathrm{cm}^{-1}$ (Carmello, 1997).

De acordo com Carmello (1997), a condutividade elétrica pode ser utilizada como parâmetro para a tomada de decisões do momento de troca da solução nutritiva ou reposição de sais, porém não se trata de um parâmetro preciso uma vez que indica a quantidade total de sais e não a quantidade de cada sal, portanto se o objetivo for o conhecimento exato dos nutrientes presentes na solução em questão, deve-se fazer uso das análises químicas (Castellane \& Araújo, 1994).

Em vista disso é preciso ter critério para a utilização da CE como base para manejar a solução nutritiva, para não causar um desbalanceamento da mesma, o que pode prejudicar severamente a cultura.

\section{$2.4 .4 \mathrm{pH}$}

Trata-se de um indice que mede a concentração de hidrogênio ou potencial hidrogeniônico da solução nutritiva e é medido por um aparelho chamado peagâmetro. $\mathrm{O}$ mecanismo que controla a acidez ou alcalinidade de uma solução nutritiva, baseia-se na presença de íons $\mathrm{H}^{+}$e $(\mathrm{OH})^{-}$presentes, que são formados pela dissociação de ácidos quando ocorre mistura de ácidos e água $\left(\mathrm{H}^{+}\right)$ou mistura de bases com água $(\mathrm{OH})^{-}$. Quando há equilíbrio destes íons, o valor do $\mathrm{pH}$ se encontra próxima à neutralidade, ou seja, ao valor 7 (Moraes, 1997).

Partindo-se do pressuposto de que o $\mathrm{pH}$ é o fator isolado que mais influencia a disponibilidade de nutrientes (Malavolta et al., 1997), de que nenhuma planta consegue sobreviver satisfatoriamente a valores de $\mathrm{pH}$ menores que 3,5 pois ocorre um efeito tóxico direto dos íons H+ sobre as células vegetais (Carmello, 1997) e ainda de que a faixa mais adequada de pH para ótima disponibilidade de nutrientes está entre 5 e 7 (Haag et al., 1993), conclui-se que, em função da maior ou menor tolerância das plantas à acidez ou alcalinidade, o pH de uma solução nutritiva deva se mantido na faixa de 6 a 6,5 (Carmello, 1997). 
Segundo Jones Jr. (1983) o pH afeta principalmente a disponibilidade de micronutrientes, provocando a absorção excessiva quando os valores são baixos e precipitação em valores elevados de $\mathrm{pH}$. Quando o $\mathrm{pH}$ está abaixo de 5 a absorção de cátions é mais afetada do que a de ânions devido a competição entre os cátions $\mathrm{H}^{+} \mathrm{e}$ os essenciais $\left(\mathrm{NH}_{4}^{+} ; \mathrm{K}^{+} ; \mathrm{Ca}^{++} ; \mathrm{Mg}^{++} ; \mathrm{Cu}^{++} ; \mathrm{Fe}^{++} ; \mathrm{Mn}^{++} ; \mathrm{Zn}^{++}\right)$; ocorrendo o contrário em valores acima de 7 quando ocorre competição entre os ânions OH- e os ânions essenciais $\left(\mathrm{NO}_{3}{ }^{-} ; \mathrm{SO}_{4}^{-} ; \mathrm{Cl}^{-} ; \mathrm{MoO}_{4}^{-}\right)$(Graves, 1983; Carmello \& Furlani, 1994).

As plantas cultivadas em faixas de $\mathrm{pH}$ favoráveis possuem incrementos em seu desenvolvimento, e uma vez que o sistema NFT permite um ótimo controle sobre este fator tão limitante, é de suma importância o controle diário do $\mathrm{pH}$ da solução através do acréscimo de ácido para reduzi-lo ou de base para aumentá-lo. Normalmente, para esta correção, utiliza-se ácidos ou bases que, na dissociação dos íons, formam nutrientes, além de corrigir os valores de $\mathrm{pH}$. Para tanto, pode-se utilizar os ácidos nítrico, fosfórico e sulfúrico para abaixar os valores de $\mathrm{pH}$ e a base hidróxido de potássio para elevar o pH da solução (Moraes, 1997).

Jones Jr. (1983) afirma que há necessidade de monitoramento diário do $\mathrm{pH}$, porém ressalta que existem plantas que acidificam regiões próximas às suas raizes, para aumentar a sua habilidade de absorver certos nutrientes como o ferro. Neste caso, se a solução for, constantemente, ajustada pode ser que esta habilidade natural seja alterada. Além disso, sugere que, por ocasião de ajuste de $\mathrm{pH}$, utilize-se, de preferência, a base $\mathrm{NaOH}$ e o ácido $\mathrm{HCl}$ por não conterem elementos essenciais.

Segundo Graves (1983) a absorção desigual dos íons pelas plantas e a adição de água para reposição do volume perdido, geralmente aumentam o $\mathrm{pH}$ da solução e a utilização de ácidos, para correção, que contenham elementos essenciais como o $\mathrm{HNO}_{3}, \mathrm{H}_{2} \mathrm{SO}_{4}$ e $\mathrm{H}_{3} \mathrm{PO}_{4}$ pode promover um acúmulo de nitrato, sulfato ou fosfato, respectivamente, ions estes que contribuirão para aumentar a salinidade do sistema, e se este for controlado por uma CE constante, as medições ficarão mascaradas havendo necessidade de aumentar a CE com o tempo, ou efetuar a troca da solução nutritiva por uma nova ou ainda, aumentar o volume de solução nutritiva por planta. 
Esta correção deve ser feita sempre no período da tarde, uma vez que os valores aferidos pela manhã, sofrem alterações naturais durante o dia, devido as diferenças na solubilidade do $\mathrm{CO}_{2}$ na solução nutritiva (Moraes, 1997; Jones Jr., 1983).

De acordo com Carmello (1997) para manter um pH favorável (entre 6,5 e 7) para o crescimento das plantas, basta adicionar 1 grama de carbonato de cálcio por litro de solução. Contudo, mesmo utilizando-se este método, é imprescindível a verificação diária para a correção rápida de qualquer problema que possa ocorrer, evitando-se assim danos à cultura.

\subsection{Cultivo do tomate em hidroponia}

\subsubsection{Absorção de nutrientes e produção}

De acordo com Takahashi (1993) o tomate estaqueado é uma planta muito complexa pois, em grande parte do seu período de desenvolvimento, ocorrem simultaneamente o crescimento vegetativo e o desenvolvimento reprodutivo.

Comenta ainda que, por ocasião do crescimento dos frutos do primeiro e do segundo rácimo, provavelmente devido a demanda de nutrientes e carboidratos, ocorre uma paralisação do crescimento vegetativo e, pode-se considerar que esta é a fase de maior exigência de água, nutrientes e condições ambientais adequadas.

De acordo com Gargantini \& Blanco (1963) o crescimento inicial do tomateiro não é muito rápido, porém após 30 dias ocorre um desenvolvimento mais rápido, atingindo, aos 40 dias, o dobro do crescimento alcançado no final do primeiro mês. Comentam ainda que no final do ciclo, o fruto representa, em média $65 \%$ da matéria seca total produzida e como esse crescimento do fruto se dá em um período relativamente curto, há necessidade de que a velocidade de absorção de nutrientes seja muito grande e, para atender esta demanda deve-se disponibilizar os nutrientes necessários para que a cultura alcance bom rendimento.

Ainda de acordo com estes autores, a época de maior demanda de nutrientes coincide com o período de maior desenvolvimento dos frutos, isto é, dos 90 
aos 120 dias, época em que a planta se torna mais vulnerável a patógenos e a deficiências nutricionais.

Adams \& Massey (1989) avaliando 3 experimentos onde aferiram absorção de $\mathrm{N}, \mathrm{K}$ e água, das plantas de tomate, cultivar Sonato, observaram que nas primeiras semanas após o plantio as plantas removeram o $\mathrm{K}$ e o $\mathrm{N}$, respectivamente, em uma taxa de 1,2:1,0. Com o aparecimento dos frutos, a taxa de absorção de $\mathrm{K}$ continuou a subir, aumentando a relação para 2,5:1,0 e, após esta fase, houve um decréscimo na absorção deste elemento ficando a relação em 2:1

Wilson (1980), em estudo realizado com tomate cultivado em sistema hidropônico, avaliou 3 diferentes relações $\mathrm{K}: \mathrm{N}$ - 3:1; 2:1 e 1,5:1, concluindo que as doses recomendadas de $\mathrm{K}$ e $\mathrm{N}$ seriam $300 \mathrm{mg} / \mathrm{l} \mathrm{e} 125 \mathrm{mg} / \mathrm{l}$ respectivamente, ou seja, uma relação de $2,4: 1$.

Resh (1995) e Moraes (1997) sugerem para o cultivo de tomate no sistema NFT a relação K:N 2:1.

Segundo Takahashi (1993) o fruto de tomate é riquíssimo em K, uma vez que, do total absorvido pela planta a maior parte, cerca de $70 \%$, é acumulada nos frutos. Isso mostra que a planta de tomate é diferente da maior parte das plantas cultivadas que deixam grande parte do K absorvido nos restos de cultura. Minami \& Haag (1989) concordam com esta afirmação dizendo que o $\mathrm{K}$ é o elemento predominante nos frutos e nas folhas predominam o $\mathrm{K}$ e o N.

Filgueira (1982), afirma que numerosos experimentos comprovaram serem pequenos os efeitos do elemento $\mathrm{K}$ na produtividade do tomateiro, mas trata-se de um elemento de grande influência na qualidade dos frutos, ao contrário do nitrogênio que mostrou ser o nutriente que mais promoveu o crescimento vegetativo, sendo favorável à alta produtividade.

Segundo Harvey (1939) a eficiência do aproveitamento de N, pela planta, difere entre os genótipos de tomateiro, o que mostra ser uma característica geneticamente herdável. O'Sullivan et al. (1974) observaram que, em condições de baixa disponibilidade, genótipos eficientes produziram cerca de $47 \%$ mais matéria seca que os ineficientes para N. Entretanto, experimento realizado por Makmur et al. (1978) 
mostra que esta característica pode não ser verdadeira para todos os nutrientes como sugere o caso do elemento $\mathrm{K}$, que aplicado em doses iguais para vários genótipos, não proporcionou ganhos diferenciados em matéria seca.

Os vegetais, de maneira geral, obtêm a água e os minerais de que necessitam, diretamente do solo, porém quando cultivados em sistema hidropônico, todos os elementos necessários à vida dos mesmos devem estar presentes na solução nutritiva. (Moraes, 1997).

Segundo Martinez et al. (1997) o aumento na produtividade do tomateiro cultivado em sistema hidropônico, tem sido de 20 a $25 \%$ superior em relação ao cultivo convencional.

\subsubsection{Manejo da solução nutritiva}

De acordo com Moraes (1997), existem informações muito variadas sobre a solução nutritiva ideal para o tomateiro, que deve estar associada a épocas diferentes de plantio e fases de desenvolvimento da planta. Baseando-se nisto, o quadro 5 mostra as faixas de concentração nutricional, consideradas normais, e que têm sido utilizadạs com sucesso nas lavouras comerciais.

De acordo com Resh ( 1995), em relação aos macronutrientes, a solução nutritiva, para o cultivo do tomate, deve ser modificada de acordo com o estágio de desenvolvimento da planta, sendo dividida em 3 fases durante o ciclo (quadro 6). Para os micronutrientes a solução deve permanecer constante durante todo o ciclo.

$A$ fase $A$, compreende $o$ período entre 3 folhas,perfeitamente, desenvolvidas ( 10 a 14 dias) até a altura 35 a $40 \mathrm{~cm}$; a fase B corresponde a frutos com 0,6 a $1,2 \mathrm{~cm}$ de diâmetro e a fase $\mathrm{C}$ corresponde ao restante do ciclo. 
Quadro 5 - Valores de referência para composição de solução nutritiva para o tomateiro

\begin{tabular}{|c|c|c|}
\hline Mrmurimer & R. & 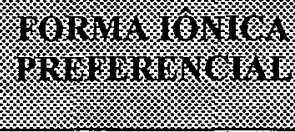 \\
\hline Nitrogênio & 150 a 200 & $\mathrm{NO}_{3}{ }^{-}, \mathrm{NH}_{4}{ }^{+}$ \\
\hline Fósforo & 40 a 60 & $\mathrm{H}_{2} \mathrm{PO}_{4}^{-}, \mathrm{H}_{2} \mathrm{PO}_{4}^{-}$ \\
\hline Potássio & 250 a 350 & $\mathrm{~K}^{+}$ \\
\hline Cálcio & 150 a 250 & $\mathrm{Ca}^{+++}$ \\
\hline Magnésio & 40 a 60 & $\mathrm{Mg}^{++}$ \\
\hline Enxofre & 50 a 150 & $\mathrm{SO}^{-}$ \\
\hline Ferro & 1,5 a 2,5 & $\mathrm{Fe}^{7+}$ \\
\hline Manganês & $0,5 \mathrm{a} 0,8$ & $\mathrm{Mn}^{++}$ \\
\hline Boro & $0,5 \mathrm{a} 0,6$ & $\mathrm{H}_{3} \mathrm{BO}_{3}$ \\
\hline Zinco & 0,1 a 0,2 & $\mathrm{Zn}^{++}$ \\
\hline Cobre & 0,1 a 0,2 & $\mathrm{Cu}^{++}$ \\
\hline Molibdênio & 0,01 & $\mathrm{Mo}_{6}{ }^{+}$ \\
\hline Cloro & 100 a 150 & $\mathrm{Cl}^{-}$ \\
\hline
\end{tabular}

Martinez et al. (1997) consideram que o conhecimento da relação N:K é essencial para a formulação da solução nutritiva ideal para a cultura do tomate, pois caso não este critério não seja levado em consideração, pode ocorrer desbalanços nutricionais graves.

Carmello (1997) comenta que altas salinidades podem afetar as relações entre os nutrientes. Altas concentrações de sulfato promovem absorção de sódio, levando à toxidez por este elemento; diminuem a absorção de cálcio, levando à deficiência deste elemento; além de interferirem na absorção de $K$. Em relação ao tomateiro, acredita-se que o excesso de sais interfira na absorção de cálcio, causando a podridão apical, recomenda-se, portanto, uma pressão osmótica de 0,4 atm como a melhor, para se ter um bom desenvolvimento de plantas de tomateiro em áreas tropicais.

Martinez et al. (1997) comentam que, em tomateiro, a porcentagem de matéria seca dos frutos parece aumentar quando a concentração salina está em torno de $10 \mathrm{mS} . \mathrm{cm}^{-1}$, embora o número e o tamanho dos frutos possam diminuir. Desta forma, muitos produtores adotam o critério de elevar a salinidade para melhorar a qualidade dos frutos de tomate. 
Quadro 6 - Formulação de nutrientes para o cultivo hidropônico

do tomateiro, de acordo com as fases do ciclo.

\begin{tabular}{|c|c|c|}
\hline 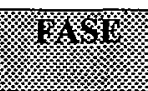 & 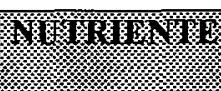 & 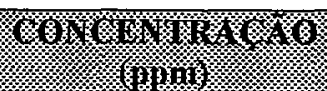 \\
\hline \multirow[t]{6}{*}{$\mathrm{A}$} & $\mathrm{N}$ & 100 \\
\hline & $P$ & 40 \\
\hline & $\mathrm{K}$ & 200 \\
\hline & $\mathrm{Ca}$ & 100 \\
\hline & $\mathrm{Mg}$ & 20 \\
\hline & $S$ & 53 \\
\hline \multirow[t]{6}{*}{$B$} & $\mathrm{~N}$ & 130 \\
\hline & $P$ & 55 \\
\hline & $\mathrm{K}$ & 300 \\
\hline & $\mathrm{Ca}$ & 150 \\
\hline & $\mathrm{Mg}$ & 33 \\
\hline & $S$ & 109 \\
\hline \multirow[t]{6}{*}{$\mathrm{C}$} & $\mathrm{N}$ & 180 \\
\hline & $P$ & 65 \\
\hline & $\mathrm{K}$ & 400 \\
\hline & $\mathrm{Ca}$ & 400 \\
\hline & $\mathrm{Mg}$ & 45 \\
\hline & $\mathrm{S}$ & 144 \\
\hline \multirow[t]{6}{*}{$\mathrm{A}, \mathrm{B}, \mathrm{C}$} & $\mathrm{B}$ & 0,3 \\
\hline & $\mathrm{Mn}$ & 0,8 \\
\hline & $\mathrm{Cu}$ & 0,07 \\
\hline & $\mathrm{Zn}$ & 0,1 \\
\hline & Mo & 0,03 \\
\hline & $\mathrm{Fe}$ & 3 \\
\hline
\end{tabular}

Fonte: Resh (1995)

De acordo com Moraes (1997) o cultivo de tomate merece algumas considerações que podem diferenciar o seu manejo quando comparado com o das folhosas, como por exemplo, a alface.

Quando se trata de folhosas, em especial a alface, sabe-se que é relativamente fácil se chegar à uma estabilidade em relação a solução nutritiva, uma vez que, ao se atingir o equilíbrio das plantas no sistema, entra-se em uma fase em que a variação nutricional se altera apenas em função das condições ambientais (Moraes, 1997). 
No sistema em equilíbrio tem-se desde mudas recém-transplantadas até plantas em estágio de colheita e, sempre que se colhe uma planta, outra é recolocada em seu lugar, definindo um número de folhas em desenvolvimento praticamente estável para determinado volume de solução nutritiva (Moraes, 1997).

Esta estabilidade permite a reposição nutricional constante e dentro de certas condições homogêneas conhecidas. Um mecanismo de reposição para alface, que tem sido muito utilizado, é o de se efetuar a adubação com base nos volumes de água consumidos (Moraes, 1997).

Ainda de acordo com este autor, o tomateiro apresenta características bem diferentes da alface, pois, seu produto final é um fruto. E neste caso, a reposição por volumes leva a uma margem de erro muito grande, pois a cultura possui um ciclo mais longo e os consumos nutricionais são diferentes em cada fase do ciclo. Posto isso, recomenda-se que sejam feitas análises periódicas da solução nutritiva, para se conhecer o consumo e assim, poder efetuar a adubação mais racionalmente.

Estas análises são feitas da seguinte maneira: faz-se uma análise inicial ou consideram-se os valores calculados como referência de concentração; após determinado período, de acordo com a fase de desenvolvimento da cultura, efetua-se outra análise laboratorial; a diferença nas concentrações das duas análises fornece o consumo médio no período; efetua-se então a média de consumo em gramas do sal ou ppm do nutriente no período, e este valor pode ser utilizado para adubações de reposição. A medida em que as plantas se desenvolvem, os consumos se alteram e deverão ser ajustados periodicamente (Moraes, 1997).

Alguns fatores podem afetar o padrão de consumo de alguns nutrientes, como os fatores ambientais e a cultivar utilizada, portanto não há como adotar um padrão fixo de adubação, que deverá ser alterado de acordo com as condições de plantio e o material genético utilizado. As análises são parâmetros técnicos que direcionam um consumo médio num determinado período, mas os ajustes finos devem ser feitos ao longo do ciclo. Quanto menor o intervalo de análises da solução hidropônica, melhores condições nutricionais serão obtidas (Moraes, 1997). 
Segundo Cooper (1982) as plantas de tomate são afetadas por exudatos advindos das raizes por ocasião do cultivo em solução nutritiva. Em vista disso, como foi observada uma relação entre o volume da caixa recipiente e o fluxo da solução nutritiva através dele, concluiu-se que para um melhor desenvolvimento das plantas do tomateiro, deve-se utilizar 8,5 litros de solução nutritiva por planta por dia.

Moraes (1997) afirma ainda que na medida em que a técnica for se expandindo, produtores mais capacitados sentirão necessidade de ter um conhecimento mais aprofundado do complexo sistema vegetal, pois a análise dos sintomas de deficiência e toxidez, junto com a análises de solução nutritiva, não proporcionam tomadas de decisão rápidas e, portanto, sempre haverá um decréscimo de rendimento.

Moraes (1997) concorda com Cooper (1995) quando afirma que o vegetal realiza funções metabólicas para a sua manutenção e desenvolvimento e, neste processo, desenvolve uma série de reações, envolvendo respiração e fotossíntese, formando em suas raízes alguns exudados característicos, que no caso do tomateiro não se apresentam como fatores limitantes. Entretanto, a simples filtragem destes exudados, com carvão, proporcionou, em alguns casos, plantas mais vigorosas e produtivas. Por este motivo, em períodos específicos de crescimento das plantas, quando ocorre um aumento da velocidade do metabolismo, a troca da solução nutritiva deve ser efetuada por completo. $\mathrm{Na}$ prática sugere-se que pelo menos na fase pré-colheita seja realizada esta troca que, além de trazer este benefício, também elimina possíveis fontes de inóculo e elementos prejudiciais às plantas, que podem ser incorporados às soluções através dos próprios adubos (Moraes, 1997).

Em relação à manutenção do volume da solução, o mesmo autor ressalta que, como as plantas consomem mais água que nutrientes, deve-se completar o volume de água do tanque diariamente, independente da adubação, complementar ou reposicional. Para se calcular o volume do tanque a ser utilizado, deve-se levar em consideração a máxima quantidade de solução que uma planta consumiria nos dias mais quentes do ciclo, para que não haja risco de que, nestes dias, o volume dentro da caixa fique muito pequeno, o que promove uma concentração exagerada da solução nutritiva não permitindo que as plantas retirem os nutrientes do meio. 


\section{MATERIAL E MÉTODOS}

\subsection{Condições experimentais}

O experimento foi realizado na área experimental do Departamento de Produção Vegetal da Escola Superior de agricultura "Luiz de Queiroz" (ESALQ), localizada em Piracicaba, São Paulo, no período de 08/07/1998 a 20/12/1998. As condições meteorológicas neste período, registradas na estação meteorológica do Departamento de Física e Meteorologia, constam no anexo 2.

Para a execução do experimento utilizou-se uma estrutura de cobertura plástica, de $350 \mathrm{~m}^{2}$, com $2,8 \mathrm{~m}$ de pé direito e antecâmara.

A estrutura para a condução das plantas constou de mourões de concreto, estruturas de metal (a cada $2,5 \mathrm{~m}$ ) que, além de auxiliarem na condução das plantas, também serviram de suporte para sustentação das tubulações recipientes. Para completar o sistema de condução, foram esticados arames e fitilhos.

Todo o solo da estrutura foi recoberto com pedrisco e cal para que o local estivesse sempre limpo e livre de plantas daninhas. A cal foi colocada sempre que houve necessidade, durante todo o experimento.

Foram utilizadas tubulações recipientes trapezoidais, de PVC, de 6", colocadas a uma distância mínima de $0,20 \mathrm{~m}$ do solo, de modo que ficassem com $3 \%$ de declividade, para que fosse possível o retorno das soluções à caixa de origem. A vazão utilizada para a entrada das soluções nutritivas nas tubulações recipientes, foi 10 litros/min/tubo. 
As tubulações recipientes foram pintadas de preto, para que não houvesse desenvolvimento de algas, e ainda foram pintadas de branco por cima, para evitar o aumento da temperatura das soluções nutritivas.

Foram utilizadas 8 linhas de tubos recipientes, interrompidas no abastecimento, a cada $9 \mathrm{~m}$, porém interligadas no retorno, formando assim 5 blocos com 8 linhas de tubo, com $9 \mathrm{~m}$ cada. Para cada 2 linhas foi utilizada uma caixa de solução nutritiva de 1500 litros, feita de fibra de vidro. Estas caixas foram colocadas em um nível abaixo das tubulações, para que fosse possível o retorno da solução nutritiva, por gravidade. A distribuição das tubulações recipientes, bem como das caixas de soluções nutritivas, pode ser melhor visualizada no croqui a seguir.

Para alimentação das caixas de solução nutritiva, foi instalada uma caixa de água, no lado de fora da estrutura, com capacidade de 10.000 litros, construída também de fibra de vidro.

Como foram utilizadas 4 soluções nutritivas diferentes, e para cada solução havia dois sistemas de aplicação da solução, um demandando alta vazão (NFT) e o outro alta pressão (NNT), foram utilizados 8 conjuntos moto-bomba, sendo que para o sistema NFT possuíam potência de $0,5 \mathrm{CV}$ e para o sistema NNT, de $1 \mathrm{CV}$.

Também foi utilizado um timer para controlar o tempo de funcionamento das bombas, para cada sistema de aplicação da solução nutritiva.

\subsection{Tratamentos e delineamento experimental}

O experimento foi instalado utilizando-se como delineamento experimental blocos, com restrição na casualização, num esquema em faixas. Um dos fatores foi 2 diferentes sistemas de aplicação das soluções (NFT e NNT) e o outro fator foi 4 diferentes soluções nutritivas (com diferentes relações K:N). Foram utilizadas 5 repetições, representadas pelos blocos. 

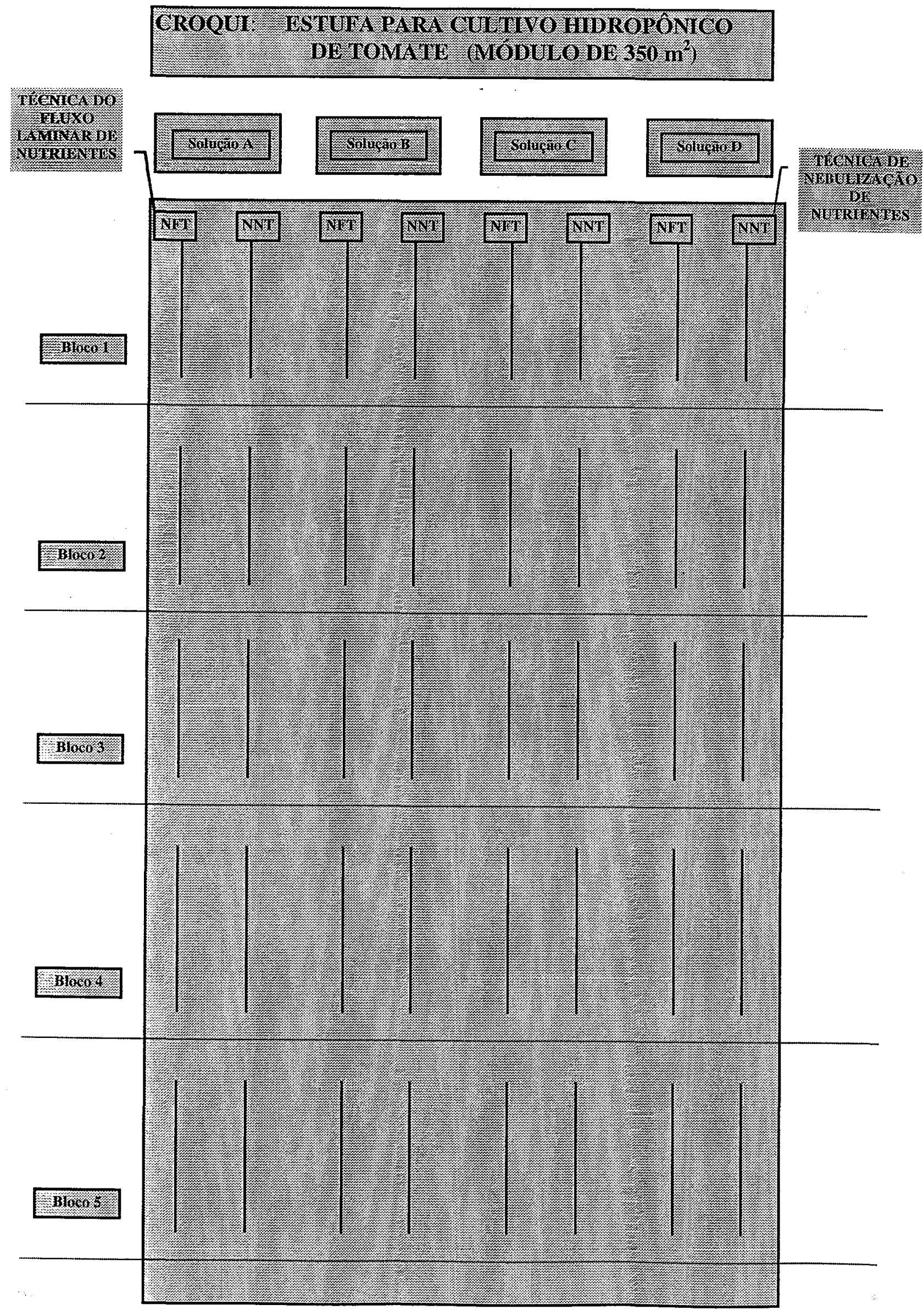
Cada parcela experimental foi composta por 18 plantas, perfazendo um total de 90 plantas por combinação. O espaçamento entre plantas adotado foi de $0,50 \mathrm{~m} \mathrm{e}$ entre linhas (tubulações) foi de $0,80 \mathrm{~m}$. Cada bloco foi constituído por 144 plantas, totalizando 720 plantas em todo o experimento.

As diferentes soluções utilizadas foram:

- solução 1A: relação $\mathrm{K}: \mathrm{N}=2: 1$ do início ao fim do ciclo;

- solução $1 \mathrm{~B}$ : relação $\mathrm{K}: \mathrm{N}=2: 1$ até o início do florescimento e 3:1 até o fim do ciclo;

- solução 2A: relação $\mathrm{K}: \mathrm{N}=3: 1$ do início ao fim do ciclo;

- solução $2 \mathrm{~B}$ : relação $\mathrm{K}: \mathrm{N}=3: 1$ até o início do florescimento e 2:1 até o fim do ciclo.

Vale salientar que, optou-se por trabalhar com duas soluções nutritivas, baseando-se nos dois estádios principais da planta: fase vegetativa e fase reprodutiva. Com isso realizou-se a mudança da solução quando as plantas iniciaram o florescimento, caracterizando o início da fase reprodutiva, com o que concorda Papadopoulos (1991), afirmando que a formação de 7 a 12 folhas e a emissão do primeiro cacho floral caracterizam o fim do primeiro estádio de crescimento da planta de tomate, dando início a fase reprodutiva.

Os demais nutrientes foram mantidos nas mesmas proporções, em todas as soluções.

Os diferentes sistemas de aplicação das soluções foram:

- sistema 1: NFT-Nutrient Film Technique-técnica do fluxo laminar de nutrientes;

- sistema 2: NNT- Nutrient Nebulization Technique - técnica de nebulização de nutrientes onde a solução nutritiva era nebulizada dentro da tubulação através de "fogers" ( $7 \mathrm{l} / \mathrm{h})$, instalados 2 por planta.

Como as soluções nutritivas foram aplicadas nos dois sistemas, totalizouse 08 combinações:

- $\quad 1 \mathrm{AN}=\mathrm{K}: \mathrm{N} 2: 1$ durante todo o ciclo; sistema NFT;

- $1 \mathrm{BN}=\mathrm{K}: \mathrm{N} 2: 1$ até o início do florescimento e 3:1 no restante do ciclo; sistema NFT; 
- $2 \mathrm{AN}=\mathrm{K}: \mathrm{N} 3: 1$ durante todo o ciclo; sistema NFT;

- $2 \mathrm{BN}=\mathrm{K}: \mathrm{N}$ 3:1 até o início do florescimento e 2:1 no restante do ciclo; sistema NFT;

- $\quad 1 \mathrm{AF}=\mathrm{K}: \mathrm{N} 2: 1$ durante todo o ciclo; sistema NNT;

- $1 \mathrm{BF}=\mathrm{K}: \mathrm{N} 2: 1$ até o início do florescimento e 3:1 no restante do ciclo; sistema NNT;

- $2 \mathrm{AF}=\mathrm{K}: \mathrm{N} 3: 1$ durante todo o ciclo; sistema NNT;

- $2 \mathrm{BF}=\mathrm{K}: \mathrm{N}$ 3:1 até o início do florescimento e 2:1 no restante do ciclo; sistema NNT;

\subsection{Instalação e condução do experimento}

\subsubsection{Produção das mudas}

Foi utilizado um híbrido F1 comercial, de tomate tipo caqui, para salada, do segmento longa vida, de crescimento indeterminado, denominado Carmem, da Empresa Agroflora / Sakata.

A semeadura foi realizada no dia 08/07/1998.

Utilizou-se como substrato espuma fenólica, que pode ser transplantada junto com a muda. Porém esta espuma precisou sofrer um tratamento, para retirada de sua acidez, que consistiu na sua imersão em água limpa por 24 horas.

Foram separadas 8 bandejas convencionais, de isopor, de 128 células, que foram devidamente limpas e desinfectadas com água sanitária.

Após imersão em água limpa e secagem, as espumas fenólicas, que foram adquiridas em placas cortadas em cubos de $3 \mathrm{~cm}^{3}$, foram colocadas nas bandejas, um cubo por célula.

Já dentro das células das bandejas, estas espumas foram novamente encharcadas com água limpa e em cada um dos cubos foi feito um orificio de 
aproximadamente $5 \mathrm{~mm}$ de profundidade onde foram colocadas as sementes, uma por célula.

A semeadura foi realizada em laboratório, e as bandejas foram mantidas no mesmo local, devidamente umedecidas, até a germinação, que ocorreu no quinto dia após a semeadura, em 12/07/98.

No dia $14 / 07 / 98$ as bandejas foram levadas para uma estufa para que a produção das mudas se realizasse em um sistema hidropônico com solução diluída. As bandejas ficaram flutuando em uma piscina de fibra de vidro, no sistema denominado "floating", cuja solução diluída circulava, controlada por um "timer", por 6 minutos a cada 30 minutos durante o dia e a cada duas horas durante a noite. Quando a solução atingia um determinado nível na piscina de fibra de vidro, escoava por um orificio e retornava a um reservatório ao qual foi acoplado uma bomba que impulsionava a solução para o "floating".

Para a adubação das mudas foi utilizado, desde que as bandejas foram transferidas para o "floating", o adubo Plant Prod 20-20-20 (fertilizante concentrado solúvel com micronutrientes), cujos percentuais nutricionais são descritos no quadro 7 .

Quadro 7 - Porcentagem de nutrientes contidos no adubo utilizado para produção de mudas

\begin{tabular}{|l|c|}
\hline Nitrogênio total (N) & (1) \\
\hline Ácido fosfórico disponível (P2O5) & 20 \\
\hline Potassa solúvel (K2O) & 20 \\
\hline Boro (B) & 20 \\
\hline Cobre quelato (Cu) & 0,02 \\
\hline Ferro quelato (Fe) & 0,05 \\
\hline Manganês quelato (Mn) & 0,1 \\
\hline Molibdênio (Mo) & 0,05 \\
\hline Zinco quelato (Zn) & 0,0005 \\
\hline EDTA (agente quelante) & 0,05 \\
\hline
\end{tabular}

A cada 10 dias a solução utilizada, para a produção das mudas, foi renovada, pois como tratava-se de uma solução nutritiva bem diluída, o consumo dos nutrientes ocorria relativamente rápido. 
Houve uma preocupação maior em relação aos nutrientes oferecidos, pois, o substrato utilizado, espuma fenólica, por ser totalmente inerte, não fornecia nenhum tipo de nutrientes, ao contrário dos substratos comerciais utilizados na produção convencional de mudas de hortaliças, que recebem uma adição de nutrientes, o que, normalmente, garante um bom estado nutricional das mudas até o transplante.

$\mathrm{O}$ método utilizado na produção de mudas, aliado à qualidade das sementes híbridas, proporcionou germinação e desenvolvimento, bastante uniforme.

\subsubsection{Preparo da solução nutritiva}

Para o preparo da solução nutritiva, inicialmente atentou-se para a necessidade nutricional da planta de tomate, ou seja, a quantidade de nutrientes que esta planta extrai. Para tanto foram utilizados dados de literatura (Takahashi, 1993 ; Resh, 1995) e também dados obtidos no trabalho de residência agronômica desenvolvido por Pontes, $1996^{1}$.

Como foram estudadas duas relações $\mathrm{K}: \mathrm{N}$, foram calculadas duas soluções nutritivas, cuja composição se encontra no quadro 8 .

Quadro 8 - Exigência nutricional da planta, adubos utilizados e solução nutritiva final utilizada.

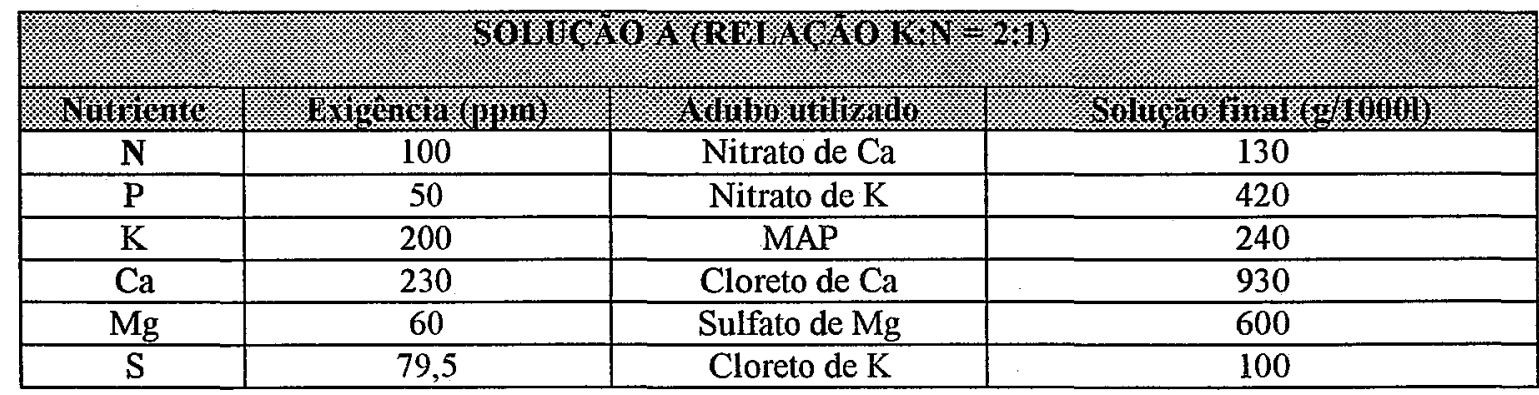

${ }^{1}$ PONTES, A.L.. Produção de tomate (Lycopersicon esculentum ) em hidroponia, no sistema NFT (Nutriet Film Tecnique), em ambiente protegido. Trabalhos de residência agronômica, 1996 - não publicado. 


\begin{tabular}{|c|c|c|c|}
\hline \multicolumn{4}{|c|}{ 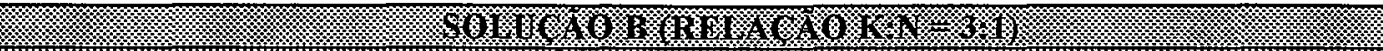 } \\
\hline Writan & 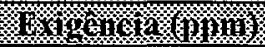 & 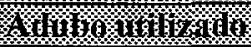 & 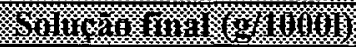 \\
\hline $\mathbf{N}$ & 100 & Nitrato de Ca & 130 \\
\hline $\bar{P}$ & 50 & Nitrato de K & 420 \\
\hline $\mathrm{K}$ & 300 & MAP & 240 \\
\hline $\mathrm{Ca}$ & 230 & Cloreto de $\mathrm{Ca}$ & 930 \\
\hline $\mathrm{Mg}$ & 60 & Sulfato de Mg & 600 \\
\hline $\mathbf{S}$ & 79,5 & Cloreto de $\mathrm{K}$ & 300 \\
\hline
\end{tabular}

Com relação aos micronutrientes, foi utilizada uma solução com todos os micronutrientes quelatizados, cujas porcentagens, de cada elemento, foram as seguintes: $\mathrm{B}=0,28 ; \mathrm{Cu}=0,05 ; \mathrm{Fe}=5,7 ; \mathrm{Mn}=1,2 ; \mathrm{Mo}=0,08 ; \mathrm{Zn}=0,37$.

Para maior facilidade, por ocasião da troca ou complemento da solução nutritiva, foi preparada uma solução estoque para cada um dos macronutrientes. Esta solução estoque foi preparada baseada na solubilidade mais baixa dos nutrientes utilizados que é a do cloreto de potássio. Foram preparados 50 litros de solução estoque para cada macronutriente, a $28 \%$, a qual era inserida no sistema, de acordo com a necessidade. Como as concentrações de solução estoque eram idênticas para todos os adubos, por ocasião da utilização das mesmas, o que variava era a quantidade em $\mathrm{ml}$, utilizada de cada um deles.

\subsubsection{Transplante das mudas}

O transplante das mudas ocorreu no dia 10/08/98, portanto com 34 dias desde a semeadura.

A idade das mudas foi previamente calculada para que ficassem um pouco mais desenvolvidas, tanto no que diz respeito ao sistema radicular quanto ao caule, pois, com isso, a quantidade de raiz seria maior, por ocasião do transplante para a tubulação recipiente, evitando-se assim problemas de absorção e adaptação. Devido às mudas se apresentarem maiores, a fixação das plantas no sistema de condução foi facilitada.

O manejo da cultura foi realizado da maneira convencional no que diz respeito as desbrotas e condução das plantas, com apenas 1 haste. 
As plantas foram conduzidas até a sexta penca, e não houve o raleio de frutos.

O monitoramento das soluções nutritivas foi realizado da seguinte maneira: diariamente era medido o consumo de solução pelas plantas e o nível da caixa era completado com água; para a troca ou reposição de nutrientes utilizou-se um procedimento sugerido por Jansen \& Collins, 1983 que se baseava no monitoramento diário da condutividade elétrica das soluções nutritivas, medida através de um condutivímetro portátil, quando a condutividade elétrica atingia $50 \%$ da inicial, os nutrientes eram repostos nesta mesma proporção, porém como este índice mede a quantidade total de nutrientes, e não de cada nutriente em particular, quando a condutividade elétrica atingia novamente $50 \%$ da inicial toda a solução era trocada por uma nova.

$\mathrm{O}$ pH foi corrigido diariamente para ficar na faixa de 6-6,5. Diariamente, após a complementação das caixas de solução com água limpa, o pH era medido com um peagâmetro portátil e se a solução estivesse muito ácida ( $\mathrm{pH}$ abaixo de 6) era corrigida com hidróxido de potássio ou se estivesse muito básica ( $\mathrm{pH}$ acima de 6,5) era corrigida com ácido fosfórico.

\subsubsection{Aplicação dos tratamentos}

Cada solução foi aplicada através de um sistema independente, composto de 1 caixa de solução nutritiva (capacidade de 1500 litros), tubulações recipientes trapezoidais, de abastecimento e de retorno. Para que cada sistema de solução recirculante pudesse funcionar, foi necessário acoplar a cada um deles um conjunto moto-bomba.

O timer controlador dos sistemas foi colocado com o objetivo de controlar o tempo que os recipientes ficariam com a solução nutritiva circulando, e o tempo em que eles ficariam com o sistema desligado para que houvesse um bom arejamento para as raízes. 
O esquema de intermitência foi diferente para cada sistema de aplicação de solução nutritiva, portanto, para o NFT havia circulação da solução por 5 minutos a cada 20 minutos, ou seja, 5 funcionando e 15 desligado, e para o NNT havia circulação da solução nutritiva por 3 minutos a cada 10 minutos, ou seja 3 funcionando e 7 desligado.

\subsection{Avaliação do experimento}

Foi avaliada a produção de frutos, até a $6^{\mathrm{a}}$ penca, no período de 24/10/98 a 22/12/98. Para cada fruto foram avaliados os parâmetros, número, peso e diâmetro. Na análise estatística não foram considerados os frutos com defeitos graves, conforme descrito no item 4.6 .

Foram avaliados os seguintes parâmetros, por penca e combinação sistema x solução:

- Produção total em número de frutos;

- Produção total em peso de frutos;

- Peso médio de frutos;

- Diâmetro médio de frutos;

Classificou-se como fruto refugo aqueles que não se enquadravam nos parâmetros de comercialização, de acordo com o sistema de classificação CEAGESP sistema corrente e, para efeito comparativo, foi proposto um sistema denominado supermercado. Os critérios de classificação, para os dois sistemas, estão descritos a seguir.

De acordo com o CEAGESP (1998), o critério de classificação, segundo o diâmetro de frutos é o seguinte:

- Oblongos - de 40 a $50 \mathrm{~mm}=$ pequenos;

- de 50 a $60 \mathrm{~mm}=$ médios;

- de 60 a $80 \mathrm{~mm}=$ grandes. 
- Redondos - de 50 a $65 \mathrm{~mm}=$ pequenos;

- de 65 a $80 \mathrm{~mm}=$ médios;

- de 80 a $100 \mathrm{~mm}=$ grandes.

O segundo o critério adotado para determinação de frutos refugos baseou-se nos parâmetros adotados para comercialização de frutos embalados, em bandejas de 4 e 6 frutos, em supermercados (Ortelan, 1998) ${ }^{2}$, onde os seguintes tipos são considerados:

- 100 e $150 \mathrm{~g}$ - tipo 6 (6 frutos na bandeja de isopor);

- 150 e $220 \mathrm{~g}$ - tipo 4 (4 frutos na bandeja de isopor);

- Peso abaixo de $100 \mathrm{~g}$ - refugo.

Vale ressaltar que os tipos 4 e 6 resultam em bandejas com peso médio igual a $750 \mathrm{~g}$.

\subsection{Análise estatística}

Para o parâmetro peso foram geradas as seguintes estatísticas: somatório, média aritmética, coeficiente de variação e contagem, para os diferentes níveis de agrupamento.

Uma análise gráfica foi realizada para os parâmetros peso, número e diâmetro de frutos, a fim de comparar as médias em diferentes níveis de agrupamento.

Os somatórios, em peso e número (produção), foram avaliados em porcentagens, média e acumulada.

As freqüências absoluta e porcentagem dos frutos não analisados, por possuírem graves defeitos (rachamento, fundo preto, lóculo aberto, vira-cabeça e zíper), foram quantificadas e classificadas quanto ao tipo de defeito. Uma análise gráfica também foi realizada para comparar as freqüências de frutos rachados e normais.

\footnotetext{
${ }^{2}$ ORTELAN, W. Eng. Agrónomo, Empresa Ortelan \& Yamane - comunicação pessoal."
} 
A análise estatística deste experimento baseou-se na parcela experimental (18 plantas) e consistiu na realização da análise de variância (Teste F) segundo o delineamento de blocos em faixas, com restrição na casualização e de um teste de comparação múltipla de médias, teste de Tukey, para detectar diferenças estatisticamente significativas entre os sistemas de aplicação de solução nutritiva, entre as soluções nutritivas e a significância da interação sistema $x$ solução dentro de cada penca.

\begin{tabular}{|ll|}
\hline Tonuede Vunncho: & UI U \\
\hline Bloco & 4 \\
Doses & 3 \\
Residuo (a) & 12 \\
\hline Aplicação & 1 \\
Resíduo (b) & 4 \\
Doses x aplicação & 3 \\
Resíduo (c) & 12 \\
\hline Total & $\mathbf{3 9}$ \\
\hline
\end{tabular}




\section{RESULTADOS E DISCUSSÃo}

A tabela 1 mostra os resultados do teste $\mathrm{F}$, aplicado à análise de variância, para os parâmetros avaliados.

De acordo com a tabela 1, houve interação (solução $\mathrm{x}$ sistema), para algumas pencas, nas variáveis avaliadas:

- Produção total em número de frutos - pencas 1 e 6;

- Produção total em peso de frutos - pencas 1 e 2;

- Peso médio de fruto - pencas 1,2 e 6 ;

- Diâmetro médio de fruto - pencas1, 2 e 6.

Para estas pencas, onde houve interação, foi feito um desdobramento para análise das diferenças encontradas.

A tabela 2 mostra os resultados do teste de Tukey, para estudo das diferenças entre os sistemas de aplicação da solução nutritiva, para cada parâmetro avaliado, para as pencas onde não ocorreu interação (solução x sistema). 
Tabela 1-Resultado do teste $\mathrm{F}$, aplicado à análise de variância, para os fatores produção total em $\mathrm{n}^{\circ}$ de frutos, produção total em peso de frutos, peso médio de frutos e diâmetro médio de frutos, ESALQ-USP, Piracicaba, SP.

\begin{tabular}{|c|c|c|c|c|c|}
\hline Fatores & Solução & Sistema & SolxSist & $\mathrm{CV}(\%)$ & Média Exper. \\
\hline \multicolumn{6}{|c|}{ Prod. total em $n^{0}$ de frutos } \\
\hline penca1 & $0,0263^{*}$ & 0,389516 & $0,006146^{* *}$ & 9,65 & 115,58 \\
\hline penca2 & 0,276209 & 0,440755 & 0,173357 & 12,72 & 112,28 \\
\hline penca3 & 0,5042 & 0,073402 & 0,467014 & 9,73 & 109,08 \\
\hline penca4 & 0,096962 & 0,087743 & 0,731076 & 16,58 & 94,2 \\
\hline penca5 & 0,084951 & 0,900238 & 0,353378 & 23,27 & 77,3 \\
\hline penca6 & 0,735351 & 0,214977 & $0,017616^{*}$ & 18,18 & 63,8 \\
\hline \multicolumn{6}{|c|}{ Prod. Total em peso de frutos } \\
\hline penca1 & $0,000683^{\star \star}$ & 0,809091 & $0,001784^{* *}$ & 11,03 & 15378,38 \\
\hline penca2 & $0,018676^{*}$ & 0,262001 & $0,047876^{*}$ & 12,91 & 15881,23 \\
\hline penca3 & 0,369357 & $0,04605^{\star}$ & 0,62289 & 12,59 & 14791,95 \\
\hline penca4 & 0,103145 & 0,117251 & 0,586899 & 15,62 & 11913,68 \\
\hline penca 5 & $0,031361^{*}$ & 0,866344 & 0,238638 & 21,64 & 8450,83 \\
\hline penca6 & 0,333195 & 0,83658 & 0,189715 & 16,9 & 6483,55 \\
\hline \multicolumn{6}{|c|}{ Peso médio de fruto } \\
\hline penca1 & $0,000001^{\star *}$ & 0,247588 & $0,004828^{\star \star}$ & 5,5 & 132,64 \\
\hline penca2 & $0,00158^{* *}$ & 0,118737 & $0,023079^{*}$ & 4,16 & 141,15 \\
\hline penca3 & 0,531847 & 0,843788 & 0,067531 & 6,52 & 135,64 \\
\hline penca4 & $0,033952^{*}$ & 0,068638 & 0,528208 & 5,96 & 131 \\
\hline penca5 & $0,024151^{\star}$ & 0,125398 & 0,77313 & 6,48 & 109,03 \\
\hline penca6 & $0,003808^{\star *}$ & 0,130658 & $0,003618^{\star *}$ & 6,17 & 102,3 \\
\hline \multicolumn{6}{|c|}{ Diâmetro médio de fruto } \\
\hline penca1 & $0,000001^{* *}$ & 0,292654 & $0,003172^{\star \star}$ & 2,04 & 65,47 \\
\hline penca2 & $0,000177^{\star \star}$ & $0,016882^{*}$ & $0,007853^{\star *}$ & 1,49 & 66,56 \\
\hline penca3 & 0,521395 & 0,370681 & 0,088338 & 2,5 & 66,1 \\
\hline penca 4 & $0,005499^{\star *}$ & $0,048817^{*}$ & 0,827417 & 2,05 & 65 \\
\hline penca5 & $0,033809^{*}$ & $0,047716^{*}$ & 0,419508 & 2,28 & 60,74 \\
\hline penca6 & $0,000526^{\star \star}$ & 0,129326 & $0,000679^{\star \star}$ & 2,12 & 58,57 \\
\hline
\end{tabular}


Tabela 2 - Resultados do teste de Tukey para sistema, por penca, de acordo com os parâmetros avaliados, ESALQ-USP, Piracicaba, SP.

\begin{tabular}{|c|c|c|c|c|c|c|c|}
\hline \multirow[t]{2}{*}{ Parâmetro } & \multirow[t]{2}{*}{ Sistema } & \multicolumn{6}{|c|}{ Pencas } \\
\hline & & 1 & 2 & 3 & 4 & 5 & 6 \\
\hline Prod. Total em $\mathbf{n}^{\circ}$ de & NFT & $117,5 \mathrm{~A}$ & $113,9 \mathrm{~A}$ & $105,2 \mathrm{~A}$ & $95,5 \mathrm{~A}$ & $76,9 \mathrm{~A}$ & $62,2 \mathrm{~A}$ \\
\hline frutos & NNT & $113,5 \mathrm{~A}$ & $110,6 \mathrm{~A}$ & $112,9 \mathrm{~A}$ & $86,9 \mathrm{~A}$ & $77,6 \mathrm{~A}$ & $65,5 \mathrm{~A}$ \\
\hline Prod. total em peso & NFT & $15,4 \mathrm{~A}$ & $16,3 \mathrm{~A}$ & $14,3 \mathrm{~B}$ & $12,3 \mathrm{~A}$ & $8,5 \mathrm{~A}$ & $6,4 \mathrm{~A}$ \\
\hline de frutos $(\mathrm{kg})$ & NNT & $15,31 \mathrm{~A}$ & $15,5 \mathrm{~A}$ & $15,3 \mathrm{~A}$ & $11,5 \mathrm{~A}$ & $8,4 \mathrm{~A}$ & $6,5 \mathrm{~A}$ \\
\hline Peso médio de frutos & NFT & $130,8 \mathrm{~A}$ & $142,8 \mathrm{~A}$ & $135,5 \mathrm{~A}$ & $129,8 \mathrm{~A}$ & $110,1 \mathrm{~A}$ & $104,6 \mathrm{~A}$ \\
\hline & NNT & $134,4 \mathrm{~A}$ & $139,4 \mathrm{~A}$ & $135,8 \mathrm{~A}$ & $132,2 \mathrm{~A}$ & $107,9 \mathrm{~A}$ & $100,0 \mathrm{~A}$ \\
\hline Diâmetro médio de & NFT & $65,2 \mathrm{~A}$ & $67,1 \mathrm{~A}$ & $66,2 \mathrm{~A}$ & $64,8 \mathrm{~B}$ & $61,1 \mathrm{~A}$ & $59,1 \mathrm{~A}$ \\
\hline Frutos & NNT & $65,7 \mathrm{~A}$ & $66,1 \mathrm{~B}$ & $66,0 \mathrm{~A}$ & $65,1 \mathrm{~A}$ & $60,2 \mathrm{~B}$ & $58,0 \mathrm{~A}$ \\
\hline
\end{tabular}

NFT $=$ Nutrient Film Tecnique; NNT $=$ Nutrient Nebulization Tecnique

De acordo com o teste de Tukey, para os parâmetros avaliados, observa-se, na tabela 2, que para:

- produção total em número de frutos, não houve diferença significativa;

- produção total em peso de frutos, houve diferença significativa apenas para a penca 3 onde o sistema NNT proporcionou uma maior média;

- peso médio de frutos, não houve diferença significativa;

- diâmetro médio de frutos houve diferença significativa para as pencas 4 e 5 , onde na penca 4 o sistema NNT proporcionou a maior médio e na penca 5 o sistema NFT proporcionou a maior média.

A tabela 3 mostra os resultados do teste de Tukey, para estudo das diferenças entre as soluções nutritivas, para cada parâmetro avaliado, para as pencas onde não ocorreu interação (solução x sistema). 
Tabela 3 - Resultados do teste de Tukey para solução, por penca, de acordo com os parâmetros avaliados, ESALQ-USP, Piracicaba, SP.

\begin{tabular}{|c|c|c|c|c|c|c|c|}
\hline \multirow[t]{2}{*}{ Parâmetro } & \multirow[t]{2}{*}{ Solução } & \multicolumn{6}{|c|}{ Pencas } \\
\hline & & 1 & 2 & 3 & 4 & 5 & 6 \\
\hline \multirow{4}{*}{$\mathrm{N}^{0}$ total de frutos } & $1 \mathrm{~A}$ & $107,1 \mathrm{~B}$ & $113,3 \mathrm{~A}$ & $111,8 \mathrm{~A}$ & $89,0 \mathrm{~A}$ & $72,4 \mathrm{~A}$ & $63,2 \mathrm{~A}$ \\
\hline & IB & $120,1 \mathrm{AB}$ & $118,7 \mathrm{~A}$ & $113,2 \mathrm{~A}$ & $85,9 \mathrm{~A}$ & $74,2 \mathrm{~A}$ & $60,7 \mathrm{~A}$ \\
\hline & $2 \mathrm{~A}$ & $125,7 \mathrm{~A}$ & $110,1 \mathrm{~A}$ & $103,5 \mathrm{~A}$ & $90,3 \mathrm{~A}$ & $71,9 \mathrm{~A}$ & $65,3 \mathrm{~A}$ \\
\hline & 2B & $109,4 \mathrm{AB}$ & $107,0 \mathrm{~A}$ & $107,8 \mathrm{~A}$ & $99,6 \mathrm{~A}$ & $90,7 \mathrm{~A}$ & $66,1 \mathrm{~A}$ \\
\hline \multirow{4}{*}{ Produção total (kg) } & $1 \mathrm{~A}$ & $14,3 \mathrm{~B}$ & $15,6 \mathrm{AB}$ & $15,1 \mathrm{~A}$ & $11,1 \mathrm{~A}$ & $8,0 \mathrm{AB}$ & $6,8 \mathrm{~A}$ \\
\hline & IB & $17,0 \mathrm{~A}$ & $17,4 \mathrm{~A}$ & $15,8 \mathrm{~A}$ & $11,5 \mathrm{~A}$ & $7,6 \mathrm{~B}$ & $6,1 \mathrm{~A}$ \\
\hline & $2 \mathrm{~A}$ & $17,0 \mathrm{~A}$ & $16,1 \mathrm{AB}$ & $14,0 \mathrm{~A}$ & $12,2 \mathrm{~A}$ & $7,8 \mathrm{AB}$ & $6,2 \mathrm{~A}$ \\
\hline & $2 B$ & $13,2 \mathrm{~B}$ & $14,3 \mathrm{~B}$ & $14,3 \mathrm{~A}$ & $12,8 \mathrm{~A}$ & $10,4 \mathrm{~A}$ & $6,9 \mathrm{~A}$ \\
\hline \multirow{4}{*}{ Peso médio de frutos } & $1 \mathrm{~A}$ & $132,5 \mathrm{~B}$ & $136,8 \mathrm{~B}$ & $135,2 \mathrm{~A}$ & $124,2 \mathrm{~B}$ & $110,0 \mathrm{AB}$ & $108,4 \mathrm{~A}$ \\
\hline & 1B & $141,8 \mathrm{~A}$ & $146,7 \mathrm{~A}$ & $139,1 \mathrm{~A}$ & $135,1 \mathrm{~A}$ & $103,1 \mathrm{~B}$ & $100,1 \mathrm{AB}$ \\
\hline & $2 \mathrm{~A}$ & $135,6 \mathrm{~B}$ & $146,1 \mathrm{~A}$ & $135,1 \mathrm{~A}$ & $135,0 \mathrm{AB}$ & $108,3 \mathrm{AB}$ & $95,4 \mathrm{~B}$ \\
\hline & 2B & $120,5 \mathrm{C}$ & $135,0 \mathrm{~B}$ & $133,2 \mathrm{~A}$ & $129,7 \mathrm{AB}$ & $114,6 \mathrm{~A}$ & $105,3 \mathrm{~A}$ \\
\hline \multirow{4}{*}{$\begin{array}{l}\text { Diâmetro médio de } \\
\text { Frutos }\end{array}$} & IA & $65,2 \mathrm{~B}$ & $65,3 \mathrm{~B}$ & $65,7 \mathrm{~A}$ & $62,9 \mathrm{~B}$ & $60,4 \mathrm{AB}$ & $59,9 \mathrm{~A}$ \\
\hline & IB & $67,1 \mathrm{~A}$ & $67,7 \mathrm{~A}$ & $66,8 \mathrm{~A}$ & $65,7 \mathrm{~A}$ & $59,7 \mathrm{~B}$ & $58,1 \mathrm{BC}$ \\
\hline & $2 \mathrm{~A}$ & $65,9 \mathrm{~B}$ & $67,5 \mathrm{~A}$ & $66,1 \mathrm{~A}$ & $65,8 \mathrm{~A}$ & $60,3 \mathrm{AB}$ & $56,7 \mathrm{C}$ \\
\hline & $2 B$ & $63,4 \mathrm{C}$ & $65,7 \mathrm{~B}$ & $65,8 \mathrm{~A}$ & $65,6 \mathrm{~A}$ & $62,1 \mathrm{~A}$ & $59,4 \mathrm{AB}$ \\
\hline
\end{tabular}

De acordo com o teste de Tukey, para os parâmetros avaliados, observase, na tabela 3, que para:

- produção total em número de frutos, não houve diferença significativa;

- produção total em peso de frutos, houve diferença significativa apenas para a penca 5 onde as soluções $2 \mathrm{~B}, 1 \mathrm{~A}$ e $2 \mathrm{~A}$, respectivamente, proporcionaram as maiores médias, não diferindo estatisticamente entre si;

- peso médio de frutos, houve diferença significativa para as pencas 4 e 5 onde, na penca 4 as soluções $1 \mathrm{~B}, 2 \mathrm{~A}$ e $2 \mathrm{~B}$, respectivamente, proporcionaram maiores médias e na penca 5 as soluções $2 \mathrm{~B}, 1 \mathrm{~A}$ e $2 \mathrm{~A}$, respectivamente, proporcionaram maiores médias, não diferindo entre si; 
- diâmetro médio de frutos houve diferença significativa, para as pencas 4 e 5 onde, na penca 4 as soluções $2 \mathrm{~A}, 1 \mathrm{~B}$ e $2 \mathrm{~B}$, respectivamente, proporcionaram maiores médias e na penca 5 as soluções $2 \mathrm{~B}, 1 \mathrm{~A}$ e $2 \mathrm{~A}$, respectivamente, proporcionaram maiores médias, não diferindo entre si.

Para os itens 4.1 a 4.4, efetuou-se o desdobramento estatístico para as penca onde ocorreu a interação (solução $\mathrm{x}$ sistema), nos diferentes parâmetros avaliados.

\subsection{Produção total, em número de frutos}

As tabelas 4 e 6 mostram os valores de produção em número de frutos por penca, por combinação (solução e sistema de aplicação da solução).

Tabela 4 - Produção total, em número de frutos, por penca, por combinação, ESALQUSP, Piracicaba, SP.

\begin{tabular}{|c|c|c|c|c|c|c|c|}
\hline \multirow[t]{2}{*}{ Combinação } & \multicolumn{6}{|c|}{$N^{\circ}$ Total de Frutos por Penca } & \multirow{2}{*}{$\begin{array}{l}\mathbf{N}^{\circ} \text { Tot./ } \\
\text { Parcela }\end{array}$} \\
\hline & 1 & 2 & 3 & 4 & 5 & 6 & \\
\hline IAN & $118,8 \mathrm{a}$ & $123,8 \mathrm{a}$ & $105,0 \mathrm{a}$ & $94,2 a$ & $64,6 \mathrm{a}$ & $57,0 \mathrm{a}$ & 563,40 \\
\hline IBN & $127,0 \mathrm{a}$ & $118,8 \mathrm{a}$ & $108,4 a$ & $87,0 \mathrm{a}$ & $81,6 \mathrm{a}$ & $64,8 \mathrm{a}$ & 587,60 \\
\hline $2 A N$ & $116,4 a$ & $105,6 \mathrm{a}$ & $104,2 \mathrm{a}$ & $98,6 \mathrm{a}$ & $71,0 \mathrm{a}$ & $54,4 \mathrm{a}$ & 550,20 \\
\hline 2BN & $108,4 a$ & $107,4 a$ & $103,4 a$ & $102,2 \mathrm{a}$ & $90,6 a$ & $72,4 a$ & 584,40 \\
\hline Produção total & 470,60 & 455,60 & 421,00 & 382,00 & $\mathbf{3 0 7 , 8 0}$ & 248,60 & 2285,60 \\
\hline Produção média & 117,65 & 113,90 & 105,25 & 95,50 & 76,95 & 62,15 & 95,23 \\
\hline Média acumulada & 117,65 & 231,55 & 336,80 & 432,30 & 509,25 & 571,40 & - \\
\hline Prod. média (\%) & 20,59 & 19,93 & 18,42 & 16,71 & 13,47 & 10,88 & 16,67 \\
\hline Prod.MédiaAc. (\%) & 20,59 & 40,52 & 58,94 & 75,66 & 89,12 & 100,00 & - \\
\hline $\mathrm{CV}(\%)$ & 10,24 & 10,72 & 9,43 & 13,72 & 16,51 & 20,18 & - \\
\hline
\end{tabular}




\begin{tabular}{|c|c|c|c|c|c|c|c|}
\hline \multirow[t]{2}{*}{ Combinação } & \multicolumn{6}{|c|}{$\mathrm{N}^{\circ}$ Total de Frutos por Penca } & \multirow{2}{*}{$\begin{array}{l}\mathrm{N}^{\circ} \text { Tot./ } \\
\text { parcela }\end{array}$} \\
\hline & $\mathbf{1}$ & 2 & 3 & 4 & 5 & 6 & \\
\hline $1 \mathrm{AF}$ & $95,4 b$ & $102,8 \mathrm{a}$ & $118,6 a$ & $83,8 \mathrm{a}$ & $80,2 a$ & $69,4 a b$ & 550,2 \\
\hline 1BF & $113,2 \mathrm{ab}$ & $118,6 \mathrm{a}$ & $118,0 \mathrm{a}$ & $84,8 \mathrm{a}$ & $66,8 a$ & $56,6 \mathrm{~b}$ & 558,0 \\
\hline $2 \mathrm{AF}$ & $135,0 \mathbf{a}$ & $114,6 a$ & $102,8 \mathrm{a}$ & $82,0 \mathrm{a}$ & $72,8 \mathbf{a}$ & $76,2 \mathrm{a}$ & 583,4 \\
\hline $2 \mathrm{BF}$ & $110,4 b$ & $106,6 \mathrm{a}$ & $112,2 \mathrm{a}$ & $97,0 \mathrm{a}$ & $90,8 \mathrm{a}$ & $59,8 \mathrm{ab}$ & 576,0 \\
\hline Produção total & 454,00 & 442,60 & 451,60 & 347,60 & 310,60 & 262,00 & 2268,40 \\
\hline Produção média & 113,50 & 110,65 & 112,90 & 86,90 & 77,65 & 65,50 & 94,52 \\
\hline Média acumulada & 113,50 & 224,15 & 337,05 & 423,95 & 501,60 & 567,10 & - \\
\hline Prod. média (\%) & 20,01 & 19,51 & 19,91 & 15,32 & 13,69 & 11,55 & 16,67 \\
\hline Prod.MédiaAc. (\%) & 20,01 & $\mathbf{3 9 , 5 3}$ & 59,43 & 74,76 & 88,45 & 100,00 & - \\
\hline CV (\%) & 10,98 & 13,59 & 13,86 & 15,80 & 27,31 & 16,23 & - \\
\hline
\end{tabular}

Obs: Médias seguidas de mesma letra nas colunas, não diferem entre si ao nível de $5 \%$

Legenda: $1 \mathrm{AN}=\mathrm{K}: \mathrm{N} 2: 1$ durante todo o ciclo; sistema NFT;

$1 \mathrm{BN}=\mathrm{K}: \mathrm{N} 2: 1$ até o inicio do florescimento e 3:1 no restante do ciclo; sistema NFT;

$2 A N=K: N 3: 1$ durante todo o ciclo; sistema NFT;

$2 \mathrm{BN}=\mathrm{K}: \mathrm{N} 3: 1$ até o início do florescimento e 2:1 no restante do ciclo; sistema NFT;

$1 \mathrm{AF}=\mathrm{K}: \mathrm{N} 2: 1$ durante todo o ciclo; sistema NNT;

$1 \mathrm{BF}=\mathrm{K}: \mathrm{N} 2: 1$ até o inicio do florescimento e 3:1 no restante do ciclo; sistema NNT;

$2 \mathrm{AF}=\mathrm{K}: \mathrm{N}$ 3:1 durante todo o ciclo; sistema NNT;

$2 \mathrm{BF}=\mathrm{K}: \mathrm{N}$ 3:1 até o início do florescimento e 2:1 no restante do ciclo; sistema NNT;

Observa-se, na tabela 4, que houve diferenças significativas apenas para o sistema NNT:

Neste sistema (NNT) houve diferença significativa para as pencas 1 e 6 cujas combinações que proporcionaram as maiores médias foram $2 \mathrm{AF}$ e $1 \mathrm{BF}$ para a penca 1 ; e $2 \mathrm{AF}, 1 \mathrm{AF}$ e $2 \mathrm{BF}$ para a penca 6.

Observa-se na tabela 4 que, considerando-se os valores absolutos, para o sistema NFT, em média, a produção total da penca 1 foi $89,3 \%$ maior que a penca 6; as pencas 2 e 3 apresentaram $83,3 \%$ e $69,3 \%$, respectivamente, maior produção que a penca 6; enquanto que as pencas 4 e 5 apresentaram, respectivamente, $53,7 \%$ e $23,8 \%$ maior produção que a penca 6 .

Observa-se pelos dados apresentados na tabela 4 que, o número de frutos acumulados até a $3^{a}$ penca corresponde a $58,94 \%$ da produção total, enquanto que até a $4^{\mathrm{a}}$ penca estes valores atingem $75,66 \%$ do total de número de frutos produzidos.

Para o sistema NNT, em média, a produção total da penca 1 foi $73,28 \%$ maior que a penca 6; a penca 2 apresentou $68,90 \%$, maior produção que a penca 6 ; enquanto que as pencas 3,4 e 5 apresentaram, respectivamente, $72,36 \%, 32,67 \%$ e $18,54 \%$ maior produão que a penca 6 . 
Observa-se pelos dados apresentados na tabela 4 que, o número de frutos acumulados até a $3^{\text {a }}$ penca corresponde a $59,43 \%$ da produção total, enquanto que até a $4^{\text {a }}$ penca estes valores atingem $74,76 \%$ do total de número de frutos produzidos.

A figura 1 mostra a tendência de produção, para todas as pencas, em cada combinação.

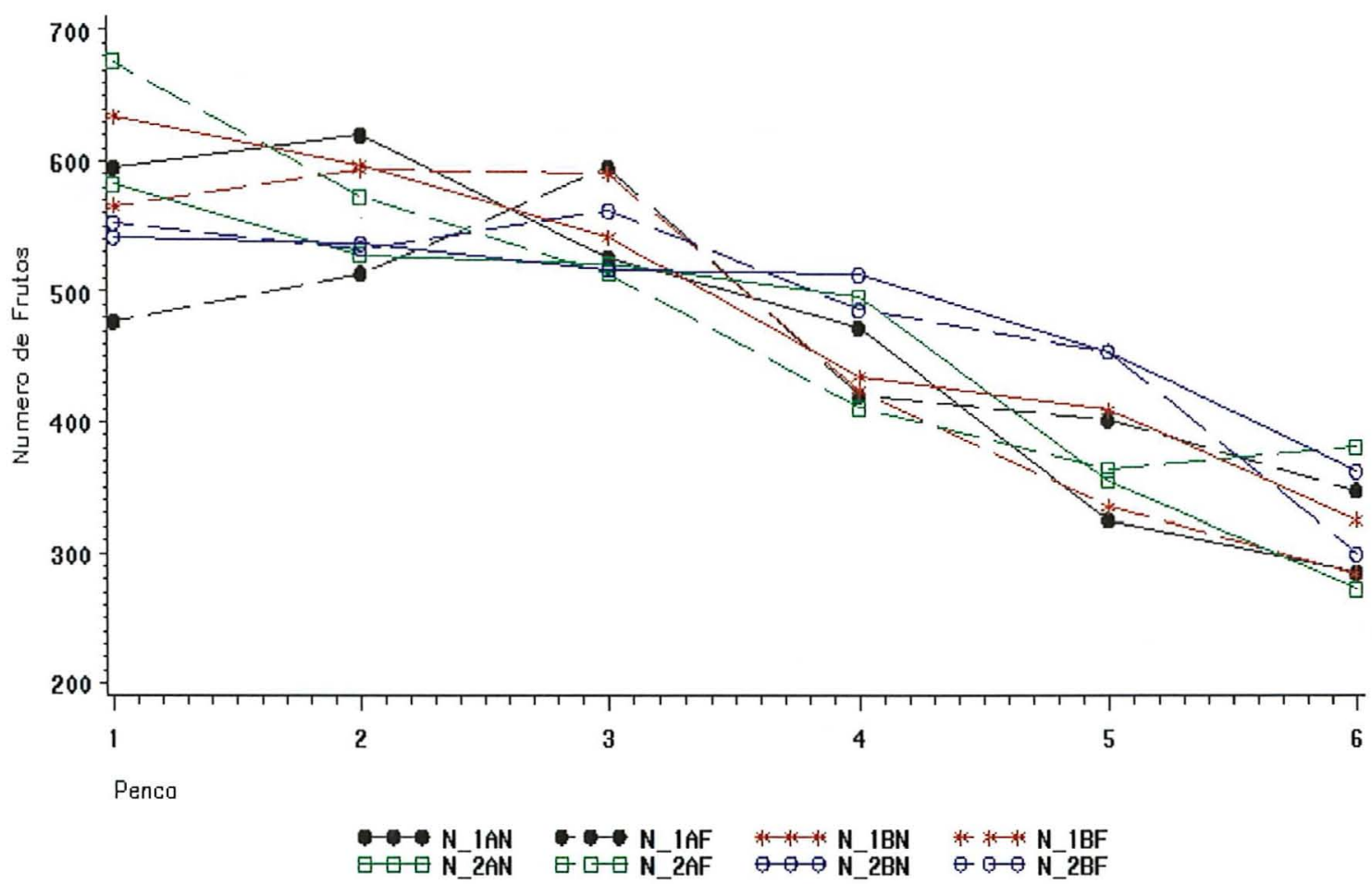

Figura 1 - Produção total, em número de frutos, por penca, por combinação, ESALQ-USP, Piracicaba, SP.

A penca 6 foi a que expressou o menor número de frutos produzidos, para todos as combinações, exceto para a combinação $2 \mathrm{AF}$ onde esta penca apresentou resultados melhores que a penca 5 .

A tabela 5 mostra as diferenças de produção de uma penca em relação à outra, considerando-se todas as pencas avaliadas. 
Tabela 5 - Variação de rendimento (\%) entre pencas, considerando as médias de número total de frutos por, combinação, ESALQ-USP, Piracicaba, SP.

\begin{tabular}{c|cccccc}
\multicolumn{6}{l}{ Sistema NFT } \\
\hline Penca & $\mathbf{1}$ & $\mathbf{2}$ & $\mathbf{3}$ & $\mathbf{4}$ & $\mathbf{5}$ & $\mathbf{6}$ \\
\hline $\mathbf{1}$ & 0,00 & $\mathbf{+ 3 , 2 9}$ & $+11,78$ & $+23,19$ & $+52,89$ & $+89,30$ \\
$\mathbf{2}$ & & 0,00 & $\mathbf{+ 8 , 2 0}$ & $+19,30$ & $+48,00$ & $+83,30$ \\
$\mathbf{3}$ & & & 0,00 & $\mathbf{+ 1 0 , 2 0}$ & $+36,77$ & $+69,34$ \\
$\mathbf{4}$ & & & & 0,00 & $\mathbf{+ 2 4 , 1 0}$ & $+53,66$ \\
$\mathbf{5}$ & & & & & 0,00 & $+23,80$ \\
$\mathbf{6}$ & & & & & & 0,00 \\
\hline
\end{tabular}

\begin{tabular}{c|cccccc}
\multicolumn{2}{l}{ Sistema NNT } & \multicolumn{6}{l}{} \\
\hline Penca & $\mathbf{1}$ & $\mathbf{2}$ & $\mathbf{3}$ & $\mathbf{4}$ & $\mathbf{5}$ & $\mathbf{6}$ \\
\hline $\mathbf{1}$ & 0,00 & $\mathbf{+ 2 , 5 7}$ & $+0,53$ & $+30,60$ & $+46,16$ & $+73,28$ \\
$\mathbf{2}$ & & 0,00 & $\mathbf{- 1 , 9 9}$ & $+27,33$ & $+42,49$ & $+68,90$ \\
$\mathbf{3}$ & & & 0,00 & $\mathbf{+ 2 9 , 9 0}$ & $+45,39$ & $+72,36$ \\
$\mathbf{4}$ & & & & 0,00 & $\mathbf{+ 1 1 , 9 1}$ & $+32,67$ \\
$\mathbf{5}$ & & & & & 0,00 & $\mathbf{+ 1 8 , 5 4}$ \\
$\mathbf{6}$ & & & & & & 0,00 \\
\hline
\end{tabular}

De acordo com a tabela 5, houve uma variação de rendimentos, em relação ao número total de frutos, entre as pencas, para os 2 sistemas:

- sistema NFT: decréscimo de $3,29 \%$ da $1^{\text {a }}$ para a $2^{\text {a }}$ penca, de $8,20 \%$ da $2^{a}$ para a $3^{a}$ penca, de $10,20 \%$ da $3^{a}$ para a $4^{a}$ e de $24,10 \%$ e $23,80 \%$ da $4^{a}$ para a $5^{a}$ e da $5^{\mathrm{a}}$ para a $6^{\mathrm{a}}$ penca respectivamente. Baseando-se nos dados acima citados, podese observar que as perdas foram menores da $1^{\mathrm{a}}$ para a $4^{\mathrm{a}}$ penca $(23,19 \%)$ quando comparadas com as perdas da $1^{\mathrm{a}}$ até a $6^{\mathrm{a}}$ penca $(89,30 \%)$;

- sistema NNT: decréscimo de $2,57 \%$ da $1^{\mathrm{a}}$ para a $2^{\text {a }}$ penca, de $-1,99 \%$ da $2^{\mathrm{a}}$ para a $3^{\mathrm{a}}$ penca, de $29,90 \%$ da $3^{\mathrm{a}}$ para a $4^{\mathrm{a}}$ e de $11,91 \%$ e $18,54 \%$ da $4^{\mathrm{a}}$ para a $5^{\mathrm{a}}$ e da $5^{\text {a }}$ para a $6^{\text {a }}$ penca respectivamente. Baseando-se nos dados acima citados, podese observar que as perdas foram menores da $1^{\mathrm{a}}$ para a $4^{\mathrm{a}}$ penca $(30,60 \%)$ quando comparadas com as perdas da $1^{\mathrm{a}}$ até a $6^{\mathrm{a}}$ penca $(73,28 \%)$. 
Comparando-se os 2 sistemas observa-se que a diferença de produção da $1^{\mathrm{a}}$ para a $4^{\mathrm{a}}$ penca foi menor no sistema NFT. Porém a diferença de produção da $1^{\mathrm{a}}$ para a $6^{a}$ penca foi menor no sistema NNT.

A tabela 6 mostra o comportamento de todas as pencas, para cada combinação, posicionando-as dentro de um "ranking" decrescente de produção.

Tabela 6 - Produção total, em número de frutos por penca, segundo um "ranking" decrescente, produção relativa em número de frutos e diferença entre as pencas com maior e menor número de frutos, de acordo com as combinações, ESALQ-USP, Piracicaba, SP.

\begin{tabular}{|c|c|c|c|}
\hline \multirow[t]{2}{*}{ Combinação } & \multirow[t]{2}{*}{ Ranking } & \multicolumn{2}{|c|}{$\begin{array}{c}\text { Diferença de Produção } \\
\text { (pencas mais e menos produtivas) }\end{array}$} \\
\hline & & $\mathbf{N}^{\mathbf{0}}$ de Frutos & Produção Relativa \\
\hline $1 \mathrm{AN}$ & $2,1,3,4,5$ e 6 & 66,8 & 217 \\
\hline $1 \mathrm{BN}$ & $1,2,3,4,5$ e 6 & 62,2 & 195 \\
\hline $2 \mathrm{AN}$ & $1,2,3,4,5$ e 6 & 62,0 & 213 \\
\hline $2 \mathrm{BN}$ & $1,2,3,4,5$ e 6 & 36,0 & 149 \\
\hline MÉDIA $^{1 /}$ & $1,2,3,4,5$ e 6 & 56,75 & 193,50 \\
\hline \multirow[t]{2}{*}{ Combinação } & \multirow[t]{2}{*}{ Ranking } & \multicolumn{2}{|c|}{$\begin{array}{c}\text { Diferença de Produção } \\
\text { (pencas mais e menos produtivas) }\end{array}$} \\
\hline & & $N^{0}$ de Frutos & Produção Relativa \\
\hline$\overline{\mathrm{AAF}}$ & $3,2,1,4,5$ e 6 & 49,2 & 170 \\
\hline IBF & $2,3,1,4,5$ e 6 & 62,0 & 209 \\
\hline $2 \mathrm{AF}$ & $1,2,3,4,6$ e 5 & 62,2 & 185 \\
\hline $2 \mathrm{BF}$ & $3,1,2,4,5$ e 6 & 52,4 & 187 \\
\hline MÉDIA $^{1 /}$ & $1,3,2,4,5$ e 6 & 56,45 & 187,75 \\
\hline
\end{tabular}

Obs: Foi utilizado índice 100 para penca menos produtiva, visando o cálculo da diferença entre as pencas Com maior e menor número de frutos.

1/ Média- obtida com base nos valores médios da tabela 04

A tabela 6 mostra que as plantas, dentro das combinações, se comportaram de maneira semelhante com relação ao número total de frutos, ou seja, as pencas 5 e 6 foram as que apresentaram os menores números totais de frutos produzidos. As pencas que apresentaram o maior e menor número total, respectivamente, foram: a $1^{\mathrm{a}}$ da combinação $2 \mathrm{AF}$ e a $6^{\mathrm{a}}$ da combinação $2 \mathrm{AN}$ (tabela 04). Deve-se salientar que, 
para a totalidade das combinações, as 4 primeiras pencas apresentaram os melhores resultados (tabela 6).

As menores diferenças de rendimento, em número de frutos, entre as pencas que produziram maior e menor número de frutos, de acordo com a tabela 6 , foram:

- sistema NFT - combinações 2BN (destaque), 2AN, 1BN e 1AN, respectivamente;

- sistema NNT - combinações $1 \mathrm{AF}, 2 \mathrm{BF}, 1 \mathrm{BF}$ e $2 \mathrm{AF}$, respectivamente.

Os resultados mostram que o sistema NFT proporcionou maior estabilidade produtiva na planta, uma vez que a relação de desempenho de produção por penca manteve uma ordem decrescente seqüencial, para 3 das 4 combinações (1BN, $2 \mathrm{AN}$ e $2 \mathrm{BN}$.

No caso das pencas 1 e 2 a produção esperada é semelhante, portanto, uma inversão de posição de ambas seria previsto o que é o caso da combinação 1 AN. Para o caso da penca 3 ou 4 , uma inversão para $1^{\circ}$ ou $2^{\circ}$ lugar em produção, sugere um desequilíbrio nutricional o que é o caso das combinações $1 \mathrm{AF}, 2 \mathrm{BF}$ e $1 \mathrm{BF}$ descartando assim a exclusiva interferência ambiental.

Este comportamento pode ser explicado pelo manejo adotado, ou seja, ausência de raleio dos frutos, gerando uma desuniformidade na distribuição de frutos por todas as pencas cultivadas na planta, concentrando a produção nas 4 primeiras pencas em detrimento das duas últimas, o que também foi observado por Tanaka et al. (1974) em trabalho sobre desponte de plantas de tomateiro, onde as plantas testemunhas (não despontadas e não raleadas) apresentaram número médio decrescente de frutos por penca em uma mesma planta: 5,18 (pencal); 4,18 (penca 2); 2,85 (penca 3); 2,31 (penca 4); 1,62 (penca 5 a 7 ).

A diferença significativa observada para número médio de frutos por penca, nos diferentes tratamentos diferem dos dados encontrados por Marschner (1995) que diz que o elemento potássio não possui papel importante sobre o pegamento de frutos, sendo o mesmo mais voltado a qualidade geral dos mesmos; e por Boaretto et al. (1980) que, trabalhando com tomate estaqueado, em condições de solo, não 
encontraram diferença significativa para 5 diferentes doses de $\mathrm{K}$, em relação ao número de frutos, apesar da maior dose incrementar a produção, em número de frutos, em $25 \%$, em relação a menor dose. Dados similares foram encontrados por Conceição \& Pinho (1975).

Adams \& Massey (1984) realizaram um trabalho onde foram medidas as absorções de $\mathrm{N}, \mathrm{K}$ e água em plantas de tomate cultivadas em hidroponia, concluindo-se que nas primeiras semanas após o plantio, as plantas removeram o $\mathrm{K}$ e o $\mathrm{N}$ numa taxa de 1,2:1,0 e com o aparecimento dos frutos, a taxa de absorção de $\mathrm{K}$ continuou a subir, aumentando essa relação para 2,5:1,0, ou seja, valores similares aos utilizados na solução que proporcionou maior estabilidade de produção.

Por outro lado, Fayad (1998), trabalhando com a cultivar EF-50 (tipo caqui determinado) em condições de estufa, com cultivo em solo e uso de fertirrigação, variando as relações $K: N$, observou, de acordo com a marcha de absorção de nutrientes, a relação de acúmulo de $\mathrm{N}$ e $\mathrm{K}$, da seguinte maneira: aos 15, 30, 45, 60, 75, 90, 105 dias após o transplante, relação $1: 1$; aos 120 e 135 dias após o transplante a relação foi de 1,2:1 e 1,5:1 respectivamente, com exclusão do elemento $\mathrm{k}$ aplicados via fertirrigação, no referido período.

O menor número de frutos nas pencas 5 e 6 pode também ter sido influenciado pelas altas temperaturas, uma vez que, como pode ser observado na tabela relativa ao ciclo (anexo 5) das plantas no experimento, estas se desenvolveram em pleno verão quando as temperaturas dentro da estufa atingiram, por várias vezes, valores acima de $35^{\circ} \mathrm{C}$ (anexo 2); temperaturas que podem provocar abortamento de frutos pois, de acordo com Ho \& Hewitt (1986) no estágio de florescimento, o tomateiro tolera poucas horas com temperatura acima de $40^{\circ} \mathrm{C}$ o que pode afetar negativamente a viabilidade dos óvulos, a deiscência das anteras e a transferência do pólen. Calvert (1969) concorda com esta afirmação especificando que a alta temperatura, antes da antese, ocasiona aborto de flores, principalmente quando associada a baixa luminosidade.

Anteriormente, Johnson \& Hall (1953) explicavam que a abscisão de flores é controlada por um balanço das quantidades relativas de auxinas e etileno. No tomateiro, em condições de alta temperatura e alta intensidade luminosa, o estágio 
crítico, ou seja, favorecimento do etileno e baixos teores de auxina, é atingido precocemente, antes da restauração dos teores de auxina pelo ovário para auxiliar a polinização, provocando a queda das flores.

Silva (1994), trabalhando com tomate Santa Cruz até a quarta penca, chegou a valores de 30,2 frutos por planta, na relação $\mathrm{K}: \mathrm{N}=3: 1$, que decresceram, conforme as relações foram se invertendo de acordo $\mathrm{cm}$ os tratamentos. Porém os melhores resultados foram obtido com a relação 1,5:1.

\subsection{Produção total, em peso de frutos}

A tabela 7 e 8 apresentam os valores de produção em peso, por penca, por combinação.

Tabela 07 - Produção total em peso $(\mathrm{kg})$ de frutos, por penca, por combinação, ESALQUSP, Piracicaba, SP.

\begin{tabular}{|c|c|c|c|c|c|c|c|}
\hline \multirow[t]{2}{*}{ Combinação } & \multicolumn{7}{|c|}{ Produção Total de frutos por penca } \\
\hline & 1 & 2 & 3 & 4 & 5 & 6 & P.T. parc \\
\hline $1 \mathrm{AN}$ & $16,56 \mathrm{a}$ & $17,60 \mathrm{ab}$ & $14,95 \mathrm{a}$ & $11,60 \mathrm{a}$ & $7,14 a$ & $6,58 \mathrm{a}$ & 74,43 \\
\hline IBN & $17,35 a$ & $17,92 \mathrm{a}$ & $14,71 \mathrm{a}$ & $11,81 \mathrm{a}$ & $8,56 a$ & $6,43 a$ & 76,78 \\
\hline $2 \mathrm{AN}$ & $15,63 a$ & $15,25 b c$ & $13,82 \mathrm{a}$ & $13,21 a$ & $7,67 \mathrm{a}$ & $5,55 \mathrm{a}$ & 71,13 \\
\hline $2 \mathrm{BN}$ & $12,23 b$ & $14,31 \mathrm{c}$ & $13,59 \mathrm{a}$ & $12,77 \mathrm{a}$ & $10,64 \mathrm{a}$ & $7,21 \mathrm{a}$ & 70,75 \\
\hline Produção Total & 61,77 & 65,08 & 57,07 & 49,39 & 34,01 & 25,77 & 293,09 \\
\hline Producão Média & 15,44 & 16,27 & 14,27 & 12,35 & $\mathbf{8 , 5 0}$ & 6,44 & 12,21 \\
\hline Media Acumulada & 15,44 & 31,71 & 45,98 & 58,33 & 66,83 & 73,27 & - \\
\hline Prod. Média (\%) & 21,08 & 22,21 & 19,47 & 16,85 & 11,60 & 8,79 & 16,67 \\
\hline Prod. Média Ac. (\%) & 21,08 & 43,28 & 62,75 & 79,61 & 91,21 & 100,00 & - \\
\hline $\mathrm{CV}(\%)$ & 10,98 & 8,67 & 10,13 & 13,30 & 15,85 & 16,35 & - \\
\hline \multirow[t]{2}{*}{ Combinação } & \multicolumn{7}{|c|}{ Produção Total de frutos por penca } \\
\hline & 1 & 2 & 3 & 4 & 5 & 6 & P.T. parc \\
\hline $1 \mathrm{AF}$ & $12,04 \mathrm{c}$ & $13,56 a$ & $15,19 \mathrm{a}$ & $10,48 \mathrm{a}$ & $8,85 a$ & $7,07 \mathrm{a}$ & 67,19 \\
\hline $1 \mathrm{BF}$ & $16,58 \mathrm{ab}$ & $16,88 \mathrm{a}$ & $16,82 \mathrm{a}$ & $11,26 \mathrm{a}$ & $6,75 a$ & $5,70 \mathrm{a}$ & 73,99 \\
\hline $2 \mathrm{AF}$ & $18,38 \mathrm{a}$ & $16,95 a$ & $14,13 a$ & $11,15 \mathrm{a}$ & $7,86 a$ & $6,76 a$ & 75,23 \\
\hline $2 \mathrm{BF}$ & $14,22 \mathrm{bc}$ & $13,56 \mathrm{a}$ & $15,10 \mathrm{a}$ & $12,99 \mathrm{a}$ & $10,11 \mathrm{a}$ & $6,53 a$ & 72,51 \\
\hline Produção Total & 61,22 & 60,95 & 61,24 & 45,88 & 33,57 & 26,06 & 288,92 \\
\hline Produção Média & 15,31 & 15,24 & 15,31 & 11,47 & 8,39 & 5,52 & 12,04 \\
\hline Media Acumulada & 15,31 & 30,54 & 45,85 & 57,32 & 65,72 & 17,23 & - \\
\hline Prod. Média (\%) & 20,89 & 20,80 & 20,90 & 15,65 & 11,45 & 8,89 & 16,43 \\
\hline Prod. Média Ac. (\%) & 20,89 & 41,68 & 62,58 & 78,23 & 89,69 & 98,58 & - \\
\hline $\mathrm{CV}(\%)$ & 11,49 & 14,86 & 17,08 & 15,72 & 28,10 & 19,09 & - \\
\hline
\end{tabular}

Obs: Médias seguidas de mesma letra nas colunas, não diferem entre si ao nível de $5 \%$ $\mathrm{Obs}_{2}$ : P.T. parc = produção total por parcela 
Observa-se, na tabela 7 , que houve diferenças significativas para os 2 sistemas utilizados:

- sistema NFT: houve diferença significativa para as pencas 1 e 2. Com relação a penca 1 , as combinações que proporcionaram as maiores médias foram $1 \mathrm{BN}$, $1 \mathrm{AN}, 2 \mathrm{AN}$; para a penca 2 as combinações que expressaram os maiores valores foram $1 \mathrm{BN}$ e $1 \mathrm{AN}$;

- sistema NNT: houve diferença significativa apenas para a penca 1 cujas combinações que proporcionaram as maiores médias foram $2 \mathrm{AF}$ e $1 \mathrm{BF}$.

Observa-se na tabela 7 que, para o sistema NFT, em média, a produção total da penca 2 foi $153 \%$ maior que a penca 6; as pencas 1 e 3 apresentaram $139 \%$ e $122 \%$, respectivamente, maior produção que a penca 6 ; enquanto que as pencas 4 e 5 apresentaram, respectivamente, $92 \%$ e $32 \%$ maior produção que a penca 6 .

Para o sistema NNT, em média, a produção total das pencas 1 e 3 foi $192 \%$ maior que a penca 6 ; a penca 2 apresentou $176 \%$, maior produção que a penca 6 ; enquanto que as pencas 4 e 5 apresentaram, respectivamente, $108 \%$ e $52 \%$ maior produção que a penca 6 .

A utilização do sistema NNT poderia proporcionar uma maior produção, em todas as pencas, em virtude da maior quantidade de raízes, porém este fato não ocorreu de maneira consistente.

Esperava-se que o sistema NNT proporcionasse melhores resultados para todas as pencas porque, como havia solução nebulizada por todo o interior da tubulação, e as raizes ficavam soltas e não imersas; talvez isso pudesse propiciar maior quantidade de pelos absorventes, aumentando assim a eficiência de absorção e consequentemente de produção. Entretanto, esta maior produção esperada não ocorreu.

A figura 02 mostra a tendência de produção, em peso, para todas as pencas, em cada combinação. 


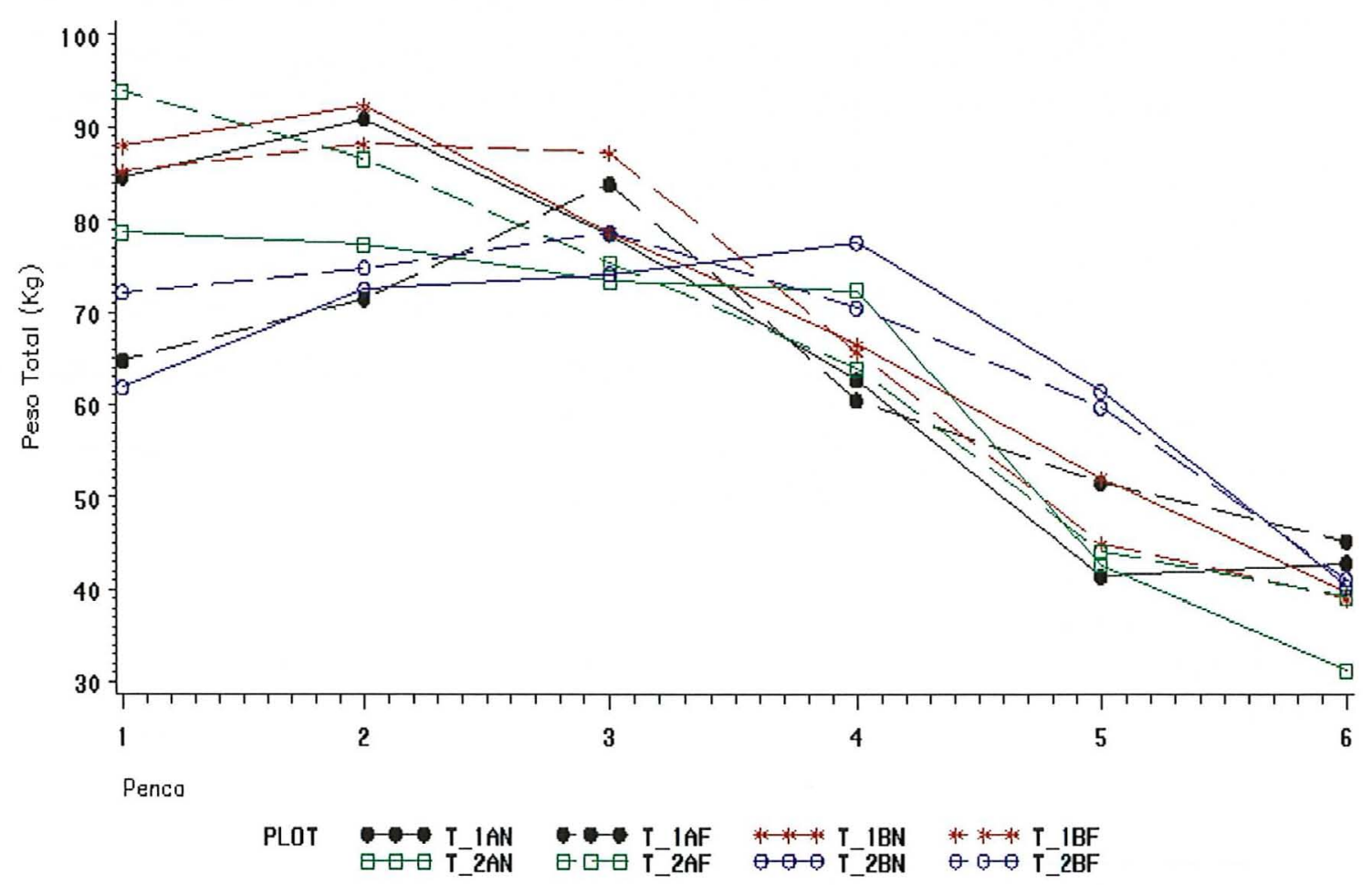

Figura 02 - Produção total, em peso de frutos, por penca, por combinação, ESALQ-USP, Piracicaba, SP.

Pela figura 2, observa-se a distribuição da produção através das 6 pencas avaliadas. Nota-se, conforme foi comentado na tabela 7 , que a maior parte da produção se concentra até a $4^{a}$ penca. Para todas as combinações, a penca 6 foi a que expressou o menor peso total, seguida pela penca 5 .

A tabela 8 mostra o comportamento de todas as pencas, para cada combinação, posicionando-as dentro de um "ranking" decrescente de produção. 
Tabela 8 - Produção total, em peso de frutos $(\mathrm{kg})$, por penca, segundo um "ranking" decrescente, produção relativa de frutos e diferença entre as pencas mais e menos produtivas, de acordo com as combinações, ESALQ-USP, Piracicaba, SP.

\begin{tabular}{|c|c|c|c|}
\hline \multirow[t]{2}{*}{ Combinação } & \multirow[t]{2}{*}{ Ranking } & \multicolumn{2}{|c|}{$\begin{array}{l}\text { Diferença entre Produção Média } \\
\text { (pencas mais e menos produtivas) }\end{array}$} \\
\hline & & Produção(kg) & Prod. Relativa \\
\hline $1 \mathrm{AN}$ & $2,1,3,4,5$ e 6 & 9,98 & 267 \\
\hline $1 \mathrm{BN}$ & $2,1,3,4,5$ e 6 & 11,49 & 271 \\
\hline $2 \mathrm{AN}$ & $1,2,3,4,5$ e 6 & 10,08 & 282 \\
\hline $2 \mathrm{BN}$ & $2,3,4,1,5$ e 6 & 7,10 & 169 \\
\hline MEDIA $^{1 /}$ & $2,1,3,4,5$ e 6 & 9,66 & 247,30 \\
\hline \multirow[t]{2}{*}{ Combinação } & \multirow[t]{2}{*}{ Ranking } & \multicolumn{2}{|c|}{$\begin{array}{l}\text { Diferença entre Produção Média } \\
\text { (pencas mais e menos produtivas) }\end{array}$} \\
\hline & & Produção & Prod. Relativa \\
\hline IAF & $3,2,1,4,5$ e 6 & 8,12 & 214 \\
\hline $1 \mathrm{BF}$ & $2,3,1,4,5$ е 6 & 11,18 & 296 \\
\hline $2 \mathrm{AF}$ & $1,2,3,4,5$ e 6 & 11,62 & 288 \\
\hline $2 \mathrm{BF}$ & $3,1,2,4,5$ e 6 & 8,57 & 231 \\
\hline MÉDIA $^{1 /}$ & $3=1,2,4,5$ e 6 & 9,87 & 257,25 \\
\hline
\end{tabular}

A tabela 8 mostra, que as plantas, dentro das combinações, se comportaram de maneira semelhante com relação ao peso total de frutos, ou seja, as pencas 5 e 6 foram as que apresentaram os menores valores em pesos de frutos. As pencas que apresentaram o maior e menor peso total, respectivamente, foram a $2^{\mathrm{a}} \mathrm{da}$ combinação $1 \mathrm{BN}$ e a $6^{\mathrm{a}}$ da combinação $2 \mathrm{AN}$ (tabela 7). Deve-se salientar que, para a totalidade das combinações, as 4 primeiras pencas apresentaram os melhores resultados.

As menores diferenças de produção, em peso de frutos, entre as pencas que produziram maior e menor peso de frutos, de acordo com a tabela 8 , foram:

- sistema NFT - combinações 2BN, 1AN, 2AN e 1BN, respectivamente;

- sistema NNT - combinações $1 \mathrm{AF}, 2 \mathrm{BF}, 1 \mathrm{BF}$ e $2 \mathrm{AF}$, respectivamente. 


\subsection{Peso médio de frutos}

Segundo Ho \& Hewitt (1986) a produção da cultura do tomate é determinada não só pelo número de frutos, que determina valores quantitativos, mas também pelo peso deles, como sendo um dos fatores determinantes para a qualidade, por ocasião da comercialização dos mesmos.

A tabela 9 mostra os valores de peso médio de frutos por penca, por planta, por combinação.

Tabela 9 -Peso médio de fruto, por penca, por planta, por combinação, ESALQ-USP, Piracicaba, SP.

\begin{tabular}{|c|c|c|c|c|c|c|c|}
\hline \multirow[t]{2}{*}{ Combinação } & \multicolumn{6}{|c|}{ Peso médio de Fruto por Penca } & \multirow{2}{*}{$\begin{array}{l}\text { P.M. } \\
\text { fr } / \text { pI }\end{array}$} \\
\hline & 1 & 2 & 3 & 4 & 5 & 6 & \\
\hline $1 \mathrm{AN}$ & $138,9 \mathrm{a}$ & $142,5 \mathrm{ab}$ & $142,4 a$ & $123,8 \mathrm{a}$ & $110,0 \mathrm{a}$ & $115,5 \mathrm{a}$ & 128,85 \\
\hline IBN & $136,8 \mathrm{a}$ & $151,3 \mathrm{a}$ & $135,5 a$ & $136,0 \mathrm{a}$ & $104,9 \mathrm{a}$ & $99,3 b$ & 127,30 \\
\hline $2 \mathrm{AN}$ & $134,9 \mathrm{a}$ & $144,4 \mathrm{ab}$ & $132,6 a$ & $133,7 \mathrm{a}$ & $108,1 \mathrm{a}$ & $102,4 \mathrm{ab}$ & 125,92 \\
\hline 2BN & $112,7 \mathrm{~b}$ & $133,3 b$ & $131,4 a$ & $125,5 \mathrm{a}$ & $117,3 \mathrm{a}$ & $101,3 \mathrm{ab}$ & 120,25 \\
\hline Média & 130,83 & 142,87 & 135,25 & 129,75 & 110,07 & 104,62 & 125,58 \\
\hline Peso Méd.(\%) & 17,36 & 18,96 & 17,96 & 17,22 & 14,61 & 13,89 & - \\
\hline CV (\%) & 5,0 & 4,23 & 2,50 & 5,49 & 5,87 & 7,26 & - \\
\hline \multirow[t]{2}{*}{ Combinação } & \multicolumn{6}{|c|}{ Peso médio de Fruto por Penca } & P.M. \\
\hline & 1 & 2 & 3 & 4 & 5 & 6 & $\mathrm{fr} / \mathrm{pl}$ \\
\hline $\mathrm{IAF}$ & $126,1 \mathrm{c}$ & $131,0 b$ & $128,0 \mathrm{a}$ & $124,5 a$ & $109,9 \mathrm{a}$ & $101,3 a$ & 120,13 \\
\hline $\mathrm{IBF}$ & $146,8 \mathrm{a}$ & $142,2 \mathrm{ab}$ & $142,6 a$ & $134,2 \mathrm{a}$ & $101,3 a$ & $100,8 \mathbf{a}$ & 127,98 \\
\hline $2 \mathrm{AF}$ & $136,3 b$ & $147,7 \mathrm{a}$ & $137,4 a$ & $136,2 \mathrm{a}$ & $108,5 \mathrm{a}$ & $88,4 b$ & 125,75 \\
\hline $2 \mathrm{BF}$ & $128,4 \mathrm{bc}$ & $136,7 \mathrm{ab}$ & $134,9 a$ & $133,9 \mathrm{a}$ & $112,0 \mathrm{a}$ & $109,3 \mathbf{a}$ & 125,87 \\
\hline Média & 134,40 & 139,40 & 135,73 & 132,20 & 107,92 & 99,95 & 124,93 \\
\hline Peso Méd.(\%) & 17,93 & 18,60 & 18,11 & 17,64 & 14,40 & 13,33 & - \\
\hline CV $(\%)$ & 3,85 & 4,33 & $\mathbf{8 , 8 7}$ & 6,64 & 7,08 & 4,93 & - \\
\hline
\end{tabular}

Obs: Médias seguidas de mesma letra nas colunas, não diferem entre sí ao nível de $5 \%$

Observa-se, na tabela 9, que houve diferenças significativas para os 2 sistemas utilizados:

- sistema NFT: houve diferença significativa para as pencas 1, 2 e 6 . Com relação a penca 1 , as combinações que proporcionaram as maiores médias foram $1 \mathrm{AN}, 1 \mathrm{BN}$ e $2 \mathrm{AN}$; para a penca 2 as combinações que expressaram os maiores 
valores foram 1BN, $1 \mathrm{AN}$ e 2AN; e para a penca 6 foram as combinações $1 \mathrm{AN}$, $2 \mathrm{AN}$ e $2 \mathrm{BN}$;

- sistema NNT: houve diferença significativa para as pencas 1, 2 e 6 . Com relação a penca 1, a combinação que proporcionou a maior média foi 1BF; para a penca 2 as combinações que expressaram os maiores valores foram $2 \mathrm{AF}, 1 \mathrm{BF}$ e $2 \mathrm{BF}$; e para a penca 6 foram $2 \mathrm{BF}, 1 \mathrm{AF}$ e $1 \mathrm{BF}$.

Observa-se na tabela 9 que, para o sistema NFT, o peso médio de frutos da penca que proporcionou o maior resultado (penca 2) foi $36,56 \%$ superior ao peso médio apresentado pela penca 6 (menores valores); para as pencas 1 e 3 os valores foram $25,05 \%$ e $29,27 \%$, respectivamente, superiores à penca 6 ; enquanto que para as pencas 4 e 5 os valores foram $24,02 \%$ e $5,21 \%$, respectivamente, também superiores à penca 6.

Para o sistema NNT, o peso médio de frutos da penca que proporcionou o maior resultado (penca 2) foi $71,70 \%$ superior ao peso médio da penca 6 (menores valores); para as pencas 1 e 3 os valores foram $34,46 \%$ e $35,79 \%$, respectivamente, superiores à penca 6; enquanto que para as pencas 4 e 5 os valores foram $32,26 \%$ e $7,97 \%$, respectivamente, também à penca 6 .

A tabela 9 mostra que, de modo geral, as plantas, dentro das combinações, se comportaram de maneira semelhante com relação ao peso médio de frutos, ou seja, as pencas 5 e 6 foram as que mostraram as menores médias para peso médio de frutos, sendo a menor média apresentada pela penca 6 da combinação $2 \mathrm{AF}$.

Segundo Zehler \& Foster (1972) o K contribui, principalmente, para aumentar o número de frutos por planta, porém é favorável também ao peso médio dos frutos.

A média das combinações, até a $4^{a}$ penca, considerando as relações $2: 1$ ( $1 \mathrm{AN}$ e $1 \mathrm{AF})$ e 3:1 (2AN e $2 \mathrm{AF}$ ), indica a ocorrência de incremento de peso médio de frutos (133,3 e 139,2 respectivamente) com o aumento da relação $\mathrm{K}: \mathrm{N}$, corroborando com os dados observados pelos autores acima. 
A tabela 9 mostra que as 4 primeiras pencas, de maneira geral, apresentaram frutos com peso médio adequado para comercialização.

Este comportamento pode ser explicado, pelo manejo adotado, ou seja, ausência de raleio dos frutos, gerando uma desuniformidade na distribuição e peso de frutos por todas as pencas cultivadas na planta, concentrando frutos com melhor peso nas 4 primeiras pencas em detrimento das duas últimas, o que também foi observado por Tanaka et al. (1974) em trabalho sobre desponte de plantas de tomateiro, onde as plantas testemunhas (não despontadas e não raleadas) apresentaram peso de matéria seca de frutos decrescente por penca em uma mesma planta: 8,41 (penca 1); 8,04 (penca 2); 7,86 (penca 3); 6,65 (penca 4); 3,94 (penca 5 a 7).

Boaretto et al. (1980) trabalhando com tomate estaqueado, do grupo Santa Cruz, em condições de solo, não encontraram diferença significativa para 5 diferentes doses de $\mathrm{K}$, sobre o peso médio de frutos, apesar de haver um incremento de $5,0 \%$ da melhor dose em relação à menor, além de ser observado também que houve uma queda do peso médio de fruto considerando a maior dose .

Por outro lado Costa (1999) trabalhando com tomate do tipo caqui (cv Momotaro), em cultivo hidropônico, observou um aumento de $10,1 \%$ no peso médio de frutos para a maior dosagem de $\mathrm{K}$, apesar de não encontrar diferenças significativas entre as doses, de $\mathrm{K}$, aplicadas.

A figura 3 mostra o peso médio, para todas as pencas, em cada combinação.

Observa-se na figura 3 que a penca 6 foi a que expressou o menor peso médio, para todos as combinações, exceto para a combinação $1 \mathrm{AN}$, cujo menor peso médio de fruto ocorreu na penca 5 


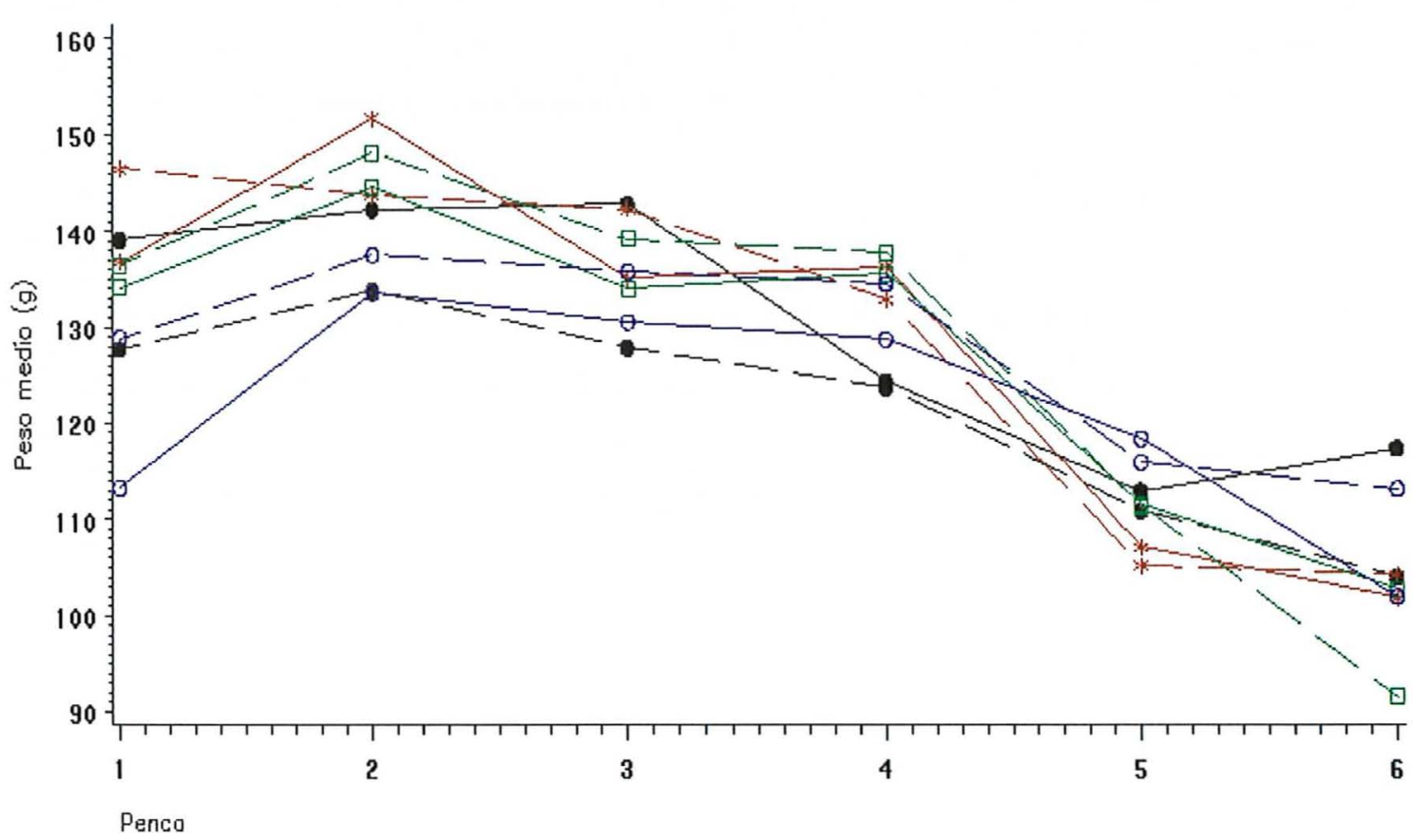

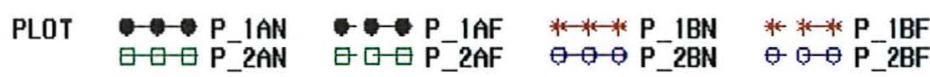

Figura 3 - Peso médio de frutos, por penca, por combinação, ESALQ-USP, Piracicaba, SP.

A tabela 10 mostra o comportamento de todas as pencas, para cada combinação, posicionando-as dentro de um "ranking" decrescente de produção.

Tabela 10 - Peso médio de frutos, por penca, por planta, segundo um "ranking" decrescente, peso médio relativo de frutos e diferença entre os frutos com maior e menor peso médio, de acordo com as combinações, ESALQUSP, Piracicaba, SP.

\begin{tabular}{|c|c|c|c|}
\hline \multirow[t]{2}{*}{ Combinação } & \multirow[t]{2}{*}{ Ranking } & \multicolumn{2}{|c|}{$\begin{array}{l}\text { Diferença entre Peso Médio } \\
\text { (frutos de maior e menor peso) }\end{array}$} \\
\hline & & Peso de fruto (g) & Peso Relativo \\
\hline $1 \mathrm{AN}$ & $2,3,1,4,6$ e 5 & 32,5 & 129 \\
\hline $1 \mathrm{BN}$ & $2,1,4,3,5$ e 6 & 52,0 & 152 \\
\hline $2 \mathrm{AN}$ & $2,1,4,3,5$ e 6 & 42,0 & 141 \\
\hline 2BN & $2,3,4,1,5$ e 6 & 32,0 & 131 \\
\hline MÉDIA $^{1 /}$ & $2,3,1,4,5$ e 6 & 39,6 & 138,2 \\
\hline
\end{tabular}




\begin{tabular}{|c|c|c|c|}
\hline \multirow{2}{*}{ Combinação } & \multirow{2}{*}{ Ranking } & \multicolumn{2}{|c|}{$\begin{array}{l}\text { Diferença entre Peso Médio } \\
\text { (frutos de maior e menor peso) }\end{array}$} \\
\hline & & Peso de fruto (g) & Peso Relativo \\
\hline $1 \mathrm{AF}$ & $2,3,1,4,5$ e 6 & 29,7 & 129 \\
\hline $1 B F$ & $1,3,2,4,5$ e 6 & 46,0 & 145 \\
\hline $2 \mathrm{AF}$ & $2,3,1,4,5$ e 6 & 59,3 & 167 \\
\hline $2 \mathrm{BF}$ & $2,3,4,1,5$ e 6 & 27,4 & 125 \\
\hline MÉDIA $^{1 /}$ & $2,3,1,4,5$ e 6 & 40,6 & 141,5 \\
\hline
\end{tabular}

A tabela 10 mostra que, de modo geral as plantas, dentro das combinações, se comportaram de maneira semelhante com relação ao peso médio de frutos, ou seja, as pencas 5 e 6 foram as que apresentaram os menores pesos médios de frutos produzidos. As pencas que apresentaram o maior e menor peso médio, respectivamente, foram a $2^{\mathrm{a}}$ da combinação $1 \mathrm{BN}$ e a $6^{\mathrm{a}}$ da combinação $2 \mathrm{AF}$ (tabela 9). Deve-se salientar que, para a totalidade das combinações, as 4 primeiras pencas apresentaram os melhores resultados (tabela 10).

As menores diferenças peso médio de frutos, entre as pencas que produziram maior e menor peso médio de frutos, de acordo com a tabela 10, foram:

- sistema NFT - combinações $2 \mathrm{BN}, 1 \mathrm{AN}, 2 \mathrm{AN}$ e 1BN, respectivamente;

- sistema NNT - combinações $2 \mathrm{BF}, 1 \mathrm{AF}, 1 \mathrm{BF}$ e $2 \mathrm{AF}$, respectivamente.

De acordo com a tabela 10 , observa-se que a penca 2 seguida pelas pencas 3, 1 e 4 apresentaram maiores médias de peso médio de frutos respectivamente, considerando todas as combinações, enquanto que as pencas 6 e 5 apresentaram os menores valores.

\subsection{Diâmetro médio de frutos}

A tabela 11 mostra os valores de diâmetro médio de frutos por penca, por combinação. 
Tabela 11 - Diâmetro médio de frutos, por penca, por combinação, ESALQ-USP, Piracicaba, SP.

\begin{tabular}{|c|c|c|c|c|c|c|c|}
\hline \multirow[t]{2}{*}{ Combinação } & \multicolumn{7}{|c|}{ Diâmetro Médio de frutos por penca } \\
\hline & 1 & 2 & 3 & 4 & 5 & 6 & $\phi$ médio/pl \\
\hline $1 \mathrm{AN}$ & $66,6 \mathrm{a}$ & $66,7 \mathrm{~b}$ & $67,1 \mathrm{a}$ & $62,7 \mathbf{a}$ & $60,7 \mathrm{a}$ & $61,3 a$ & 64,20 \\
\hline $1 B N$ & $66,3 a$ & $68,5 \mathrm{a}$ & $66,3 a$ & $65,8 \mathrm{a}$ & $59,8 \mathrm{a}$ & $58,0 \mathrm{~b}$ & 64,10 \\
\hline $2 \mathrm{AN}$ & $65,8 \mathrm{a}$ & $67,2 \mathrm{ab}$ & $65,7 a$ & $65,4 a$ & $60,4 a$ & $58,6 a b$ & 63,90 \\
\hline 2BN & $61,9 a$ & $65,6 \mathrm{~b}$ & $65,6 a$ & $65,2 a$ & $63,1 \mathrm{a}$ & $58,4 \mathrm{~b}$ & 63,30 \\
\hline Média & 65,15 & 67,00 & 66,17 & 64,77 & 61,00 & 59,07 & 63,90 \\
\hline CV (\%) & 1,89 & 1,29 & 0,99 & 2,48 & 2,13 & 2,46 & - \\
\hline \multirow[t]{2}{*}{ Combinação } & \multicolumn{7}{|c|}{ Diâmetro médio de frutos por penca } \\
\hline & 1 & 2 & 3 & 4 & 5 & 6 & $\phi$ média/pl \\
\hline $1 \mathrm{AF}$ & $63,9 \mathrm{c}$ & $63,8 b$ & $64,3 a$ & $63,0 a$ & $60,0 a$ & $58,5 \mathrm{ab}$ & 62,30 \\
\hline IBF & $67,9 \mathrm{a}$ & $66,9 \mathrm{a}$ & $67,2 \mathrm{a}$ & $65,5 \mathrm{a}$ & $59,6 a$ & $58,2 b$ & 64,20 \\
\hline $2 \mathrm{AF}$ & $66,1 b$ & $67,7 \mathrm{a}$ & $66,4 a$ & $66,0 \mathrm{a}$ & $60,1 \mathrm{a}$ & $54,8 \mathrm{c}$ & 63,50 \\
\hline $2 B F$ & $64,9 \mathrm{bc}$ & $65,7 \mathrm{ab}$ & $65,9 \mathrm{a}$ & $65,9 \mathrm{a}$ & $61,0 \mathrm{a}$ & $60,4 a$ & 64,00 \\
\hline Média & 62,70 & 66,02 & 65,95 & 65,10 & 60,17 & 57,97 & 63,50 \\
\hline $\mathrm{CV}(\%)$ & 1,35 & 1,66 & 3,49 & 2,46 & 2,75 & 1,78 & - \\
\hline
\end{tabular}

Obs : Médias seguidas de mesma letra nas colunas, não diferem entre si ao nível de $5 \%$

$\mathrm{Obs}_{2}$ : P.T. fr/pc = produção total por fruto por penca

Observa-se, na tabela 11, que houve diferenças significativas para os 2 sistemas utilizados:

- sistema NFT: houve diferença estatística significativa para as pencas 2, 4 e 6 . Com relação a penca 2 , as combinações que proporcionaram as maiores médias foram $1 \mathrm{BN}$ e $2 \mathrm{AN}$; para a penca 4 foram as combinações $1 \mathrm{BN}, 2 \mathrm{AN}$ e $2 \mathrm{BN}$; e para a penca 6 foram as combinações $1 \mathrm{AN}$ e $2 \mathrm{AN}$;

- sistema NNT: houve diferença estatística significativa para as pencas 1, 2, 4 e 6 .

Com relação a penca 1 , a combinação que proporcionou a maior média foi 1BF; para a penca 2 as combinações que expressaram os maiores valores foram $2 \mathrm{AF}$, $1 \mathrm{BF}$ e $2 \mathrm{BF}$; para a penca 4 foram $2 \mathrm{AF}, 2 \mathrm{BF}$ e $1 \mathrm{BF}$; e para a penca 6 foram $2 \mathrm{BF}$ e $1 \mathrm{AF}$.

Observa-se na tabela 11 que, para o sistema NFT, o diâmetro médio de frutos da penca que proporcionou o maior resultado (penca 2) foi $13,42 \%$ superior ao diâmetro médio apresentado pela penca 6 (menores valores); para as pencas 1 e 3 os valores foram $10,29 \%$ e $12,01 \%$, respectivamente, superiores à penca 6 ; enquanto que para as pencas 4 e 5 os valores foram $9,64 \%$ e $3,30 \%$, respectivamente, superiores à penca 6. 
Para o sistema NNT, o diâmetro médio de frutos da penca que proporcionou o maior resultado (penca 2) foi $13,88 \%$ superior ao diâmetro médio da penca 6 (menores valores); para as pencas 1 e 3 os valores foram 8,15\% e 13,76\%, respectivamente, superiores à penca 6; enquanto que para as pencas 4 e 5 os valores foram $12,29 \%$ e 3,80\%, respectivamente, superiores à penca 6 .

A tabela 11 mostra que, de modo geral, as plantas, dentro das combinações, se comportaram de maneira semelhante com relação ao diâmetro médio de frutos, ou seja, as pencas 5 e 6 foram as que mostraram as menores médias para diâmetro médio de frutos, exceto para a combinação 2BN, sendo a menor média apresentada pela penca 6 da combinação $2 \mathrm{AF}$.

A figura 4 mostra o diâmetro médios de fruto para todas as pencas, em cada combinação.

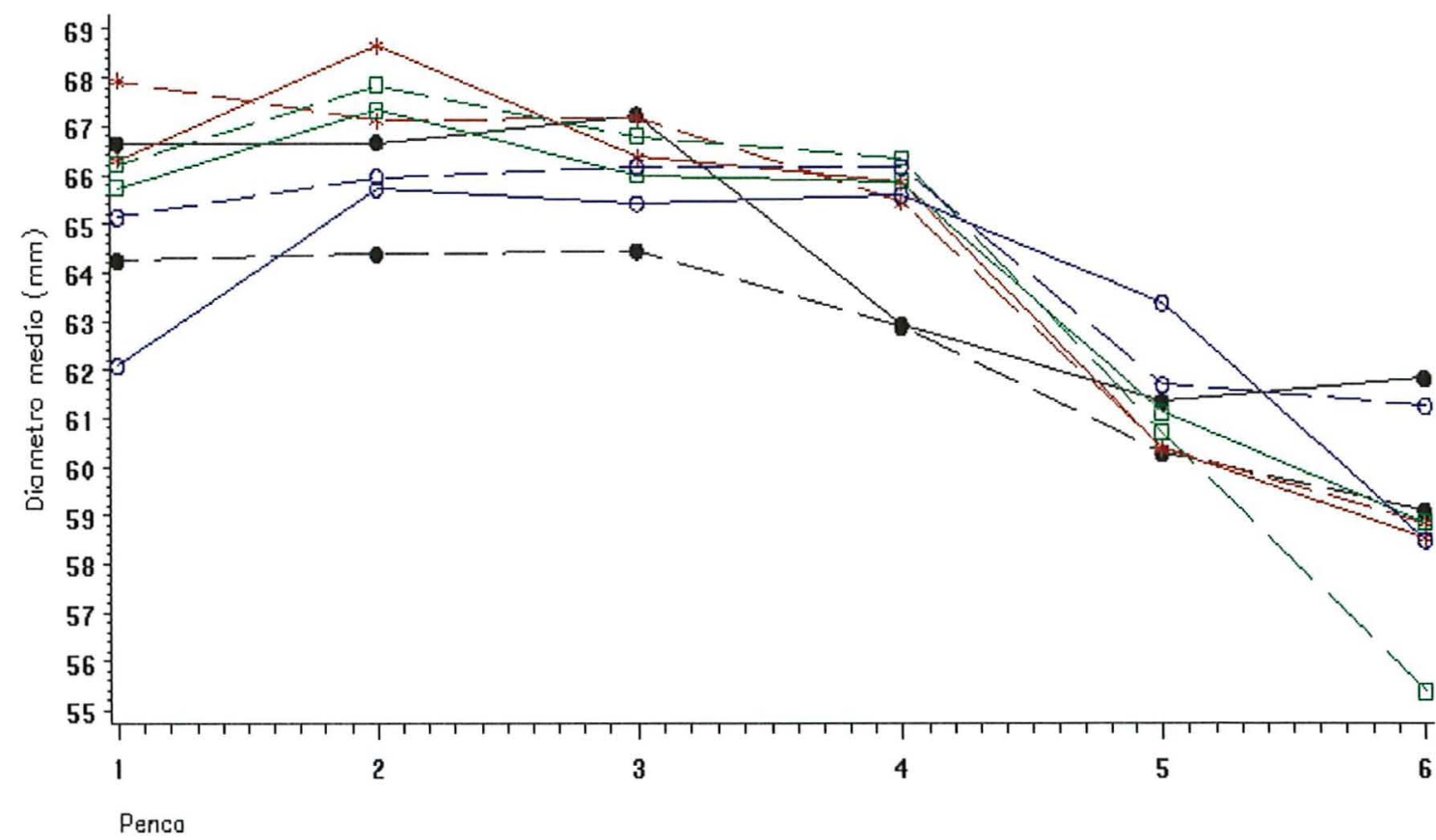

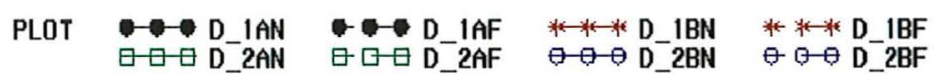

Figura 4 - Diâmetro médio de frutos, por penca, por combinação, ESALQ-USP, Piracicaba, SP. 
A figura 4 mostra que para o diâmetro médio de frutos, houve pouca variação entre as combinações que mostraram resultados semelhantes para as pencas, ou seja, conforme os frutos foram diminuindo de tamanho da primeira para a última penca, o diâmetro também foi diminuindo.

A tabela 12 mostra o comportamento de todas as pencas, para cada combinação, posicionando-as dentro de um "ranking" decrescente de produção.

Tabela 12- Diâmetro médio de frutos, por penca, por planta, segundo um "ranking" decrescente, Diâmetro médio relativo de frutos e diferença entre os frutos com maior e menor diâmetro médio, de acordo com as combinações, ESALQ-USP, Piracicaba, SP.

\begin{tabular}{|c|c|c|c|}
\hline \multirow[t]{2}{*}{ Combinação } & \multirow[t]{2}{*}{ Ranking } & \multicolumn{2}{|c|}{$\begin{array}{l}\text { Diferença entre Diâmetro Médio } \\
\text { (frutos de maior e menor } \phi \text { ) }\end{array}$} \\
\hline & & $\phi$ de fruto $(\mathrm{cm})$ & $\phi$ Relativo \\
\hline IAN & $3,2,1,4,5$ e 6 & 5,8 & 109 \\
\hline $1 \mathrm{BN}$ & $2,1=3,4,5$ e 6 & 10,5 & 118 \\
\hline $2 \mathrm{AN}$ & $2,1,3,4,5$ e 6 & 8,6 & 114 \\
\hline 2BN & $2=3,4,5,1$ e 6 & 7,2 & 112 \\
\hline MÉDIA $^{1 /}$ & $2,3,1,4,5$ e 6 & 8,02 & 113,25 \\
\hline \multirow[t]{2}{*}{ Combinação } & \multirow[t]{2}{*}{ Ranking } & \multicolumn{2}{|c|}{$\begin{array}{l}\text { Diferença entre Diâmetro Médio } \\
\text { (frutos de maior e menor } \phi \text { ) }\end{array}$} \\
\hline & & $\phi$ de fruto $(\mathrm{cm})$ & $\phi$ Relativo \\
\hline IAF & $3,1,2,4,5$ e 6 & 5,8 & 109 \\
\hline $1 \mathrm{BF}$ & $1,3,2,4,5$ e 6 & 9,7 & 116 \\
\hline $2 \mathrm{AF}$ & $2,3,1,4,5$ e 6 & 12,9 & 123 \\
\hline $2 \mathrm{BF}$ & $3=4,2,1,5$ e 6 & 5,5 & 109 \\
\hline MÉDIA $^{1 /}$ & $2,3,4,1,5$ e 6 & 8,47 & 114,25 \\
\hline
\end{tabular}

Obs: Foi utilizado índice 100 para o fruto de menor peso, visando o cálculo da diferença entre os frutos com maior e menor peso médio.

1/ Média- obtida com base nos valores médios da tabela 11

A tabela 12 mostra que, de modo geral as plantas, dentro das combinações, se comportaram de maneira semelhante com relação ao diâmetro médio de frutos, ou seja, as pencas 5 e 6 foram as que apresentaram os menores diâmetro médios de frutos produzidos, exceto a combinação $2 \mathrm{BN}$ onde a peca 5 apresentou valores superiores. As pencas que apresentaram o maior e menor diâmetro médio, respectivamente, foram a $2^{\mathrm{a}}$ da combinação $1 \mathrm{BN}$ e a $6^{\mathrm{a}}$ da combinação $2 \mathrm{AF}$ (tabela 11). 
Deve-se salientar que, para a totalidade das combinações, as 4 primeiras pencas apresentaram os melhores resultados, exceto para a combinação 2BN (tabela 12).

As menores diferenças de rendimento, em diâmetro médio de frutos, entre as pencas que produziram maior e menor diâmetro médio de frutos, de acordo com a tabela 14, foram:

- sistema NFT - combinações $1 \mathrm{AN}, 2 \mathrm{BN}, 2 \mathrm{AN}$ e $1 \mathrm{BN}$, respectivamente;

- sistema NNT - combinações $2 \mathrm{BF}, 1 \mathrm{AF}, 1 \mathrm{BF}$ e $2 \mathrm{AF}$, respectivamente.

De acordo com a tabela 12, considerando-se o sistema NFT, observa-se que a penca 2 seguida pelas pencas 3,1 e 4 apresentaram maiores médias de diâmetro médio de frutos, respectivamente; enquanto que para o sistema NNT, observa-se que as pencas 2, 3, 4 e 1, respectivamente, apresentaram os maiores valores.

De maneira geral, para todas as combinações, as pencas 5 e 6 apresentaram os menores valores de diâmetro médio de frutos.

\subsection{Porcentagem de frutos refugos}

$\mathrm{Na}$, tabela 13 observam-se as porcentagens de frutos refugo das respectivas combinações, considerando-se os 2 sistemas de comercialização avaliados (granel - tipo CEAGESP e embalado - tipo supermercado)

Tabela 13 - Porcentagem de frutos refugo por penca, por combinação, de acordo com 2 sistemas de classificação: CEAGESP e supermercado ESALQ-USP, Piracicaba, SP.

\section{Sistema NFT}

\begin{tabular}{|c|c|c|c|c|c|c|c|c|c|c|c|c|}
\hline \multirow{3}{*}{ Comb. } & \multicolumn{12}{|c|}{ \% de Refugos por Penca } \\
\hline & \multicolumn{2}{|c|}{1} & \multicolumn{2}{|c|}{2} & \multicolumn{2}{|c|}{3} & \multicolumn{2}{|c|}{4} & \multicolumn{2}{|c|}{5} & \multicolumn{2}{|c|}{6} \\
\hline & $\mathbf{S}$ & $\mathbf{C}$ & $\mathbf{S}$ & $\mathbf{C}$ & $\mathbf{S}$ & $\mathbf{C}$ & $\bar{S}$ & $\mathbf{C}$ & $\mathbf{S}$ & $\mathbf{C}$ & $\mathbf{S}$ & $\mathbf{C}$ \\
\hline $1 \mathrm{AN}$ & 19,7 & 20,7 & 20,8 & 22,7 & 18,5 & 21,4 & 32,5 & 35,3 & 40,7 & 43,2 & 34 & 41,4 \\
\hline IBN & 23,6 & 24,6 & 22,2 & 21,0 & 26,0 & 25,0 & 23,4 & 24,6 & 46,3 & 51,2 & 47,2 & 54,1 \\
\hline $2 \mathrm{AN}$ & 22,4 & 22,3 & 19,2 & 21,1 & 22,8 & 22,5 & 27,5 & 28,5 & 45,0 & 39,0 & 50,0 & 58,2 \\
\hline 2BN & 37,9 & 38,4 & 28,3 & 27,4 & 29,0 & 29,4 & 29,7 & 26,7 & 32,9 & 32,5 & 50,6 & 56,7 \\
\hline Média & 25,90 & 26,50 & 22,60 & 23,05 & 24,07 & 24,58 & 28,30 & 28,77 & 41,23 & 41,48 & 45,45 & 52,60 \\
\hline
\end{tabular}


Sistema NNT

\begin{tabular}{|c|c|c|c|c|c|c|c|c|c|c|c|c|}
\hline \multirow{3}{*}{ Comb. } & \multicolumn{12}{|c|}{$\%$ de Refugos por Penca } \\
\hline & \multicolumn{2}{|c|}{$\mathbf{1}$} & \multicolumn{2}{|c|}{2} & \multicolumn{2}{|c|}{3} & \multicolumn{2}{|c|}{4} & \multicolumn{2}{|c|}{5} & \multicolumn{2}{|c|}{6} \\
\hline & $\mathbf{S}$ & C & $\mathbf{S}$ & C & $\mathbf{S}$ & C & $\mathbf{S}$ & C & $\mathbf{S}$ & C & $\mathbf{S}$ & C \\
\hline $1 \mathrm{AF}$ & 30,0 & 32,3 & 28,8 & 31,6 & 30,6 & 32,2 & 33,5 & 38,5 & 42,6 & 49,2 & 46,4 & 53,8 \\
\hline IBF & 15,6 & 16 & 22,5 & 23,0 & 18,6 & 19,7 & 25,7 & 27,0 & 48,0 & 51,2 & 46,2 & 52,7 \\
\hline $2 \mathrm{AF}$ & 24,0 & 23 & 19,0 & 18,3 & 19,7 & 20,3 & 4 & 3 & 45,0 & 50,0 & 61,0 & 67,8 \\
\hline $2 \mathrm{BF}$ & 26,0 & 26,4 & 27,0 & 27,4 & 22,0 & 23,5 & 24,6 & 25,2 & 36,0 & 40,7 & 40,0 & 43,7 \\
\hline Média & 23,90 & 24,75 & 24,33 & 25,08 & 22,73 & 23,93 & 27,3 & 28,8 & 42,90 & 49,78 & 48,40 & 54,50 \\
\hline
\end{tabular}

De acordo com a tabela 13 tem-se:

CEAGESP: a $\sigma^{\text {a }}$ penca apresentou, no sistema NFT, $23,83 \%$ mais refugos que a $4^{\mathrm{a}}$ penca, ou seja, $52,60 \%$ contra $28,77 \%$. Entretanto, quando se compara com a penca $1\left(26,50 \%\right.$ de refugo) a $4^{\mathrm{a}}$ penca apresentou apenas $2,27 \%$ mais refugos $(28,77 \%)$. A $5^{\mathrm{a}}$ penca apresentou $12,71 \%$ mais refugo do que a $4^{\mathrm{a}}$ penca.

CEAGESP: a $6^{\mathrm{a}}$ penca apresentou, no sistema NNT, 25,70\% mais refugos que a $4^{\mathrm{a}}$ penca, ou seja, $54,50 \%$ contra $28,80 \%$. Entretanto, quando se compara com a penca $1\left(24,75 \%\right.$ de refugo) a $4^{\text {a }}$ penca apresentou apenas $4,05 \%$ mais refugos $(28,80 \%)$. A $5^{\mathrm{a}}$ penca apresentou $20,98 \%$ mais refugo do que a $4^{\mathrm{a}}$ penca.

Supermercado: analisando-se as mesmas pencas, observa-se um menor percentual de refugos. Para o sistema NFT, a $6^{a}$ penca apresentou $17,15 \%$ mais refugos que a $4^{a}$ penca,. Entretanto, quando se compara com a penca $1\left(25,9 \%\right.$ de refugo) a $4^{\mathrm{a}}$ penca apresentou apenas $2,4 \%$ mais refugos $(28,3 \%)$. A $5^{\text {a }}$ penca apresentou $12,93 \%$ mais refugo do que a $4^{\mathrm{a}}$ penca.

Supermercado: analisando-se as mesmas pencas, observa-se um menor percentual de refugos. Para o sistema NNT, a $6^{\text {a }}$ penca apresentou $21,1 \%$ mais refugos que a $4^{\mathrm{a}}$ penca, Entretanto, quando se compara com a penca $1\left(23,9 \%\right.$ de refugo) a $4^{\mathrm{a}}$ penca apresentou apenas $3,4 \%$ mais refugos $(27,3 \%)$. A $5^{\text {a }}$ penca apresentou $15,60 \%$ mais refugo do que a $4^{\mathrm{a}}$ penca.

A explicação do maior aproveitamento para a classificação tipo supermercado refere-se ao fato de que este tipo de comercialização, em bandejas de 4 e 6 frutos, aceita frutos menores desde que a aparência geral tenha qualidade. 
Tabela 14 - Porcentagem de frutos refugo acumulada, com base na produção total, por combinação, de acordo com 2 sistemas de classificação: CEAGESP e Supermercado ESALQ-USP, Piracicaba, SP.

\section{Sistema NFT}

\begin{tabular}{|c|c|c|c|c|c|c|c|c|c|c|c|c|}
\hline \multirow{3}{*}{ Comb. } & \multicolumn{12}{|c|}{ \% de Refugos acumulada por Penca } \\
\hline & \multicolumn{2}{|c|}{1} & \multicolumn{2}{|c|}{2} & \multicolumn{2}{|c|}{3} & \multicolumn{2}{|c|}{4} & \multicolumn{2}{|c|}{5} & \multicolumn{2}{|c|}{6} \\
\hline & $\mathbf{S}$ & $\mathbf{C}$ & $\mathbf{S}$ & $\mathbf{C}$ & $\underline{S}$ & $\mathbf{C}$ & $\mathbf{S}$ & $\mathbf{C}$ & $\underline{\mathbf{S}}$ & $\mathbf{C}$ & $\mathbf{S}$ & $\mathbf{C}$ \\
\hline $1 \mathrm{AN}$ & 4,1 & 4,3 & 8,8 & 9,5 & 12,4 & 13,6 & 17,4 & 19,0 & 21,8 & 23,7 & 25,5 & 28,2 \\
\hline $1 \mathrm{BN}$ & 4,9 & 5,1 & 9,8 & 9,7 & 14,6 & 14,4 & 18,4 & 18,3 & 24,2 & 24,8 & 28,9 & 30,2 \\
\hline $2 \mathrm{AN}$ & 4,5 & 4,5 & 8,4 & 8,7 & 12 & 13 & 18,0 & 18,5 & 23,4 & 23,1 & 28,1 & 28,6 \\
\hline 2BN & 6,0 & 6,0 & 11,2 & 11,1 & 16,7 & 16,7 & 22,7 & 22,0 & 28,0 & 27,4 & 33,3 & 33,2 \\
\hline Média & $\mathbf{4 , 8 8}$ & 4,98 & 9,55 & $\mathbf{9 , 7 5}$ & 14,13 & 14,46 & 19,13 & 19,45 & 24,35 & 24,75 & 28,95 & 30,05 \\
\hline
\end{tabular}

\section{Sistema NNT}

\begin{tabular}{|c|c|c|c|c|c|c|c|c|c|c|c|c|}
\hline \multirow{3}{*}{ Comb. } & \multicolumn{12}{|c|}{$\%$ de Refugos acumulada por Penca } \\
\hline & \multicolumn{2}{|c|}{$\mathbf{1}$} & \multicolumn{2}{|c|}{2} & \multicolumn{2}{|c|}{3} & \multicolumn{2}{|c|}{4} & \multicolumn{2}{|c|}{5} & \multicolumn{2}{|c|}{6} \\
\hline & $\mathbf{S}$ & $\mathbf{C}$ & $\mathbf{S}$ & C & $\mathbf{S}$ & $\mathbf{C}$ & $\mathbf{S}$ & $\mathbf{C}$ & $\mathbf{S}$ & $\mathbf{C}$ & $\mathbf{S}$ & $\mathbf{C}$ \\
\hline $1 \mathrm{AF}$ & 5,1 & 5,5 & 10,7 & 11,7 & 16,4 & 17,8 & 22,8 & 24,7 & 28,0 & 30,6 & 34,1 & 37,6 \\
\hline $1 \mathrm{BF}$ & 3,2 & 3,4 & 8,0 & 8,3 & 11,8 & 12,3 & 16,1 & 16,8 & 21,5 & 22,6 & 26,0 & 27,6 \\
\hline $2 \mathrm{AF}$ & 5 & 5,5 & 9,6 & 9,4 & 13,2 & 13,1 & 17,2 & 17,0 & 22,3 & 22,6 & 28,5 & 29,5 \\
\hline $2 \mathrm{BF}$ & 4,8 & 4,8 & 9,8 & 9,9 & 14,1 & 14,5 & 18,4 & 18,9 & 23,9 & 25,1 & 28,2 & 29,8 \\
\hline Média & 4,65 & $\mathbf{4 , 8 0}$ & 9,50 & $\mathbf{9 , 8 2}$ & 13,88 & 14,43 & 18,63 & 19,35 & 23,93 & 25,23 & 29,20 & 31,13 \\
\hline
\end{tabular}

De acordo com a tabela 14, observa-se que, para a classificação do CEAGESP, os valores acumulados mostram uma vantagem para o sistema NFT, promovendo $1,08 \%$ menos refugo que o sistema NNT. Com relação a classificação para comercialização em supermercado, observa-se comportamento semelhante com vantagem de $0,3 \%$ para o sistema NFT.

Os tratamentos que proporcionaram menor quantidade de refugo foram:

- CEAGESP: 1BF, 1AN e 2AN, respectivamente;

- supermercado: $1 \mathrm{AN}, 1 \mathrm{BF}$ e $2 \mathrm{AN}$, respectivamente.

\subsection{Principais defeitos encontrados nos frutos}

A tabela 15 mostra as porcentagens de frutos com defeitos encontrados durante as avaliações de colheita do experimento. 
Tabela 15 -Principais defeitos encontrados nos frutos durante o experimento, ESALQUSP, Piracicaba, SP.

\begin{tabular}{|c|c|c|c|c|c|c|c|}
\hline TRAT & PC & RACH. & FP & $\mathbf{L A}$ & $\mathrm{VC}$ & ZIPER & TOTAL \\
\hline $1 \mathrm{AN}$ & 1 & 1,15 & 0,33 & 0 & 0,66 & 0,16 & 2,30 \\
\hline $1 \mathrm{AN}$ & 2 & 1,25 & 0,63 & 0 & 0,94 & 0,16 & 2,98 \\
\hline $1 \mathrm{AN}$ & 3 & 4,00 & 0,18 & 0,18 & 0 & 0,18 & 4,54 \\
\hline $1 \mathrm{AN}$ & 4 & 4,76 & 0,20 & 0,40 & 0,99 & 0 & 6,35 \\
\hline $1 \mathrm{AN}$ & 5 & 9,56 & 0 & 0 & 1,64 & 0 & 11,20 \\
\hline $1 \mathrm{AN}$ & 6 & 21,92 & 0 & 0 & 0 & 0 & 21,92 \\
\hline Média & & 7,11 & 0,22 & 0,10 & 0,71 & 0,08 & 8,21 \\
\hline $1 \mathrm{BN}$ & 1 & 1,09 & 0 & 0 & 0 & 0,16 & 1,25 \\
\hline $1 \mathrm{BN}$ & 2 & 1,64 & 0,16 & 0 & 0 & 0 & 1,8 \\
\hline $1 \mathrm{BN}$ & 3 & 6,35 & 0 & 0,17 & 0 & 0,51 & 7,03 \\
\hline $1 \mathrm{BN}$ & 4 & 10,45 & 0 & 0,20 & 0 & 0,20 & 10,85 \\
\hline $1 \mathrm{BN}$ & 5 & 15,43 & 0,21 & 0 & 0 & 0,21 & 15,85 \\
\hline $1 \mathrm{BN}$ & 6 & 16,11 & 0 & 0 & 0 & 0,77 & 16,88 \\
\hline Média & & 8,51 & 0,06 & 0,06 & 0,00 & 0,31 & 8,94 \\
\hline $2 \mathrm{AN}$ & 1 & 0,34 & 0,17 & 0 & 0 & 0,34 & 0,85 \\
\hline $2 \mathrm{AN}$ & 2 & 0,75 & 0,37 & 0 & 0,19 & 0 & 1,31 \\
\hline $2 \mathrm{AN}$ & 3 & 4,20 & 0,18 & 0,18 & 0 & 0,18 & 4,56 \\
\hline $2 \mathrm{AN}$ & 4 & 5,62 & 0,19 & 0,37 & 0,37 & 0,56 & 7,11 \\
\hline $2 \mathrm{AN}$ & 5 & 7,07 & 0 & 0 & 0 & 0 & 7,07 \\
\hline $2 \mathrm{AN}$ & 6 & 10,53 & 0 & 0 & 0 & 0 & 10,53 \\
\hline Média & & 4,75 & 0,15 & 0,09 & 0,09 & 0,18 & 5,24 \\
\hline $2 \mathrm{BN}$ & 1 & 0,37 & 0 & 0 & 0 & 0,37 & 0,74 \\
\hline $2 \mathrm{BN}$ & 2 & 0,74 & 0,37 & 0 & 0 & 0 & 1,11 \\
\hline $2 \mathrm{BN}$ & 3 & 8,80 & 0 & 0 & 0 & 0,18 & 8,98 \\
\hline $2 \mathrm{BN}$ & 4 & 14,26 & 0,17 & 0,33 & 0 & 0,17 & 14,93 \\
\hline $2 \mathrm{BN}$ & 5 & 12,33 & 0,19 & 0 & 0 & 0 & 12,52 \\
\hline $2 \mathrm{BN}$ & 6 & 7,85 & 0 & 0 & 0 & 1,01 & 8,86 \\
\hline Média & & 7,39 & 0,12 & 0,06 & 0,00 & 0,29 & 7,86 \\
\hline $1 \mathrm{AF}$ & 1 & 2,76 & 0,59 & 0 & 2,56 & 0 & 5,91 \\
\hline $1 \mathrm{AF}$ & 2 & 3,18 & 0 & 0,37 & 0,75 & 0 & 4,3 \\
\hline $1 \mathrm{AF}$ & 3 & 7,93 & 0,30 & 0,46 & 0,61 & 0,30 & 9,6 \\
\hline $1 \mathrm{AF}$ & 4 & 13,29 & 0 & 0,61 & 0,20 & 0 & 14,1 \\
\hline $1 \mathrm{AF}$ & 5 & 12,9 & 0 & 0,22 & 0,43 & 0,22 & 13,77 \\
\hline $1^{A} \mathrm{~F}$ & 6 & 19,77 & 0,46 & 0 & 0 & 0 & 20,23 \\
\hline Média & & 9,97 & 0,23 & 0,28 & 0,76 & 0,09 & 11,32 \\
\hline $1 \mathrm{BF}$ & 1 & 1,55 & 0,17 & 0 & 0,69 & 0,34 & 2,75 \\
\hline 1BF & 2 & 2,12 & 0,49 & 0 & 0,16 & 0,33 & 3,1 \\
\hline $1 \mathrm{BF}$ & 3 & 2,61 & 0 & 0 & 0,98 & 0,16 & 6,85 \\
\hline $1 \mathrm{BF}$ & 4 & 13,77 & 0 & 0 & 0,20 & 0,20 & 14,17 \\
\hline IBF & 5 & 21,08 & 0,23 & 0,23 & 0,23 & 0,23 & 22 \\
\hline $1 \mathrm{BF}$ & 6 & 23,53 & 0 & 0 & 0,27 & 0,27 & 24,07 \\
\hline Média & & 10,38 & 0,15 & 0,04 & 0,42 & 0,26 & 12,16 \\
\hline $2 \mathrm{AF}$ & 1 & 1,02 & 0,15 & 0 & 0,29 & 0,29 & 1,75 \\
\hline $2 \mathrm{AF}$ & 2 & 1,71 & 0,17 & 0 & 0 & 0 & 1,88 \\
\hline $2 \mathrm{AF}$ & 3 & 4,98 & 0 & 0 & 0 & 0,18 & 5,16 \\
\hline $2 \mathrm{AF}$ & 4 & 10,34 & 0,65 & 0,22 & 0 & 0,22 & 11,43 \\
\hline $2 \mathrm{AF}$ & 5 & 8,08 & 0 & 0 & 0 & 0 & 8,08 \\
\hline $2 \mathrm{AF}$ & 6 & 8,86 & 0 & 0,23 & 0,23 & 2,10 & 11,42 \\
\hline Média & & 5,43 & 0,16 & 0,08 & 0,09 & 0,47 & 6,62 \\
\hline $2 \mathrm{BF}$ & 1 & 0,18 & 0,54 & 0 & 0,36 & 0,18 & 1,26 \\
\hline $2 \mathrm{BF}$ & 2 & 1,84 & 0 & 0,37 & 0 & 0 & 2,21 \\
\hline $2 \mathrm{BF}$ & 3 & 2,59 & 0 & 0 & 0,35 & 0 & 2,94 \\
\hline $2 \mathrm{BF}$ & 4 & 6,87 & 0 & 0 & 0,38 & 0 & 7,25 \\
\hline $2 \mathrm{BF}$ & 5 & 11,26 & 0 & 0 & 0,39 & 0,19 & 11,84 \\
\hline $2 \mathrm{BF}$ & 6 & 17,31 & 0,27 & 0 & 0 & 0 & 17,58 \\
\hline Média & & 6,68 & 0,14 & 0,06 & 0,25 & 0,06 & 7,18 \\
\hline
\end{tabular}

Legenda: $\mathrm{PC}=$ penca; $\mathrm{RACH}=$ rachado; $\mathrm{FP}=$ fundo preto; $\mathrm{VC}=$ vira-cabeça; $\mathrm{LA}=$ =óculo aberto 
De acordo com os dados da tabela 15 , podemos observar que o maior índice de defeitos foi relativo a rachamento de frutos, o que pode ser explicado principalmente pelos diferentes gradientes de temperaturas que ocorreram durante a condução do experimento, fazendo com que, por vezes o crescimento extremo do fruto não acompanhasse a sua turgescência interna, proporcionando o fenômeno do rachamento dos frutos.

A figura 5 mostra a porcentagem de frutos rachados em comparação com a porcentagem de frutos normais por combinação.

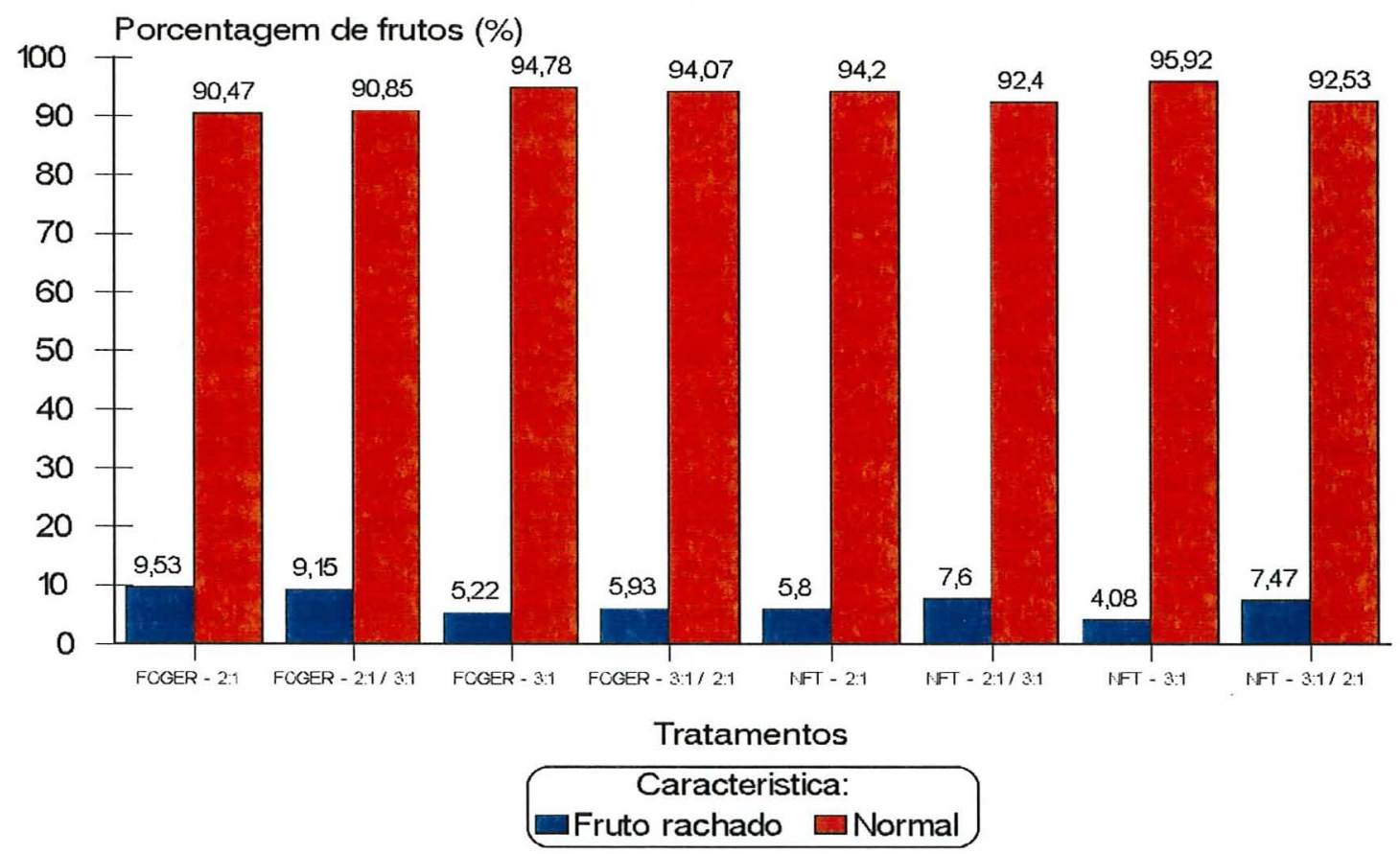

Figura 5 -Porcentagem de frutos rachados e frutos normais, por combinação, ESALQ-USP, Piracicaba, SP.

De acordo com a figura 5, observa-se que o sistema NFT apresentou menor porcentagem de frutos rachados, em detrimento do sistema NNT. Mais especificamente observa-se que, a solução $2 \mathrm{~A}$, ou seja, relação $\mathrm{K} / \mathrm{N}=3: 1 / 3: 1$, apresentou 
índices menores de rachamento de frutos para os 2 sistemas de aplicação de solução nutritiva, porém o sistema NFT apresentou menores porcentagens.

Uma vez que o defeito rachamento de frutos está relacionado a uma menor resistência de parede celular, normalmente atribuída à falta do elemento $\mathrm{Ca}$, e o elemento $\mathrm{K}$ traz à planta um maior equilíbrio osmótico favorecendo a turgescência celular, este último favorece também o transporte e redistribuição de $\mathrm{Ca}$, que já é dificil por ser um elemento praticamente imóvel no floema, portanto, quantidades mais equilibradas de $\mathrm{K}$ favorecem uma maior resistência da parede celular.

Com isso pode-se concluir que a presença de um filme de água mais contínuo na zona de interface da rizosfera (NFT) proporcionou um maior aproveitamento do K, considerando-se que, segundo Malavolta (1980), o principal processo de absorção deste nutriente é a difusão (aproximadamente 75\%). 


\section{CONSIDERAÇÕES FINAIS}

Pelo que foi observado durante a condução do experimento sugere-se:

- para o sistema NNT, mais estudos com períodos de intermitência diferenciados, procurando-se otimizar a absorção de nutrientes com um menor gasto de energia possível para, com isso aumentar o rendimento visando compensar o custo do sistema;

- para o sistema NFT, a utilização de plantas adensadas $(0,35$ a $0,40 \mathrm{~cm})$ conduzidas com uma haste e até a $4^{\text {a }}$ penca, sem raleio de frutos, possibilitando-se assim, a realização de 3,5 ciclos/ano, nas condições em que o experimento foi desenvolvido e para a cultivar utilizada. Vale ressaltar que, para se obter este número de ciclos/ano faz-se necessário transplantar a muda, para as tubulações recipientes, quando a mesma já estiver emitindo o primeiro cacho floral;

- com relação à nutrição, a utilização da relação K:N 2:1 até o florescimento e 3:1 no restante do ciclo. 


\section{CONCLUSÃo}

Pelos resultados obtidos e nas condições de realização do experimento, concluiu-se que:

- não houve diferença significativa entre os sistemas de aplicação de solução nutritiva (NFT e NNT);

- houve interação (solução x sistema) para as pencas 1,2 e 6 .

- no sistema NFT, as soluções nutritivas que proporcionaram os melhores resultados foram: 1A (2:1/2:1), $2 \mathrm{~A}(2: 1 / 3: 1)$ e $1 \mathrm{~B}(3: 1 / 3: 1)$, respectivamente;

- no sistema NNT, as soluções nutritivas que proporcionaram os melhores resultados foram: 1B (3:1/3:1) e $2 \mathrm{~A}(2: 1 / 3: 1)$, respectivamente;

- houve uma concentração maior da produção nas primeiras quatro pencas. 


\section{REFERÊNCIAS BIBLIOGRÁFICAS}

ADAMS, P., MASSEY, D.M. Nutrient uptake by tomatoes from recirculating solutions. In: INTERNATIONAL CONGRESS ON SOILLESS CULTURE, 6, , Lunteren, 1984. Proceedings. Wageningen: International Society for Soilless Culture, 1984, p.71-9.

BENOIT, F. Practical guide for simple soiless culture techniques. Sint-KatelijneWaver: European Vegetable R \& D. Centre, 1992. 72p.

BOARETTO, A.E., BULL, L.T., PIERI, J.C.de et al. Doses de potássio na adubação do tomateiro (Lycopersicon esculentum Mill) estaqueado. Revista de Agricultura, 1980.

CALVERT, A . Studies on the post-initiation development of flower buds of tomato (Lycopersucon esculentum). Journal of Horticultural Science, Ashford Kent, v. 44, p-117-126, 1969.

CARMELLO, Q.A.C. Cultivo hidropónico de plantas. Piracicaba: ESALQ-DIBD, 1997. 27p. (Série Produtor Rural, 1).

CASTEllane, P.D., ARAÚJo, J.A.C. de. Cultivo sem solo - hidroponia. 4.ed. Jaboticabal: FUNEP, 1995..43p. 
CASTEllane, P.D., ARAúJO, J.A.C. de. Cultivo sem terra - hidroponia. Jaboticabal: FUNEP, 1994..43p.

CONCEIÇÃO. F.A.D.; PINHO, S.Z. Ensaio de adubação do tomateiro (Lycopersicon esculentm Mill) em solo de cerrado do Distrito Federal. Revista de Olericultura, Botucatu, v.15, n.97, p.9. 1975.

COOPER, A. Comercial applications of NFT. London: Grower Books, 1982.

COSTA, P.C. Relações N:K:Ca na qualidade de frutos de tomateiro (Lycopersicon esculentum Mill.) híbrido Momotaro, em cultivo hidropônico. Botucatu, 1999, 72p. Dissertação - Universidade Estadual Paulista "Júlio de Mesquita Filho", Faculdade de Ciências Agronômicas.

DOUGLAS, J.S. Hidroponia: cultura sem terra, São Paulo: Nobel, 1989. 141p.

ENOIT, I. ; GABRIEL, K.R. A study of the powers of several methods of multiple comparisons, v.70, p.574-583, 1975.

FAYAD, J.A . Absorção de nutrientes, crescimento e produção do tomateiro cultivado em condições de campo e estufa. Tese, Viçosa - MG, 1998, 81 p.

FILGUEIRA, F.A .R. Manual de olericultura: cultura e comercialização de hortaliças. São Paulo. 2ed., Piracicaba: Ceres, 1982, v.2, 357 p.

FNP Consultoria \& Comércio; MENDES \& SCOTONI, Agrianual 1997- Anuário da agricultura brasileira. Editora Argos, 1996. 546p.

FNP Consultoria \& Comércio; MENDES \& SCOTONI, Agrianual 2000- Anuário da agricultura brasileira. Editora Argos, 1999. 546p. 
FURLANI, P.R. Cultivo de alface pela técnica de hidroponia - NFT. Campinas: Instituto Agronômico, 1995. 18p. (Documentos IAC, 55)

GARCIA, V.N. Sistemas de solución perdida e recirculante. Descripción, análisis y valoración. In: MARTÍNEZ, F.C., ALVAREZ, J.S.D. (Ed.). Cultivos sin suelo. Curso superior de especialización. Almeria: Servicio de Edición del Instituto de Estudios Almerienses, 1993. cap.3, p.85-130.

GARGANTINI, H.; BLANCO, H.G. Marcha de absorção de nutrients pelo tomateiro. Bragantia, v.22, p.693-714, 1963.

GEIMENDER de MORAES, C.A. Como cultivar tomates em sistema NFT. Jundiaí: DISQ Ed., 1997. 141p.

GRAVES, C.J. The nutrient technique. In: JANICK, J. (Ed.). Horticultural Reviews, 1983.v.5, c. 1, p.1-44.

HAAG, H.P.; DECHEN, A.R.; CARMELLO, Q.A.C.; MONTEIRO, F.A. Princípios de nutrição mineral; aspectos gerais. In: In: FERREIRA, M.E., CASTELLANE, P.D., CRUZ, M.C.P. Nutrição e adubação de hortaliças. Piracicaba: Potafós, 1993, p.5173.

HARVEY, P.H. Hereditary variation in plant nutrition. Genetics. V.24, p.437-61, 1939.

HO, L.C. ; HEWITT, J.D. Fruit development. In: ATHERTON, J.C.; RUDICH, J. The tomato crop. London: Chapman and Hall, 1986. p.201-39.

JENSEN, M.H.; COLLINS, W.L. Hydroponic vegetable production. In: JANICK, J. (Ed.). Horticultural Reviews, 1983, v.5, cap. 10, p.483-558. 
JOHNSON, S.P., HALL, W.C. Vegetable an fruitive responses of tomato to hight temperature and light intensity. Bot. GA2. v.114, n.4, p.449-60, 1953.

JONES Jr., J.B. A guide for the hydroponic and soiless culture grower. Portland: Timber Press, 1983. 124p.

JONES Jr., J.B. Hydroponics: its history and use in plant nutrition studies. Journal of plant nutrition, v.5, n.8, p.1003-30, 1982.

MAKMUR, A.; GERLOFF, G.C.; GABELMAN, W.H. Physiology and inheritance of efficiency in potassium utilization in tomatoes grown under potassium stress. Journal American Society Horticultural Science. v.103, n.4, p.545-49, 1978.

MALAVOLTA, E. Elementos de nutrição mineral de plantas. São Paulo: Agronômica CERES. 1980. 255p.

MALAVOLTA, E., VITTI, G.C., OLIVEIRA, S.A. Avaliação do estado nutricional das plantas. Piracicaba:Potafos, 1997. 204p.

MARSCHNER, H. Mineral nutrition of higher plants. 2.ed. San Diego: Academic Press, 1995, 889p.

MARTINEZ, H.E.P., BRACCINI, M.doC.L., BRACCINI, A.de L. Cultivo hidropônico do tomateiro (Lycopersicon esculentum Mill.). Revista UNIMAR, v.19, n.3, p.72140, 1997.

MARTINEZ, H.P.M. Cultivo de flores em hidroponia. In: ENCONTRO DE HIDROPONIA 1, Campinas, 1995. Palestra apresentada. Campinas: UNICAMP, $37 \mathrm{p}$. 
MARTINEZ, H.P.M. O cultivo hidropônico da alface (Lactuca sativa L.). In: CASALI, V.W.D. (Coord.) Seminários de olericultura. Viçosa: Imprensa Universitária, 1988 cap. 15, p. $74-111$.

MINAMI, K., HAAG, H.P. O tomateiro. 2.ed. Campinas: Fundação Cargill, 1989. $397 \mathrm{p}$.

O'SULLIVAN, J.; GABELMAN, W.H.; GERLOFF, G.C. Variation in efficiency of nitrogen utilization in tomatoes (Lycopersicon esculentum Mill) grown under nitrogen stress. Journal American Society Horticultural Science, v.99, n.5, p.54347,1974

PAPADOPOULOS, A. P. Growing greenhouse tomatoes in soil and soilless media. Ontário: Agriculture Canada Publication 1991, 79 p.

RESH, H.M. Hydroponic tomatoes for de the home gardener. California: Woodbridge Press Publishing Company, 1993. 142p.

RESH, H.M. Cultivos hidropônicos. 4.ed. Madrid: Mundi Prensa, 1997. 359p.

RESH, H.M. Cultivos hidropónicos: nuevas técnicas de produción. 3.ed. Madrid: Ed. Mundi Prensa, 1992. 318p.

RESH, H.M. Hydroponic food production. 5.ed Santa Barbara, CA: Woodbridge Press. 1995. 527p.

SHIPPERS, PA. Compositions changes in the nutrition solution during the growth of plants in recirculating nutrient culture. In: SYMPOSIUM ON RESEARCH ON RECIRCULATING WATER CULTURE, 1, Littlehampton, 1979. Acta Horticultural, v.98, p.103-18, 1980. 
SILVA, E. C. da, Efeito de doses de nitrogênio (nitrocálcio) e potássio (cloreto de potássio) na produção e em algumas características qualitativas dos frutos do tomateiro (Lycopersicon esculentum Mill) cultivar Santa Clara, podado e adensado, Lavras, 1994 . Dissertação, Universidade Federal de Lavras . 92p.

STAFF, H. Hidroponià. Cuiabá: SEBRAE/MT. 1997.86p. (Coleção Agroindústria; v.11).

STEINER, A.A. The seletive capacity of plants for ions and its importance for the composition and treatment of the nutrient dolution. In: SYMPOSIUM ON RESEARCH ON RECIRCULATING WATER CULTURE, 1, Littlehampton, 1979. Acta Horticultural, v.98, p.87-98, 1980.

TAKAHASHI, H.W. Nutrição e adubação de tomate estaqueado. In: FERREIRA, M.E., CASTELlANE, P.D., CRUZ, M.C.P. Nutrição e adubação de hortaliças. Piracicaba: Potafós, 1993, p. 301-18.

TAKAZAKI, P.E., DELLA VECCHIA, P.T. Problemas nutricionais e fisiológicos no cultivo de hortaliças em ambiente protegido. In: FERREIRA, M.E., CASTELLANE, P.D., CRUZ, M.C.P. Nutrição e adubação de hortaliças. Piracicaba: Potafós, 1993, p.481-7.

TANAKA, A.; FUJTA, K., KIKUCHI, K. Nutrio-physiological studies on the tomato plant. III Photosynthetic rate of individual leaves in relation to the dry matter production of the plants. Soil Science Plant Nutrition, v.20, n.2, p.173-83, 1974.

UEDA, S. Hidroponia: guia prático. São Paulo: Agroestufa, 1990. 50p.

VICENZONI, A. Coltivazioni senza terra. Idroponia ed aeroponica. Bologne: Edigricole, 1980. 
WILSON, G.C.S. Effect of N:K ratio in a hydroponic situation. In: SYMPOSIUM ON RESEARCH ON RECIRCULATING WATER CULTURE, 1, Littlehampton, 1979 Acta Horticultural. v.98, p.161-96, 1980.

ZEHLER, E.; FOSTER, H. Yield potential of tomatoes to potassium nutrition. Potash Review, v.8, n.22, p. 6, 1972. 
ANEXOS 
Anexo 1 - Fotos referentes ao experimento
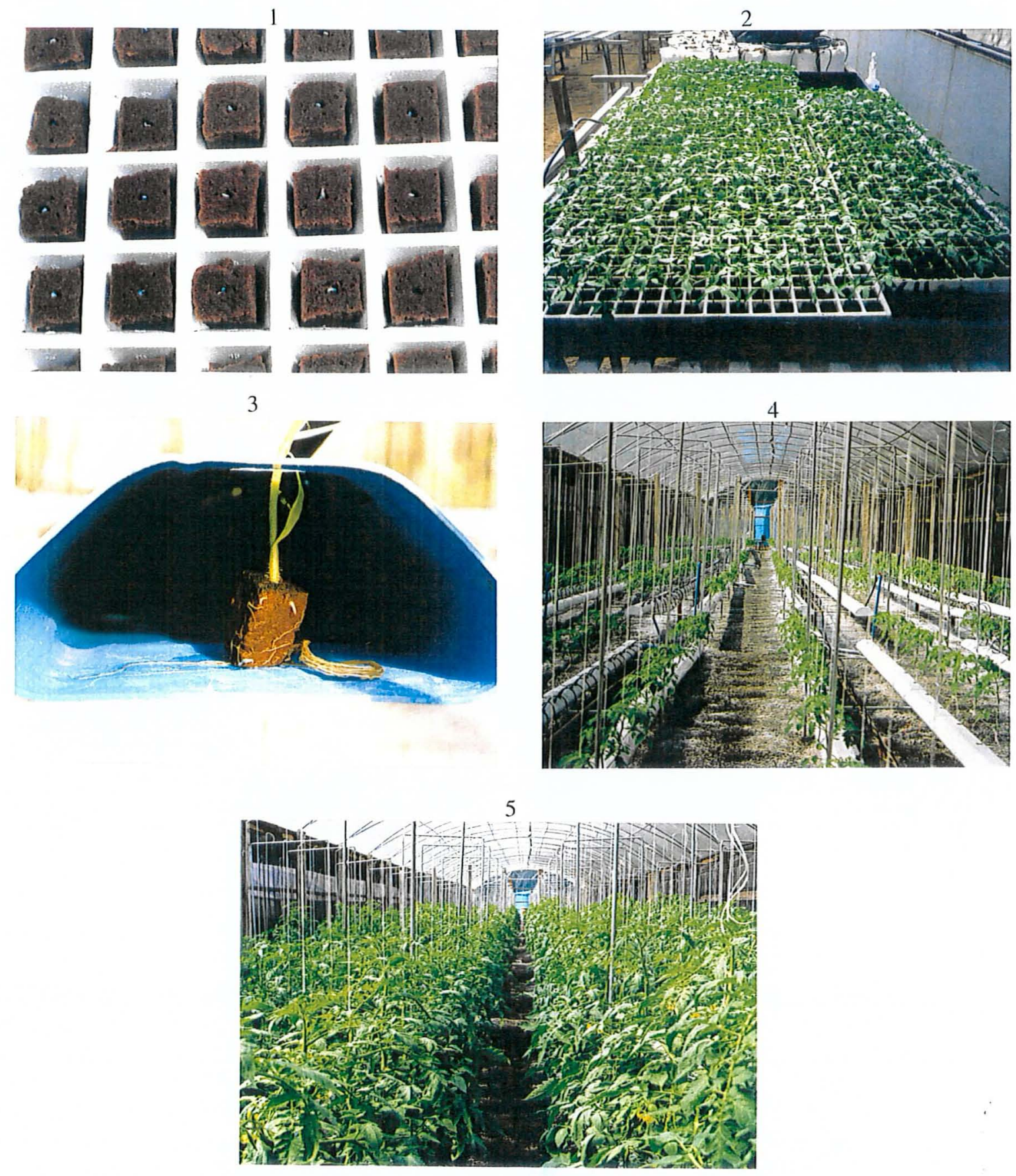

Foto 1 - Semeadura em espuma fenólica;

Foto 3 - Detalhe da muda recém-transplantada; Foto 5 - Vista geral (30 dias após transplante.
Foto 2 - Mudas no "floating";

Foto 4 - Vista geral (10 dias após transplante); 
6

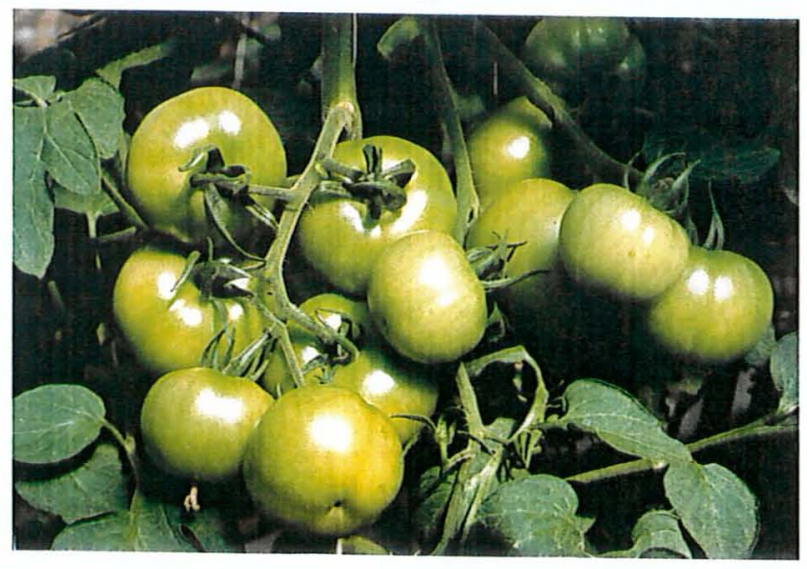

8

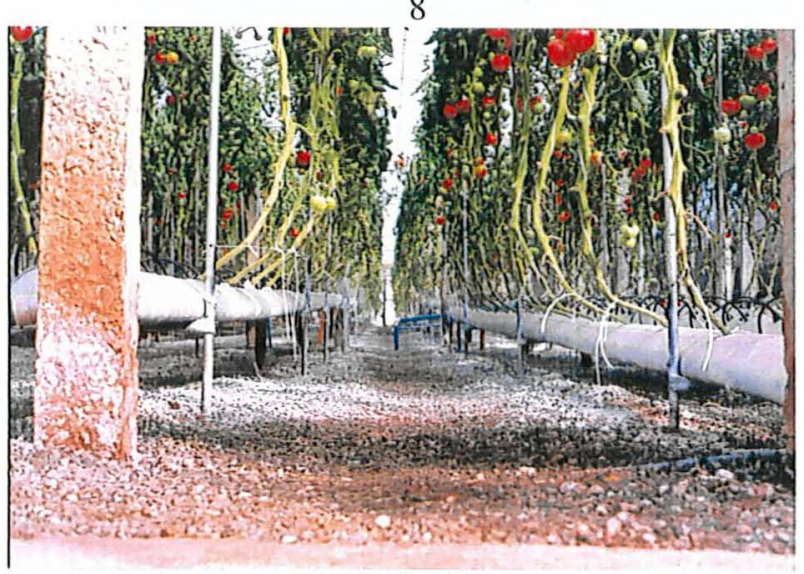

10

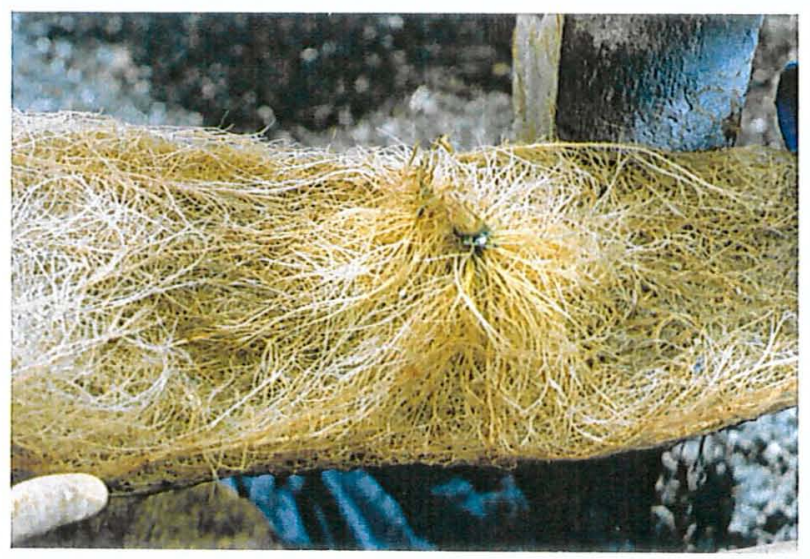

Foto 6 - Detalhe da penca;

Foto 8 -Vista geral (pico de colheita);

Foto 10 - Detalhe da raiz de uma planta adulta.

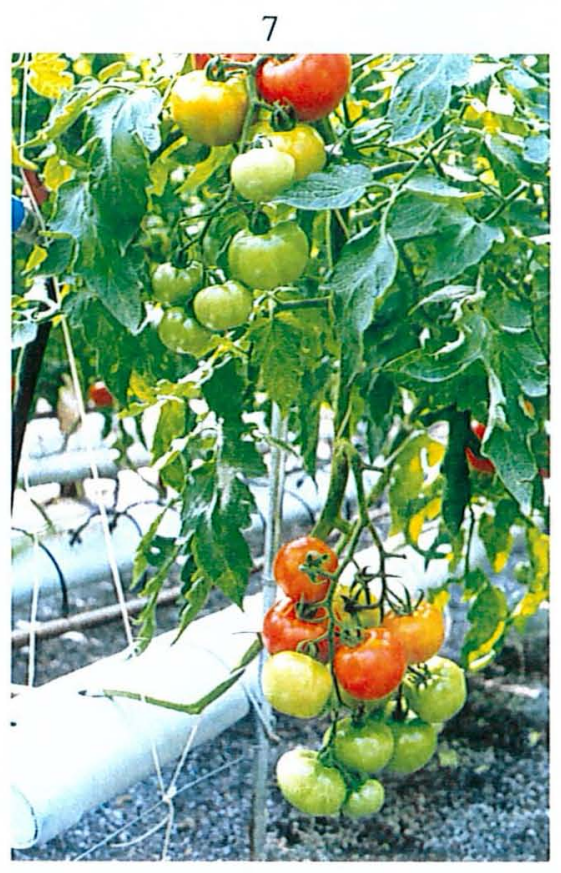

9

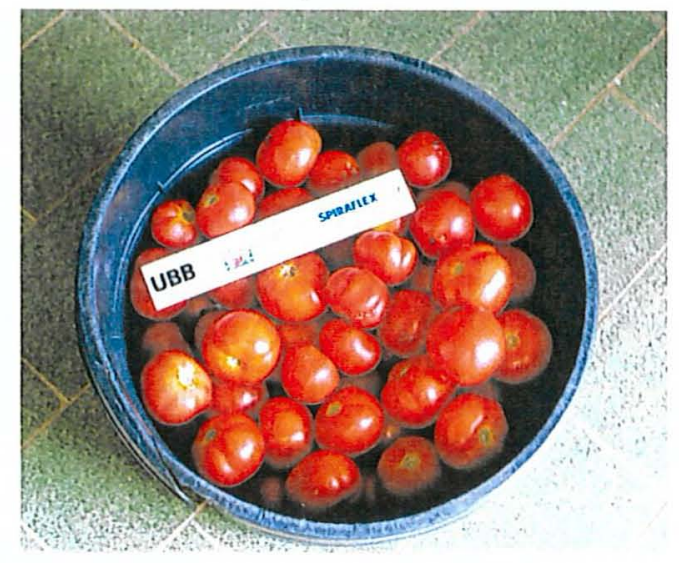

Foto 7 - Início de colheita;

Foto 9 - Refugos; 


\section{ANEXO 2}

Condições metereológicas vigentes no Campus da ESALQ/USP de 10/08* a 22/12** de 1998 (Médias de 10 dias).

\begin{tabular}{|c|c|c|c|c|c|c|c|c|c|c|}
\hline \multirow[b]{2}{*}{ Dias } & \multirow[b]{2}{*}{ Mês } & \multicolumn{6}{|c|}{ CAMPO ABERTO } & \multicolumn{3}{|c|}{ ESTUFA } \\
\hline & & $\begin{array}{c}\text { Insolação } \\
\text { (h/dia) }\end{array}$ & $\begin{array}{c}\text { Precip. } \\
\text { (mm) }\end{array}$ & $\begin{array}{c}\text { Umid. } \\
\text { relativa } \\
(\%)\end{array}$ & $\begin{array}{l}\text { Temp. } \\
\text { max. } \\
\left({ }^{\circ} \mathrm{C}\right)\end{array}$ & $\begin{array}{l}\text { Temp. } \\
\text { min.. } \\
\left({ }^{\circ} \mathrm{C}\right)\end{array}$ & $\begin{array}{l}\text { Temp. } \\
\text { med. } \\
\left({ }^{\circ} \mathrm{C}\right)\end{array}$ & $\begin{array}{l}\text { Temp. } \\
\text { max. } \\
\left({ }^{\circ} \mathrm{C}\right)\end{array}$ & $\begin{array}{l}\text { Temp. } \\
\text { min. } \\
\left({ }^{\circ} \mathrm{C}\right)\end{array}$ & $\begin{array}{l}\text { Temp. } \\
\text { med. } \\
\left({ }^{\circ} \mathrm{C}\right)\end{array}$ \\
\hline 10 a 19 & Ago & 6,2 & 0,4 & 79,2 & 29,1 & 15,8 & 22,5 & - & - & - \\
\hline 20 a 31 & Ago & 8,5 & 0,0 & 68,6 & 28,8 & 14,5 & 21,6 & 35,3 & 14,3 & 24,8 \\
\hline 01 a 10 & Set & 4,9 & 3,7 & 68,8 & 26,2 & 14,5 & 20,4 & 31,3 & 15,3 & 23,3 \\
\hline 11 a 20 & Set & 6,5 & 3,4 & 71,3 & 30,1 & 16,0 & 23,1 & 32,9 & 16,8 & 24,9 \\
\hline 21 a 30 & Set & 5,5 & 1,7 & 78,8 & 26,5 & 15,3 & 18,7 & 32,3 & 15,5 & 23,9 \\
\hline 01 a 10 & Out & 4,6 & 11,1 & 83,7 & 26,8 & 16,2 & 21,5 & 33,0 & 16,1 & 24,6 \\
\hline 11 a 20 & Out & 6,1 & 4,3 & 83,5 & 26,9 & 15,8 & 21,3 & 30,5 & 15,8 & 23,2 \\
\hline 21 a 30 & Out & 6,0 & 2,9 & 91,4 & 30,1 & 18,6 & 24,3 & 31,7 & 17,2 & 24,5 \\
\hline 01 a 10 & Nov & 6,6 & 0,5 & 70,4 & 29,3 & 15,8 & 22,6 & 30,3 & 16,4 & 23,4 \\
\hline 11 a 20 & Nov & 7,6 & 1,2 & 77,1 & 29,2 & 16,5 & 22,9 & 33,3 & 16,0 & 24,7 \\
\hline 21 a 30 & Nov & 9,1 & 0,9 & 74,1 & 31,5 & 16,9 & 24,2 & 36,6 & 16,9 & 26,8 \\
\hline 01 a 10 & Dez & 6,3 & 12,8 & 72,6 & 31,8 & 19,3 & 25,6 & 37,8 & 18,9 & 28,4 \\
\hline 11 a 22 & $\operatorname{dez}$ & 6,4 & 7,7 & 83,0 & 30,0 & 19,5 & 24,8 & 37,9 & 21,3 & 29,6 \\
\hline
\end{tabular}

*Data do transplante das mudas.

** Data da última colheita 

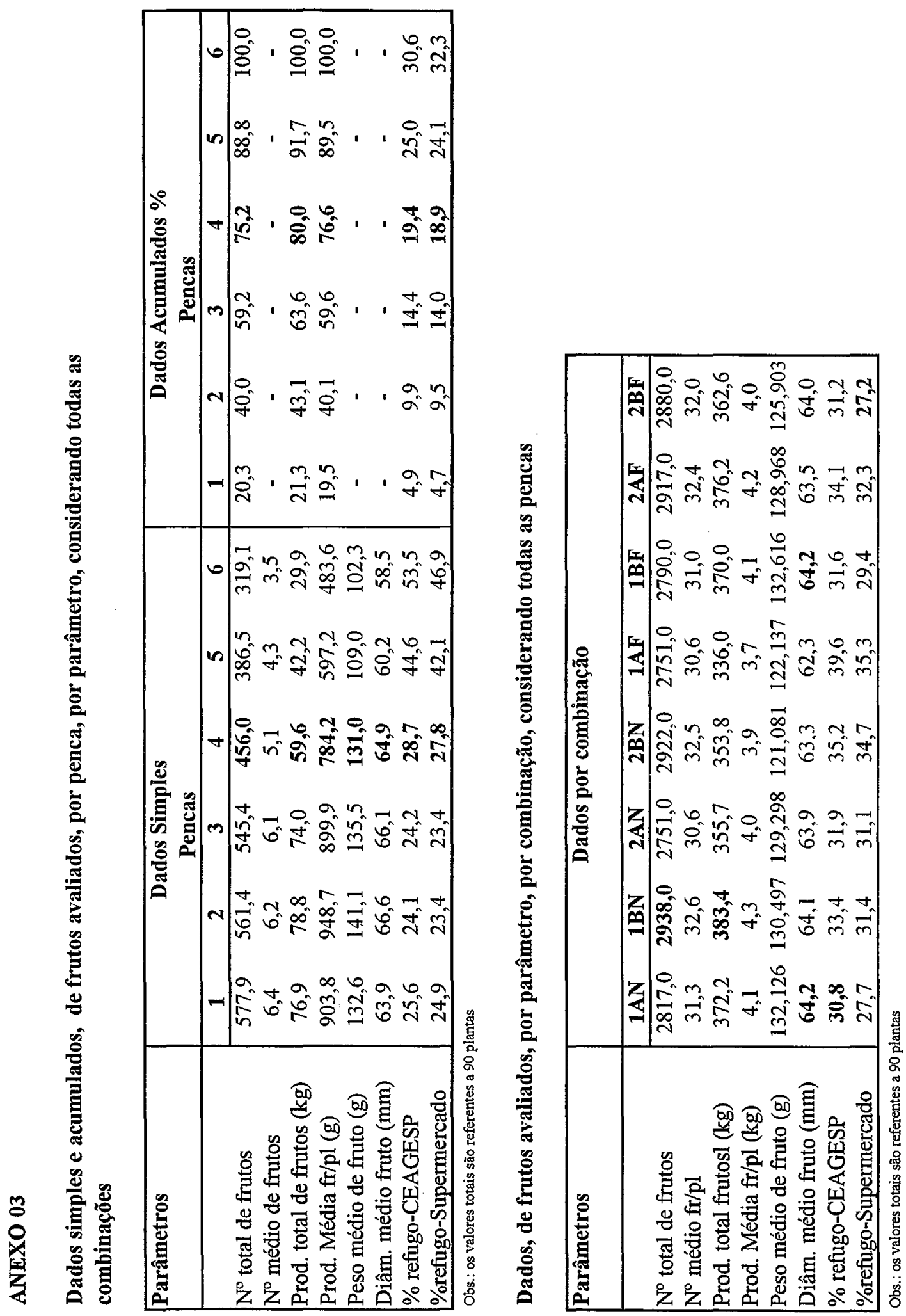

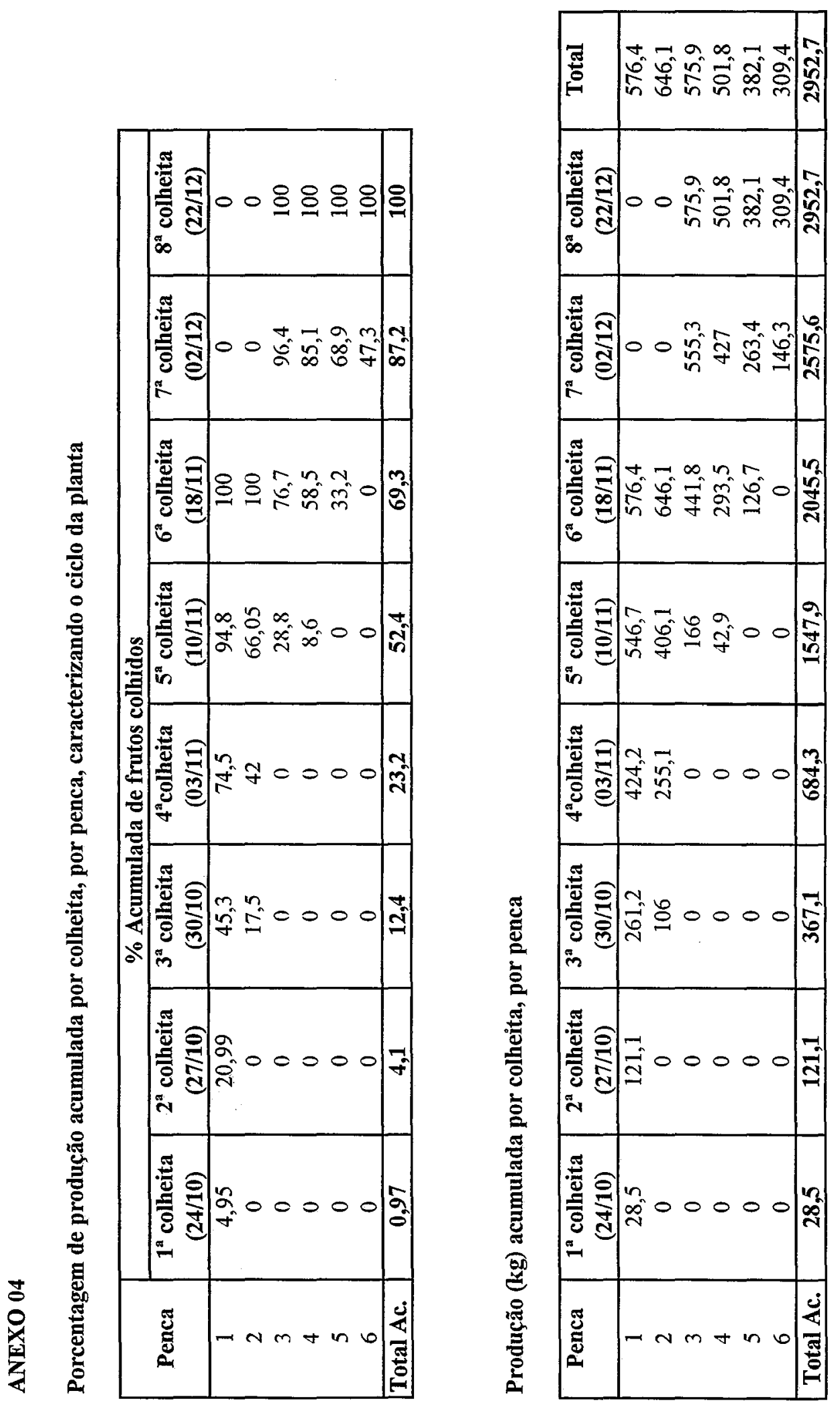


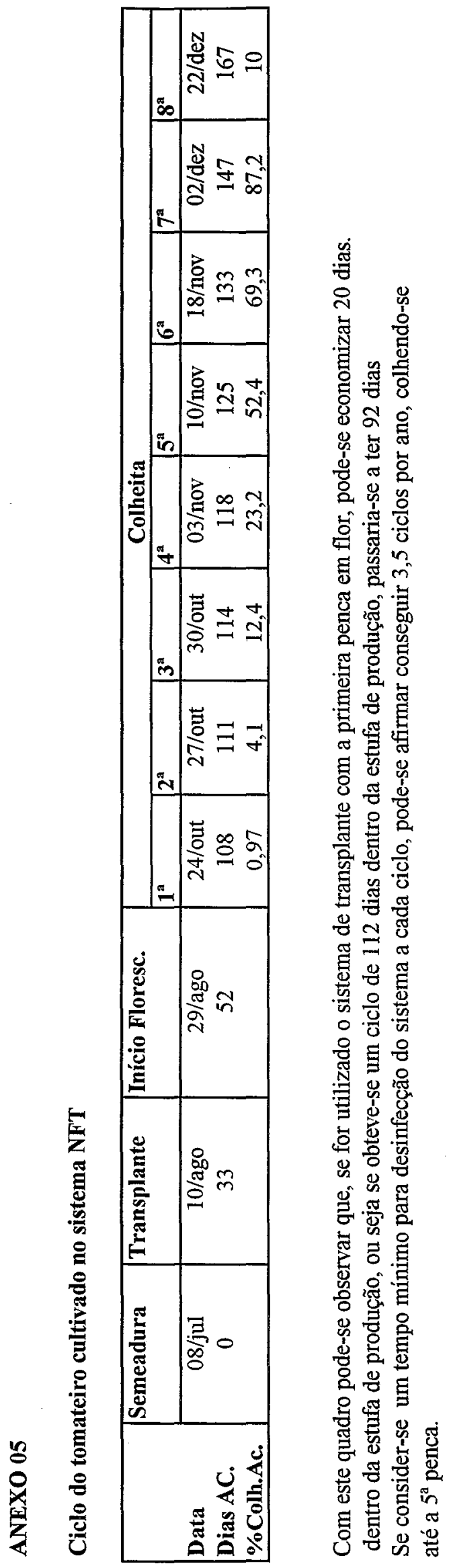




\section{ANEXO 06}

Análise de produção considerando-se as 3 últimas pencas avaliadas

\begin{tabular}{|c|c|c|c|c|c|c|c|c|c|c|c|c|c|c|c|c|c|}
\hline \multirow{2}{*}{$\begin{array}{l}\text { Combin. } \\
\text { Pencas }\end{array}$} & \multicolumn{3}{|c|}{$\begin{array}{c}\text { Prod. Ac } \\
(\mathrm{kg} / \mathrm{pl})\end{array}$} & \multicolumn{3}{|c|}{$\begin{array}{c}\text { Refugo Ac. } \\
(\%)\end{array}$} & \multicolumn{3}{|c|}{$\begin{array}{l}\text { Prod. Com. Ac. } \\
(\mathrm{kg} / \mathrm{pl})\end{array}$} & \multicolumn{3}{|c|}{$\begin{array}{l}\text { Prod. Com. } \\
(\mathrm{t} / 350 \mathrm{~m} 2)\end{array}$} & \multicolumn{3}{|c|}{$\begin{array}{c}\text { Prod. Relativa } \\
\text { (Sistema) }\end{array}$} & \multicolumn{2}{|c|}{$\begin{array}{c}\text { Prod.Rel } \\
(\text { pc6 = 100) }\end{array}$} \\
\hline & $4^{a}$ & $5^{a}$ & $6^{a}$ & $4^{a}$ & $5^{a}$ & $6^{a}$ & $4^{a}$ & $5^{a}$ & $6^{a}$ & $4^{a}$ & $5^{a}$ & $6^{a}$ & $4^{a}$ & $5^{a}$ & $6^{a}$ & $4^{a}$ & $5^{a}$ \\
\hline 1ANFT & 3,4 & 3,8 & 4,1 & 17,4 & 21,8 & 25,5 & 2,8 & 3,0 & 3,1 & 2,0 & 2,1 & 2,2 & 100 & 100 & 100 & 91,9 & 97,3 \\
\hline 1BNFT & 3,4 & 3,9 & 4,3 & 18,4 & 24,2 & 28,9 & 2,8 & 3,0 & 3,1 & 2,0 & 2,1 & 2,2 & 90,8 & 92,5 & 88,1 & 90,7 & 96,7 \\
\hline 2ANFT & 3,2 & 3,6 & 4,0 & 18,0 & 23,4 & 28,1 & 2,6 & 2,8 & 2,9 & 1,9 & 2,0 & 2,1 & 85,9 & 86,3 & 82,8 & 91,2 & 95,9 \\
\hline 2BNFT & 2,9 & 3,5 & 3,9 & 22,7 & 28,0 & 33,3 & 2,2 & 2,5 & 2,6 & 1,6 & 1,8 & 1,9 & 73,4 & 78,9 & 74,9 & 86,2 & 96,9 \\
\hline 1AFOGER & 2,9 & 3,3 & 3,7 & 22,8 & 28,0 & 34,1 & 2,2 & 2,4 & 2,4 & 1,6 & 1,7 & 1,8 & 73,3 & 74,4 & 70,2 & 91,8 & 97,4 \\
\hline 1BFOGER & 3,4 & 3,8 & 4,1 & 16,1 & 21,5 & 26,0 & 2,9 & 3,0 & 3,0 & 2,1 & 2,1 & 2,2 & 93,4 & 93,4 & 87,4 & 94,0 & 98,3 \\
\hline 2AFOGER & 3,3 & 3,8 & 4,2 & 17,2 & 22,3 & 28,5 & 2,7 & 3,0 & 3,0 & 2,0 & 2,1 & 2,2 & 89,4 & 92,4 & 86,5 & 91,0 & 98,3 \\
\hline 2BFOGER & 3,1 & 3,7 & 4,1 & 18,4 & 23,9 & 28,9 & 2,5 & 2,8 & 2,9 & 1,8 & 2,0 & 2,1 & 82,8 & 88,1 & 84,0 & 86,8 & 96,6 \\
\hline
\end{tabular}

Simulação econômica considerando-se a comercialização em supermercado, de acordo com dados de produção do experimento

\begin{tabular}{|c|c|c|c|c|c|c|c|c|c|c|c|c|}
\hline \multirow{2}{*}{$\begin{array}{l}\text { Tratam. } \\
\text { Pencas } \\
\end{array}$} & \multicolumn{3}{|c|}{$\begin{array}{c}\text { (1pl/1haste) } \\
\text { Prod.Comerc.Ac. } \\
(\mathrm{kg} / \mathrm{pl})\end{array}$} & \multicolumn{3}{|c|}{$\begin{array}{c}\text { (1pl/1haste) } \\
\text { Prod. Comerc. Ac. } \\
(t / h a)\end{array}$} & \multicolumn{3}{|c|}{$\begin{array}{c}\text { (1pl/1haste) } \\
\text { Prod. Comerc. Ac. } \\
\text { (c/ } / 1000 \mathrm{pl})\end{array}$} & \multicolumn{3}{|c|}{$\begin{array}{c}\text { Receita Br.(mR } \$ / \text { ha) } \\
\text { Prod. Comerc. Ac. } \\
\text { (1pl/1haste) }\end{array}$} \\
\hline & $4^{a}$ & $5^{a}$ & $6^{a}$ & $4^{a}$ & $5^{a}$ & $6^{a}$ & $4^{a}$ & $5^{\mathrm{a}}$ & $6^{a}$ & $4^{a}$ & $5^{a}$ & $6^{a}$ \\
\hline 1ANFT & 2,8 & 3,0 & 3,1 & 57,6 & 61,7 & 63,8 & 121,7 & 130,4 & 134,8 & 69,1 & 74,1 & 76,5 \\
\hline 1BNFT & 2,8 & 3,0 & 3,1 & 57,6 & 61,7 & 63,8 & 121,7 & 130,4 & 134,8 & 69,1 & 74,1 & 76,5 \\
\hline 2ANFT & 2,6 & 2,8 & 2,9 & 53,5 & 57,6 & 59,7 & 113,0 & 121,7 & 126,1 & 64,2 & 69,1 & 71,6 \\
\hline 2BNFT & 2,2 & 2,5 & 2,6 & 45,3 & 51,4 & 53,5 & 95,7 & 108,7 & 113,0 & 54,3 & 61,7 & 64,2 \\
\hline 1AFOGER & 2,2 & 2,4 & 2,4 & 45,3 & 49,4 & 49,4 & 95,7 & 104,3 & 104,3 & 54,3 & 59,2 & 59,2 \\
\hline 1BFOGER & 2,9 & 3,0 & 3,0 & 59,7 & 61,7 & 61,7 & 126,1 & 130,4 & 130,4 & 71,6 & 74,1 & 74,1 \\
\hline 2AFOGER & 2,7 & 3,0 & 3,0 & 55,5 & 61,7 & 61,7 & 117,4 & 130,4 & 130,4 & 66,7 & 74,1 & 74,1 \\
\hline 2BFOGER & 2,5 & 2,8 & 2,9 & 51,4 & 57,6 & 59,7 & 108,7 & 121,7 & 126,1 & 61,7 & 69,1 & 71,6 \\
\hline
\end{tabular}

Legenda:

$N^{\circ}$ de plantas / ha estimada $=20.571$

Supermercado - dados obtidos por produtores com venda direta para supermercados-contrato de compra: $\mathrm{R} \$ 1,20 / \mathrm{kg}$ 